\title{
Selection of Adjuvants for Enhanced Vaccine Potency
}

\author{
Wei Wang ${ }^{1}$, Manmohan Singh ${ }^{2}$ \\ ${ }^{1}$ BioTherapeutics Pharmaceutical Sciences, Pfizer Inc, Chesterfield, USA; ${ }^{2}$ Novartis Vaccines and Diagnostics, Cambridge, USA. \\ Email: wei.2.wang@pfizer.com \\ Received February $16^{\text {th }}, 2011$; revised March $17^{\text {th }}, 2011$; accepted March $25^{\text {th }}, 2011$.
}

\begin{abstract}
The advent of mass vaccination has saved millions of human lives and revolutionized the quality of life. Vaccination is currently one of the most cost effective ways of managing healthcare costs in both emerging and developed countries. Despite the long vaccine history and success, design and development of efficacious and safe vaccines has been traditionally semi-empirical. This is mainly due to our limited understanding of vaccination mechanism and its influencing factors. The most important factor is arguably the type and concentration of vaccine adjuvants. Until recently, however, only one type of adjuvant-aluminum salts, had been widely used within licensed human vaccines in the US, even though a variety of novel adjuvants have been evaluated in the past few decades. This review summarizes the key adjuvants that have been evaluated in recent years with an intention to facilitate more efficient development of vaccine products to combat human diseases.
\end{abstract}

Keywords: Adjuvant, Alum, Aluminum Salts, Immune Response

\section{Introduction}

The advent of mass vaccination significantly reduced the morbidity or mortality of newborns and adults alike from various infectious diseases, which are otherwise unavoidable as a vast majority of the global population concentrate in cities with close contacts with one another. It is estimated that universal influenza vaccination alone saves 250,000 - 500,000 annual deaths worldwide [1]. The gradual decrease both bvin morbidity and mortality has increased the life expectancy and quality of life as well. With the global concerns for the ever-increasing healthcare cost, vaccination remains one of the most cost effective ways of managing healthcare costs in both emerging and developed countries.

Human vaccines have now been used for over two centuries since the first vaccination trial for cow-pox by Edward Jenner. They have been proven to be very effective in preventing or controlling the occurrence and spreading of numerous deadly diseases through improvement of the host's innate and adaptive immune systems. Despite the long vaccine history and success, design and development of efficacious and safe vaccines has been traditionally semi-empirical, even though re- cently novel methods are being developed such as reverse vaccinology [2]. Various strategies have been investigated for the improvement of the vaccine efficacy. Among these, use of a vaccine adjuvant has been a top choice with many successes. However, until recent approval of AS04 adjuvant in a product licensed by GSK, only one type of adjuvant-aluminum salts, had been widely used within licensed human vaccines in the US, even though a variety of novel adjuvants have been evaluated in the past few decades. Therefore, development and identification of effective and safe vaccine adjuvants is urgent and remains to be an area of extensive investigation [3-5].

This review summarizes the key adjuvants that have been evaluated in recent years that affect the vaccine immunogenicity/efficacy with an intention to facilitate more efficient development of vaccine products to combat human diseases.

\section{Major Players in an Immune Response}

Many types of cells are involved in an immune response, including dendritic cells, macrophages, mast cells, eosinophils, neutrophils, B and T lymphocytes. A key player in the immune response is the dendritic cells (DCs), the 
most effective antigen presenting cells (APCs) [6-8]. Activated DCs drain into the local lymph node, where they present the antigen and direct the differentiation of $\mathrm{T}$ helper (Th) cells into different effector cells, leading to recognition of $\mathrm{B}$ and $\mathrm{T}$ cell epitopes.

A few types of receptors play important role in this process. Pattern-recognition receptors (PRRs) recognize conserved microbial structures-pathogen-associated molecular patterns (PAMPs) [9]. A major category of such receptors are toll-like receptors (TLR1-9) for pathogen recognition, DC activation, and induction of immune response. They are widely expressed in cells of the immune system, epithelial cells, endothelium, cardiomyocytes and adipocytes for recognition of pathogens [9] and could be utilized potentially for targeting activation pathways by the same or different adjuvants $[5,10]$. Stimulation of TLRs may lead to several events - stimulated synthesis of anti-microbial substances and pro- inflammatory cytokines (TNF- $\alpha$, IL-1, IL-6, IL-8, IL-12, etc); activation of dendritic cell maturation (increased expression of co-stimulatory molecules such as CD40, CD80, CD86; and MHC antigens); and more effective antigen presentation.

Antigen peptides are presented by DCs as a peptide/ MHC Class II protein complex, which binds to the TcRs on $\mathrm{T}$ helper cells for activation of $\mathrm{T}$ helper cells - activation of the major biochemical pathways in the cytosol of the $\mathrm{T}$ helper cells (signal 1). Interaction between CD28 on $\mathrm{T}$ helper cells and CD80 or CD86 on DCs activates the second independent biochemical pathway (signal 2). Activation of the two pathways within $\mathrm{T}$ helper cells leads to the self proliferation by releasing IL-2 ( $\mathrm{T}$ cell growth factor). After many generations, the $\mathrm{T}$ helper cells differentiate into effector $\mathrm{T}$ helper cells, memory $\mathrm{T}$ helper cells and suppressor $\mathrm{T}$ helper cells.

The $\mathrm{T}$ helper cells differentiate into two major subtypes: Th1 and Th2 cells. DCs are critical in controlling the direction of $\mathrm{T}$ helper cells' differentiation through secretion of certain cytokines [11]. Secretion of IFN- $\gamma$, IL-2, and IL12 promote Th1 differentiation, leading to secretion of IFN- $\gamma$, IL-2, and IL12, proliferation of cytotoxic CD8 + T cells, macrophage activation, and production of TNF- $\gamma$, TNF- $\beta$, and IgG2a. Secretion of IL- $1 \beta$ and IL-18 promote Th2 differentiation, leading to secretion of IL-4, IL-5, IL-6, IL-10, IL-13, and stimulation of B-cell proliferation, and subsequent $\mathrm{Ab}$ production, with a typical initial phase of IgM production, followed by more specific IgG conversion with a few days to weeks [12]. Enhancement of antigen-specific antibody production is a critical post-vaccination event, as the natural antibodies of the innate immune system is often ineffective due to their low-affinity and non-anamnesia in an immune response [13]. Secretion of host IFN- $\gamma$ is not required to initiate a Th1 immune response [14].

Vaccine-induced immune responses can be generally divided into these two different biased effects: Th1 vs Th2 types. Many factors can contribute to the type of specific immune response of a vaccine, including the type and reletive amounts of antigens and adjuvants. Even the intensity of an immune response can make a difference. A weak immune response is generally Th2biased and therefore, increasing the intensity of response may lead to a Th1 response [15]. The Th1 response to an intramuscular flu vaccine (Fluarix) increased when the dose was increased from $1 / 10$ th of a full dose to a full dose, with a relatively similar Th2 response [16].

It is generally believed that activation of Th1 and Th2 effector cells are effective against intracellular and extracellular pathogens, respectively6. However, the actual protection offered by these two pathways is still not so clear-cut. For example, it is expected that Th2 immune responses are required for protection against extracellular bacteria, such as $\mathrm{H}$. pylori but only a Th1-promoting vaccine $(\mathrm{H}$. pylori sonicate $+\mathrm{CpG}$ ) showed protection in mice [17]. Similar results were obtained where a strong Th2-inducing protein vaccine was not as effective in the protection of mice from virus challenge [18].

\section{Most Commonly Used Adjuvant Aluminum Salts}

Aluminum salts have been used extensively both in veterinary and human vaccines $[19,20]$. These salts include aluminum hydroxide (more accurately as aluminum oxyhydroxide $\mathrm{AlO}(\mathrm{OH})$ ), aluminum phosphate (more accurately as aluminum hydroxyphosphate, $\mathrm{Al}(\mathrm{OH}) \mathrm{x}$ (PO4) y), and alum (KAl(SO4)2). Alum has been used often exchangeably with the first two aluminum salts in the literature [21]. The major characteristics of the two major salt types are listed Table 1.

The regulatory limit for aluminum in biological products (including vaccines) is $0.85 \mathrm{mg} /$ dose in the US and $0.125 \mathrm{mg} / \mathrm{dose}$ in Europe. This limit is high enough to accommodate the needs of most vaccines. Nevertheless, a minimal amount of such salts is recommended for use as vaccine adjuvants to minimize possible side effect. In addition, it is still being investigated whether the cause of Gulf War Syndrome has anything to do with the subcutaneous administration of extra dose of aluminum hydroxide [22].

\subsection{Adjuvantation Mechanisms}

Aluminum salts can enhance the immunogenicity of many types of vaccine antigens, including proteins [23], virus [24], etc. Their mechanism of action for the stimulation of the immune system remains a subject of con- 
tinuous investigation [20,21,25]. Several mechanisms have been demonstrated, including recruitment of dendritic cells, retention of antigens, more efficient uptake and presentation of antigens by dendritic cells, more effective activation of antigen-specific $\mathrm{T}$ cells, complement activation and induction of necrosis at the injection site [26-31]. More recently, several studies showed simultaneously that aluminum stimulates immune response to an antigen through the nucleotide-binding oligomerization domain- like (NOD-like) receptors (NLRs; cytosolic), specifically NALP3 (Nacht Domain-, Leucine-Rich Repeat and PYD -Containing Protein 3). Aluminum adjuvants activate an intracellular innate immune response system, called the NALP3 inflammasome (also known as cryopyrin, CIAS1 or NLRP3) [32] and via NALP3, induce secretion of mature IL-1 $\beta$, IL-18, and IL-33 in human and mouse macrophages [33]. Other particulate adjuvants, such as QuilA and chitosan, induce similar inflammasome activation, suggesting that activation of the NALP3-inflammasome may be a common mechanism of action for particulate adjuvants [33]. Therefore, any activators of NLRP3 may be potentially effective adjuvants.

Aluminum salts generally induce a Th2-type immune response $[29,34]$. Th2 differentiation in mouse dendritic cells (DCs) was apparently directed by the specific secretion of IL- $1 \beta$ and IL-18 and lack of IL-12 secretion (IL-12 directs differentiation of CD4 T cells to Th1 cells) [29]. The Th2-response of alum is not purely a particulate-related consequence, as incubation of conjugated ovulbumin to polystyrene beads $(48 \mathrm{~nm})$ induced substantial Th1 responses with moderate Th2 responses in sheeps [35]. Generally, the Th2 effect is dependent on the amount and type of aluminum salts used in the formulation [29]. Differential effects have been seen between 500 and $158 \mu \mathrm{g}$ of aluminum (Alhydrogel) with 25 $\mu \mathrm{g}$ of Bacillus anthracis recombinant protective antigen (rPA) in inducing neutralizing antibodies [36].

On the other hand, aluminum salts may not always enhance immunogenicity of an antigen. Aluminum hydroxide at $0.6 \mathrm{mg}$ in $0.5 \mathrm{~mL}$ did not show any significant effect in inducing serum anti-HA antibody formation after immunization of healthy elderly adults with $7.5 \mathrm{ug}$, $15 \mu \mathrm{g}$, or $45 \mu \mathrm{g}$ HA by IM injection [37]. Aluminum hydroxide could even suppress the immune response of vaccines in some cases $[26,38]$.

\subsection{Antigen Adsorption to Aluminum Salts}

Aluminum salts have large surface areas for antigen adsorption (Table 1). Two major surface adsorption mechanisms of antigens are known-electrostatic attraction and ligand exchange $[39,40]$. Both can take place at the same time, but when the antigen and aluminum salts carry the same type of charge (repulsive to each other), ligand exchange plays a key role $[41,42]$. Other mechanism of adsorption was also proposed, including hydrophobic interactions [41], and other non-charge-associated surface interactions such as monosaccharides on the surface of aluminum oxide at PZC $(\mathrm{pH}$ 9.0) [43]. All of these mechanisms of adsorption may co-exist for a single antigen [28].

Protein adsorption to aluminum salts is generally very fast. The adsorption of several antigens - $\alpha$-casein, bovine serum albumin (BSA), myoglobin and recombinant protective antigen (rPA), to aluminum hydroxide took a minute [44]. So is the adsorption of three recombinant botulinum neurotoxin antigens to aluminum hydroxide39. It may take a little longer if ligand exchange and/or phosphorylation of aluminum hydroxide (in a phosphate buffer) takes place [45]. Therefore, it is recommended that the surface $\mathrm{OH} / \mathrm{PO} 4$ ratio be determined in early vaccine development stages [46].

Two parameters are often used to describe antigen adsorption-dsorption capacity (or maximum adsorption) and adsorption coefficient (the binding strength). The adsorption capacity seems to be limited to a monolayer coverage. This is certainly the case for ligand exchangeominant adsorption of a monoclonal antibody on aluminum hydroxide [40] and hepatitis B surface antigen (HBsAg) on aluminum hydroxide [47]. For hepatitis B surface antigen (HBsAg), the monolayer coverage is at $1.7 \mathrm{mg} / \mathrm{mg}$ Al [47].

Table 1. Major characteristics of aluminum salts.

\begin{tabular}{|c|c|c|c|c|c|c|}
\hline Salts & $\mathrm{PZC}$ & Size & Solubility & Other properties & PK properties & References \\
\hline $\begin{array}{l}\text { Aluminum } \\
\text { hydroxide } \\
\mathrm{AlO}(\mathrm{OH})\end{array}$ & 11.4 & $\begin{array}{l}\text { Primary particles, fibers, } \\
4.5 \times 2.2 \times 10 \mathrm{~nm} \\
\text { Aggregates: } 1-20 \mu \mathrm{m} \\
\text { in diameter }\end{array}$ & $\begin{array}{l}\text { Well-shaped with } \mathrm{pH} \\
<1 \mu \mathrm{g} / \mathrm{mL} \text { at } \mathrm{pH} 5-9 \text {; } \\
\text { crystalline }\end{array}$ & $\begin{array}{l}\text { Surface area of } \\
\text { primary parti- } \\
\text { cles: about } 500 \\
\mathrm{~m} 2 / \mathrm{g}\end{array}$ & $\begin{array}{l}17 \% \text { absorption in } 28 \text { days } \\
\text { following IM injection in } \\
\text { rabbits; mainly distributed } \\
\text { in kidney and spleen }\end{array}$ & $\begin{array}{c}26 \\
55 \\
461\end{array}$ \\
\hline $\begin{array}{l}\text { Aluminum } \\
\text { phosphate } \\
\mathrm{Al}(\mathrm{OH}) \mathrm{x}(\mathrm{PO} 4) \mathrm{y}\end{array}$ & $\begin{array}{l}\text { 9.6-4.0; } 5.5 \\
\text { (prepared at } \\
\text { pH 3); } 4.2 \\
\text { (prepared at } \\
\text { pH 7.5) }\end{array}$ & $\begin{array}{l}\text { Primary particles, plates } \\
\text { around } 50 \mathrm{~nm} \text {; } \\
\text { Bell-shipped with } \mathrm{pH} \text {; } \\
\text { Octahedrally/ tetrahe- } \\
\text { drally coordinated } \\
\text { aluminum }\end{array}$ & $\begin{array}{l}\text { Well-shaped with } \mathrm{pH} \\
<5 \mu \mathrm{g} / \mathrm{mL} \text { at } \mathrm{pH} 5- \\
6.5 \text {; amorphous }\end{array}$ & $\begin{array}{l}\text { Density } 2.05 \\
\mathrm{~g} / \mathrm{mL} \text { at } \mathrm{pH} 3 \text { to } \\
2.15 \mathrm{~g} / \mathrm{mL} \text { at } \mathrm{pH} \\
7\end{array}$ & $\begin{array}{l}70 \% \text { absorption in } 28 \text { days } \\
\text { following IM injection in } \\
\text { rabbits; mainly distributed } \\
\text { in kidney and spleen }\end{array}$ & $\begin{array}{c}26 \\
54,462 \\
55 \\
463 \\
461\end{array}$ \\
\hline
\end{tabular}


Similar levels of protein antigen adsorption were also reported for several other proteins. The adsorptive capacity of lysozyme, ovalbumin and bovine serum albumin at pH 7.4 is 1.4 (Adju-Phos), 1.6 (Alhydrogel), and 2.2 (Alhydrogel) $\mathrm{mg} / \mathrm{mg} \mathrm{Al}$, respectively [48]. On the other hand, the adsorptive capacity of proteins can vary significantly (> 10 times), depending on the source, preparation method, and age of the aluminum salts $[44,45$, $49,50]$. If the protein and aluminum salts carry the same charge, a significantly lower amount of antigen adsorption is expected. The maximum adsorption of endotoxin (pI about 2) at $\mathrm{pH} 7.4$ and $25 \mathrm{C}$ is only $3 \mu \mathrm{g} / \mathrm{mg} \mathrm{Al}$ on aluminum phosphate [49]. The amount adsorbed under such conditions would heavily depend on the number of phosphorylation sites on the antigen [28,51]. Another parameter similar to adsorptive capacity could also be used and has been shown to be better for characterizing time-induced changes in physical properties of these salts [52].

The binding strength of antigen can be evaluated based on its resistance to desorption in an elution buffer or in an interstitial fluid [47]. It often correlates with the adsorption capacities $[45,49]$ and can be significantly different depending on study conditions [53]. Generally, ligand exchange-based adsorption offers more binding strength than that from electrostatic attraction. The adsorption of hepatitis B surface antigen (HBsAg) was strongly adsorbed on aluminum hydroxide with an adsorptive coefficient of $6.0 \mathrm{ml} / \mu \mathrm{g}$ due to the presence of phospholipids for ligand exchange [47]. The elution of ovalbumin from aluminum hydroxide adjuvant upon exposure to interstitial fluid was inversely related to the degree of phosphorylation of the ovalbumin [28].

Many factors can influence the rate of antigen adsorption and adsorption capacity on aluminum salts. The most critical one is arguably the solution $\mathrm{pH}$, as this will determine charged states of antigen and aluminum salts. The influence of $\mathrm{pH}$ on antigen adsorption can be complex because of the presence of multiple adsorption mechanisms, and differences in pH-dependent stability of antigens, and solubility of both antigens and aluminum salts [40]. Parabolic $\mathrm{pH}$ relationships were reported on lysozyme adsorption on aluminum phosphate (minimum at $\mathrm{pH} 4$ ) [54] and ovalbumin ( $\mathrm{pI}=4.7)$ adsorption on aluminum hydroxide (maximum at $\mathrm{pH}$ 4.3-6.2) [55]. In rare cases, maximum adsorption can be found in a $\mathrm{pH}$ range, where antigens and aluminum salts carry the same charges [40].

Other solution factors can also play a significant role. Presence of phosphate ions in a solution can significantly reduce both the adsorption capacity and coefficient of antigens on aluminum hydroxide due to a variable degree of phosphorylation $[42,45]$. The adsorption capacity of a monoclonal antibody at $\mathrm{pH} 7.4$ decreased from $1.5 \mathrm{mg} /$ $\mathrm{mg} \mathrm{Al}$ in water to $0.14 \mathrm{mg} / \mathrm{mg} \mathrm{Al}$ in the presence of 100 $\mathrm{mM}$ phosphate [40]. The ionic strength of the solution may change the adsorption capacity of an antigen based on electrostatic interactions [40] but should not have a significant effect on ligand exchange-based antigen adsorption [47]. Presence of other proteins, excipients, and/or multivalent anions (such as $\alpha$-hydroxycarboxylic acid, citric acid, lactic acid and malic acid) would also influence antigen adsorption. The adsorption capacity of a monoclonal antibody at $\mathrm{pH} 7.4$ decreased from 1.5 $\mathrm{mg} / \mathrm{mg} \mathrm{Al}$ in water to $1.1,0.88$, and $0.83 \mathrm{mg} / \mathrm{mg} \mathrm{Al}$, respectively at $5 \mathrm{C}$, room temperature, and $37 \mathrm{C}$ in simulated interstitial fluid $(25 \mathrm{mg} / \mathrm{mL}$ BSA; $2.7 \mathrm{mq} / \mathrm{L}$ citrate, $5 \mathrm{mM}$ phosphate, $154 \mathrm{mM} \cdot \mathrm{NaCl}$ ) [40]. Several excipients have been shown to have negative effect on the antigen adsorption, including EDTA on the adsorptive capacity of recombinant protective antigen ( $\mathrm{pI}$ of 5.6) on aluminum hydroxide [45], trehalose or combination of trehalose and Tween 20 on the total adsorption capacity of trivalent protein antigens on Alhydrogel [51], sucrose on the adsorption capacity of all three recombinant botulinum neurotoxin antigens [39]. The negative effect of neutral molecules could be due to their stabilizing effect on antigens, preventing antigens from effective hydrophobic interactions with the aluminum surface.

\subsection{Degree and Strength of Adsorption vs Immunogenicity}

It has been a general belief that antigens need to be adsorbed on aluminum salts for optimal immunogenicity effect. However, the exact relationship between the degree of antigen adsorption and in-vivo immunogenicity has not been consistent. Subcutaneous administration of lysozyme/aluminum hydroxide mixtures with different degrees of adsorption of 3,35 or $85 \%$ led to generation of the same level of anti-lysozyme antibody titers in rabbits [23]. One study shows that administration of nonadsorbed protein antigens (dephosphorylated $\alpha$-casein, dephosphorylated ovalbumin, or lysozyme) with aluminum phosphate induced similar levels of antibody titers to that for antigens adsorbed on aluminum phosphate in mice [56]. Using recombinant $\mathrm{N}$ terminus of Als $3 p$ (rAls3p-N) as a model antigen, Lin et al. [57] found that more rAls3p-N was bound on aluminum hydroxide in saline than in phosphate-buffered saline (PBS) but the immunogenicity and efficacy were superior with antigens in PBS.

Indeed, several studies showed that a tight binding between antigens and aluminum salts would inhibit immunogenicity. Using $\alpha$-casein and dephosphorylated $\alpha$ casein as model antigens and non-treated/phosphatetreated aluminum hydroxide as adjuvants, it was shown 
that the geometric mean antibody titer in mice was inversely related to the adsorptive coefficient of antigens [58]. Similar results were obtained with $\mathrm{HBsAg}$ as a model antigen with aluminum hydroxide [53] or with aluminum hydroxyphosphate sulfate in mice [59]. These results clearly suggest that the immune response could negatively correlate with the degree of adsorption of proteins on aluminum adjuvants [40].

Would binding strength of an antigen in interstitial fluid predict immunogenicity better, as this fluid mimics the in-vivo tissue environment? Again, results are not completely consistent, either. While the degree of lysozyme adsorption on aluminum hydroxide in sheep interstitial fluid correlated with the immune response (formation of anti-lysozyme antibodies) after subcutaneous administration [23], tight binding of antigens (non-release in interstitial fluid) has generated conflicting results-negative for endotoxin vaccine with aluminum hydroxide in rats [49] but positive for $\alpha$-casein with aluminum hydroxide in mice [27]. In certain cases, enhancement of immunogenicity is achieved even when the antigens are not adsorbed on aluminum salts [56]. Therefore, the binding strength of antigen in interstitial fluid does not predict immunogenicity well.

\subsection{Storage and Process Stability of Aluminum Salts}

The storage stability of aluminum salts has not been reported extensively, partly because of its long history of use, and lack of accurate methods for monitoring its stability, such as particle size. These salts appear to be stable under normal storage conditions, but subtle changes may occur. Aging of aluminum phosphate prepared under uncontrolled $\mathrm{pH}$ conditions resulted in a drop in $\mathrm{pH}$ (as much as 0.9 unit at $\mathrm{P} / \mathrm{Al}$ ratio of 0.25 ) in 3 months at room temperature [54].

Thermal treatment of aluminum hydroxide at $80 \mathrm{C}$ for 24 hours did not affect the adsorption capacity of ovalbumin (pI 4.7) [50]. Higher temperature, however, does cause certain changes. Amorphous aluminum phosphate underwent deprotonation and dehydration when autoclaved for 30 or $60 \mathrm{~min}$ at $121 \mathrm{C}$, reducing the lysozyme adsorption capacity, rate of acid neutralization at $\mathrm{pH} 2.5$, and the point of zero charge [60]. Autoclaving aluminum hydroxide adjuvant increased the degree of crystallinity in addition to deproto nation/dehydration, reducing the protein adsorption capacity and viscosity $[50,60]$.

The aluminum salts do not tolerate the freeze-thaw process well, as freezing causes irreversible coagulation [26]. Freeze-thawing (to $-40 \mathrm{C}$ ) of $0.2 \%$ Alhydrogel at $\mathrm{pH}$ 4.0 caused particle aggregation, which is inversely related to the cooling or thawing rate [61]. Freeze-thawing of aluminum hydroxycarbonate gel caused coagulation, leading to formation of visible aggregates without changing the point of zero charge [62]. Single or repeated freezing of alum-containing hepatitis $\mathrm{B}$ vaccine (to $-10 \mathrm{C}$ or lower) resulted in aggregation of the adjuvant-antigen particles, which exacerbated with duration of freezing, lower temperature, and the number of freezing cycles [63]. The rate of freezing was inversely related to the aggregate size (aluminum hydroxycarbonate) [62].

Certain processes could reverse freezing-induced aggregation of aluminum salts, such as ultrasonic treatment or homogenization [62]. Use of proper formulation excipients could potentially inhibit the freezing-induced particle aggregation. The freezing-induced particle aggregation in a hepatitis B vaccine could be prevented by including PEG 300, propylene glycol, or glycerol [64]. At least $10 \%$ propylene glycol appeared to be needed for complete protection from freezing-induced particle aggregation [63]. The protective effect seems attributable to their general lyoprotective effect rather than reduction in freezing temperature. Other excipients are also found to be effective in inhibiting freezing-reduced aggregation, such as adsorbable polymers or surface-active agents [62], and trehalose [61].

The additional drying step after freezing also leads to aggregation of aluminum salts. It has been shown that freeze-drying of $0.2 \%$ Alhydrogel caused particle aggregation with bigger median diameter than that caused by the freeze-thawing process alone [61]. Lyophilization of a model antigen, bovine intestinal alkaline phosphatase adsorbed on aluminum hydroxide, induced adjuvant aggregation and reduced the antigen's enzymatic activity (up to $50 \%$ drop in activity) [65]. Such a process could potentially reduce the in-vivo immunogenicity [66]. In contrast, spray drying does not seem to cause particle aggregation of aluminum hydroxide in the absence of polymers [67].

The effect of process-induced aggregation of aluminum salts on immunogenicity may depend on the degree of aggregation and type/level of antigen. While lyophilization-induced particle aggregation (2-16 $\mu$ mean particle diameter) did not translate into any change in immunogenicity of alkaline phosphatase in terms of anti-antigen titers (IgG1) in mice [65], freezing-induced aggregation of aluminum salt reduced significantly the immunogenicity of hepatitis $B$ vaccine in mice $[63,64]$.

\subsection{Stability of Antigen with Aluminum Salts}

The stability of antigens adsorbed on aluminum salts has not been studied extensively, partly due to the interference of aluminum salts with different assays. Certainly, the tertiary structures of antigens can change to a variable degree upon adsorption to aluminum salts. The Tm's of three protein antigens, lysozyme, ovalbumin and bovine 
serum albumin, were all reduced Tm's upon adsorption onto aluminum salts [48]. Of course, change in antigen structure or aggregation state may or may not negatively impact the immunogenicity. In fact, the perturbed tertiary structure could possibly facilitate the presentation of antigens and thus contribute to the adjuvant activity of the aluminum salts [48].

An option to bypass the interference of aluminum salts is to analyze antigens after dissociation and separation from the salts. Dissociation could be achieved through $\mathrm{pH}$ adjustment with or without certain amount of chaotropic agents [68]. However, the dissociation process may reverse or further alter the structural changes caused by adsorption. The dissociated BSA and multiple antigens (for Group A Streptococcus; GrAS) from aluminum hydroxide were found to be structurally and functionally similar to the untreated antigen controls by several methods [68]. In such cases, the adsorption-induced structural changes in antigens can only be studied in the adsorbed state.

Aluminum salts could potentially reduce the antigen stability during storage. It was found that BSA formulated with aluminum hydroxide showed more dimer formation $(31 \%)$ relative to the control $(9 \%$ dimer) upon storage [68]. The oxidation and deamidation of aluminum-adjuvanted $\mathrm{rBoNTE}(\mathrm{Hc})$ was faster than that without adjuvant both at 4 and $30 \mathrm{C}$, and could not be improved by addition of $7.5 \%$ sucrose or combination of sucrose and $0.01 \%$ Tween 20 [51]. One possible cause for the protein instability is the different microenvironment $\mathrm{pH}$ on the aluminum particle surface. It has been shown that the surface of aluminum hydroxide is about 2 $\mathrm{pH}$ units higher than the bulk $\mathrm{pH}$ due to accumulation of hydroxyls on the particle surface [69]. Therefore, for a $\mathrm{pH}$-sensitive antigen, the bulk $\mathrm{pH}$ needs to be adjusted lower than its optimal value to maximize its stability on the adjuvant surface. Addition of formulation excipients could be effective, such as $20 \%$ propylene glycol in an aluminum hydroxide-adjuvanted hepatitis $\mathrm{B}$ vaccine (HBsAg) [70].

\section{2nd-Generation Adjuvants}

The aluminum salts clearly have a limited and in some cases, no adjuvantation effect clinically [71]. The limitation prompted extensive search and development of nonaluminum (2nd-generation) adjuvants in the past 20 years $[7,72,73]$. Novel adjuvants are highly desired for more potency, more balanced immune response and less side effect/reactogenicity [72,73]. Significant progress has been made as exemplified in the successful use of several novel adjuvants on the European market (Table 2). In general, such adjuvants works through several mechanisms-antigen presentation, adjuvant-antigen complexa-
Table 2. Non-aluminum vaccine adjuvants currently used in licensed products.

\begin{tabular}{clcc}
\hline Adjuvants & \multicolumn{1}{c}{$\begin{array}{c}\text { Adjuvant } \\
\text { composition }\end{array}$} & $\begin{array}{c}\text { Representative } \\
\text { Products }\end{array}$ & Indications \\
\hline \multirow{2}{*}{ AS03 } & $\begin{array}{l}\text { Squalene-based } \\
\text { oil-in-water } \\
\text { emulsion }\end{array}$ & Pandemrix & $\begin{array}{c}\text { Pandemic } \\
\text { flu }\end{array}$ \\
AS04 & MPL + alum & $\begin{array}{l}\text { Fendrix } \\
\text { Cervarix }\end{array}$ & HBV \\
HPV \\
MF5 & $\begin{array}{l}\text { Squalene-based } \\
\text { oil-in-water } \\
\text { emulsion }\end{array}$ & Fluad & $\begin{array}{c}\text { Seasonal } \\
\text { flu }\end{array}$ \\
$\begin{array}{l}\text { Virosomes } \\
(150 \mathrm{~nm})\end{array}$ & $\begin{array}{l}\text { Phosphatidylcholine } \\
\text { bilayer liposomes }\end{array}$ & Inflexal V & $\begin{array}{c}\text { Seasonal } \\
\text { Flu }\end{array}$ \\
\hline
\end{tabular}

tion/depot, enhanced antigen delivery to/into DCs, recruitment of immune cells, and immunomodulation, etc.

\subsection{Oligonucleotides}

Oligonuceotides (ODNs) are extensively studied as vaccine adjuvants. A major sub-class of ODNs is the unmethylated CpG ODNs resembling bacterial DNA structure. A series of review articles were recently published addressing CpGs as stand-alone or secondary immunotherapeutic agent [74], approaches for enhancement of immunostimulating effect of CpGs [75], microparticlemediated enhancement of immunostimulating effect of CpGs [76,77]; dichotomous effects of $\mathrm{CpG}$ as an cancer vaccine adjuvant [78], use of various methods [79] or lipids [80] for improvement of $\mathrm{CpG}$ stability and delivery, and use of $\mathrm{CpG}$-antigen conjugates for improvement of vaccine delivery and immunogenicity [81]. Non-CpG ODNs as TLR9 agonist include 5'-TC dinucleotide structure with a thymidine-rich sequence $[82,83]$.

Immunomodulation of oligonuceotides (ODNs) is through activation of toll-like receptor 9 (TLR9) [74]. TLR9 is localized both intracellularly (endosomes of myeloid cells) and on the surface of epithelial cells [84]. TLR9 agonists directly induce the activation and maturation of dendritic cells and enhance differentiation of B cells into antibody-secreting plasma cells [74]. Since TLR9 signaling is not absolutely required in mice [85], other mechanisms of action could also be responsible for their immune enhancement, such as up-regulation of gene expression in mice [86], and formation of antigen-adjuvant complexes $[87,88]$. Combined use of vaccines and such immunostimulants is emerging as one of the innovative approaches in adjuvant development [89].

The CpG ODNs can be further classified into several categories (A-, B-, and C-class) based on their relative activity on B cell and NK cell activation and cytokine production [90,91]. All classes can induce potent Th1 effects for a variety of antigens [90-96]. In reality, use of CpGs often generates a balanced and more effective im- 
mune response. For example, use of CpG 2007 (22-mer) not only enhanced antigen (hen egg lysozyme)-specific humoral responses, but also induced long-lasting cellmediated immune response against the model antigen (HEL) in calves after SC administration [87]. Similar examples include CpG 1826 (20-mer) for OVA [88], CpG 7909 (a 24-mer, B-class) for HBsAg [97] and for a pneumococcal vaccine [98], three classes of $\mathrm{CpGs}$ for hepatitis C virus [91], and CpG ODN 2006 for inactivated gp120-depleted HIV-1 immunogen [99]. A balanced effect can make a vaccine more effective against challenging disease such as tuberculosis [100]. A balanced immunogenicity effect can be also obtained with a DNA vaccine administered with $\mathrm{CpG}$-enriched plasmids (5-20 CpG copies) [101].

$\mathrm{CpG}$ ODNs are quite effective in comparison with other adjuvants. They were demonstrated to be more effective than alum for Trypanosoma cruzi (parasite) antigens [93] and rabies virus vaccine [24] and even more effective than modified complete Freund's adjuvant (CFA with Mycobacterium butyricum instead of Mycobacterium tuberculosis) [66]. Because the effect of $\mathrm{CpG}$ is clearly dose-dependent in several studies [93,102], reducing the dose of $\mathrm{CpG}$ to $20 \mu \mathrm{g}$ or less made it less effective than a higher amount of aluminum hydroxide in mice $[96,103]$.

CpG ODNs are often added to aluminum-based vaccines for further improvement of the immune response. Such examples include BioThrax (a licensed anthrax vaccine) in mice (ip or sc) and guinea pigs [104], hepatitis $\mathrm{B}$ virus vaccine (Engerix-B) in chimpanzees [105], poliovirus vaccine in mice [96], and Plasmodium falciparum Apical Membrane Antigen 1 vaccine in humans [106]. This also seems to be the case for non-CpG ODN, such as IMT504 (24-mer) with recombinant Hepatitis B surface antigen in monkeys [107]. When CpGs are used with aluminum-based vaccines, the immunostimulatory effect of CpG may depend on the relative association of $\mathrm{CpG}$ and antigen to the aluminum adjuvant [108]. Indeed, the highest antibody response to a AMA1-C1/CPG 7909/Alhydrogel mixture in mice corresponds to a CPG 7909 concentration of saturated binding to Alhydrogel, while unbound CpG 7909 was ineffective in enhancing antibody response [109]. In contrast, changing the percentage of bound CpG 7909 on Alhydrogel in different buffer systems did not change the peak level of antibody formation in a phase I trial of a malaria vaccine [110]. Therefore, the relative importance of $\mathrm{CpG}$ binding to aluminum adjuvants needs further verifications.

CpG ODNs could also improve the immune response of mucosal vaccines, such as those applied in vagina and GI tract [111]. CpG was shown to promote a strong antigen- specific Th1-like immune response in the mucosa and local lymph nodes after mucosal application with glycoprotein D of herpes simplex virus type 2 (HSV-2) and protection against mucosal viral challenge in mice [112]. Intranasal administration seems to be especially effective in inducing both systemic and mucosal reponses [113]. Because of this, Intranasal administration of $\mathrm{CpG}$ ODN in both murine leishmaniasis and toxoplasmosis model in mice resulted in comparable results against challenge as that after subcutaneous administration [114]. In comparison, oral delivery of $\mathrm{CpG}$ ODN has not generated consistent results. While oral delivery of $\mathrm{CpG}$ ODN (20-mer) with purified hepatitis B surface antigen (HBsAg) or tetanus toxoid (TT) in mice augmented both mucosal and systemic immune responses [115], oral uptake of uncoupled $\mathrm{CpG}$ ODN resulted in a complete failure of treatment against murine leishmaniasis and toxoplasmosis infection in mice presumably due to $\mathrm{CpG}$ degradation [114]. To overcome the stability problem, Wang et al. [116] designed "second-generation" immunomodulatory oligonucleotides including: $\mathrm{CpR}, \mathrm{YpG}$, or R'pG ( $\mathrm{R}=$ 2'-deoxy-7-deazaguanosine, $Y=2$ '-deoxy-5-hydroxycytidine, and $\mathrm{R}^{\prime}=1-[2$-deoxy-beta-d-ribofuranosyl]-2oxo-7-deaza-8-methyl-purine). Indeed, these were significantly more stable than $\mathrm{CpG}$ DNA following oral administration and induced stronger local (IgA) and systemic (serum IgG2a) immune responses to ovalbumin than CpG DNA in mice.

On the other hand, use of CpGs is not always beneficial for immunogenicity. The humoral responses to intramuscular immunization with Fluarix in healthy volunteers were not significantly enhanced by inclusion of 1 mg CPG 7909 in healthy volunteers, although a positive effect was seen at 1/10th dose of Fluarix 16. A CpG ODN (20-mer) was ineffective in enhancing the antibody titer (IgG2a) of urea-solubilized p55 antigen (from HIV-1) in mice, although positive adjuvant effect was seen when it was formulated in an emulsion or when $\mathrm{p} 55$ was bound to polylactide-co-glycolide microparticles [117]. Addition of CpG 1826 did not lead to additional immune enhancement for a peptide vaccine (complexed with an immune-enhancement dsRNA adjuvant - pI:C/E749-57) in mice [118] and for a montanide ISA720-adjuvanted opossum vaccine in rats [119]. While co-administration of $\mathrm{CpG} 1826$ with a respiratory syncytial virus vaccine increased the efficacy of the vaccine, co-administration during primary infection actually enhanced the severity of the disease in mice [120].

The neutral or negative effect of CpGs could be potentially due to its inherent property. All classes of CpGs were able to induce formation of IL-10 in healthy and HCV PBMC, which is proposed to promote formation of regulatory $\mathrm{T}$ cells (Treg), leading to inhibition of Th1type $t$ cell responses [91]. Their effect on antigen integ- 
rity and the effect of other formulation excipients can also be partially responsible. $\mathrm{CpG}$ caused dissociation of antigen from Alhydrogel in the presence of phosphate and formulation excipients strongly affected CpG 7909 adsorption on Alhydrogel [108]. Recent studies showed that effect of CpG 7909 is also related to physical training in rats [121] and the immune status of the subjects [122]. Therefore, use of CpGs needs to be carefully evaluated. Clinically, $\mathrm{CpG}$ seems to be well tolerated in general but more frequent injection site pains and headaches were observed at a high dose in healthy volunteers $[16,102]$.

\subsection{Emulsions}

Traditionally, two types of emulsions are used in pharmaceutical applications-water-in-oil (w/o) or oil-in- water $(\mathrm{o} / \mathrm{w})$. Both types have been tried as vaccine adjuvants. Complete Freund's adjuvant (CFA) is a historically- tested water-in-oil emulsion containing killed bacteria [123]. It has been proven to be a very effective adjuvant and generate balanced immune response [94]. The humoral immunogenicity enhancement of CFA is more effective than aluminum salts for a 42-amino acid amyloid-beta peptide antigen [124] and for cystein proteinase antigen in mice [94]. However, severe toxicities have been observed even at a reduced dose, such as weight loss, leukocytosis, abdominal adhesions, granulomatous peritonitis, and disrupted hyalimized myofibers in mice $[94,124]$. Other animal toxicities include skin lesions in rats and arthritis in dogs [66].

The toxicities of CFA led to the development of incomplete Freund's adjuvant (IFA). With less toxicities, this adjuvant is less potent in mice [124]. In addition, the water in oil emulsions were highly viscous and not stable [123]. Further modified IFA systems (water-in-oil emulsions) were then developed, such as Montanide ISA 51, which contains mineral oil and mannide monooleate as a surfactant. This adjuvant is being tested clinically [125]. It appears to generate similar quality and intensity of immunogenicity to aluminum hydroxide but side reactions are not desirable, including granuloma, local pain, tenderness and erythema [123]. Montanide ISA 720 is another one (containing squalene, a metabolisable oil), which was shown to increase the humoral response to a malaria vaccine candidate in rhesus macaques and more potent than Alhydrogel [126]. A dose escalating phase 1 trial of a vaccine containing recombinant Plasmodium falciparum apical membrane antigen 1 (AMA1) formulated in Montanide ISA 720 did not show any vaccine-related serious adverse events [127].

In comparison, oil-in-water $(\mathrm{o} / \mathrm{w})$ emulsions seem to be safer than water-in-oil emulsions. A representative $\mathrm{o} / \mathrm{w}$ system is MF59 from Novartis, consisting of $4.3 \%$ metabolizable oil squalene from shark liver, $0.5 \%$ polysorbate $80,0.5 \%$ sorbitan triolate, and $10 \mathrm{mM}$ sodium citrate with a size of $160 \mathrm{~nm}[30,34,128]$. The proposed mechanisms for immune enhancement by MF59 include recruitment of APCs to the injection site, enhancement of antigen uptake into APCs, and activation of innate immunity without activating TLR pathways $[25,128]$. Although MF59 may be cleared independently from soluble antigens after intramuscular injection [129], its efficacy as adjuvant is likely attributable partly to its depot effect and cellular infiltration [123]. The individual components of the emulsion do not seem to be special, as replacement of the oil and surfactant maintains satisfactory immunological properties (antibody response to an antigen) in mice [130].

MF59 has been used in licensed influenza vaccine (Fluad) with good safety in more than 20 countries since 1997 [131,132]. It has been shown to be effective for a $\mathrm{HCV}$ vaccine[133]. It can initiate greater, longer-lasting, and broader immune responses than a nonadjuvanted split flu vaccine in healthy young children $[134,135]$ and in adults [136]. As an adjuvant for flu vaccine, it is more potent than aluminum-based adjuvants in terms of both antibody and T-cell responses [131]. Therefore, MF59adjuvanted vaccines were found to be more effective than a commercial product, such as hepatitis B virus (HBV) vaccine (containing recombinant PreS2 and S antigens) in healthy adult subjects [137]. However, the species- and antigen-dependent variation in immunogenicity enhancement by MF59 appears to be a deficiency of this adjuvant system $[15,138]$. MF59 does not seem to induce significant side effects compared with vaccines without MF59 in healthy adults $[137,139]$. Recent studies show that MF59 is associated with more reports of injection site pain and tenderness (local reactogenicity) relative to a non-adjuvanted flu vaccine in children and young adults [140,141].

Other MF59-like oil-in-water $(\mathrm{O} / \mathrm{W})$ emulsions have also been developed. One such system (10\% squalene, $1.8 \%$ glycerol, $1.9 \%$ phosphatidylcholine, $0.09 \%$ Pluronic F68) was shown to increase the immunogenicity of an inactivated trivalent poliovirus vaccine [142]. Another one (5\% squalene, $4 \%$ Poloxamer 105 and $2 \%$ Abil-Care as emulsifier) increased the immunogenicity of non- potentiated rabies vaccine, more effective than aluminum hydroxide [143]. CoVaccineHTTM, a submicron emulsion of squalene-in-water emulsion containing sucrose fatty acid sulphate esters, has been shown to increase the antibody responses for a whole inactivated influenza A/ H5N1 virus vaccine through TLR4 signaling in mice [144]. AF03, another oil-in-water emulsion adjuvant, was found to induce stronger antibody responses to a pandemic influenza vaccine (at $0.3 \mu \mathrm{g} \mathrm{HA}$ ) than non-adju- 
vanted vaccine in both naive and seasonal flu-primed mice [145].

A frequently studied series of oil-in-water emulsion adjuvant system is the AS series. A representative of this series is AS03, which is a $10 \%$ oil-in-water emulsionbased adjuvant system comprising squalene, $\alpha$-tocopherol and emulsifying agent Tween 80 [146-148]. AS03 has been used in the product Prepandrix (H5N1 vaccine from GSK) in EU for a few years. This adjuvant has been shown to enhance the initial priming effect of pandemic influenza vaccination and promote a rapid humoral response to a single boosting dose with a heterologous strain, not only reducing the dose of the antigen (up to 24 times) but also offering a better cross-protection against drifted strains in young, elderly, or Asian subjects $[149,150]$. In different studies, administration of AS03adjuvanted H1N1 pandemic vaccine generated same level of immunogenicity as unadjuvanted vaccine at a four-fold higher dose in adults [151], and long-term protection in health care workers [152]. On the other hand, this adjuvant system showed limited effect for a H1N1 -like virus vaccine after administration of two doses in hematopoietic stem cell transplantation recipients [153]. Although the safety profiles of AS03 is acceptable, reactions such as fever tend to increase after a second dose for a H1N1 vaccine in children of 6-35 months [154], and delayed focal lipoatrophy was reported recently after its use in a H1N1 flu vaccine [155]. These vaccine systems are certainly promising but the added complexity of emulsion preparation and difficulty in vaccine characterization are clear disadvantages.

\subsection{Iscomatrix}

The immunostimulating complex (ISCOM) is an antigen-containing particulate system while ISCOMATRIX is the antigen-free, and structurally-similar system [156158]. It was first described more than 2 decades ago as a novel structure for antigenic presentation of membrane proteins with potent immunomodulatory capability. ISCOMATRIX system consists of a Quil A-based saponin mixture (see QS21 below) combined with cholesterol [157]. This system enhances immunogenicity through several mechanisms, including recruitment and activation of APCs, extension of antigen presentation in the draining lymph node, enhancement of CD8 cross-presentation, induction of IFN- $\gamma$ and IL-6, etc $[30,159]$. Association of antigen with ISCOMATRIX seems necessary for the optimal induction of cytotoxic T lymphocyte (CTL) responses [160].

ISCOMATRIX as an adjuvant promotes both humoral and cellular immune responses due to the powerful immunomodulatory capability of saponin both preclinically and clinically $[157,158]$. Subcutaneous injection of IS-
COMATRIX $($-adjuvanted 4 dengue virus envelope proteins $(10 \mu \mathrm{g})$ resulted in adequate protection in both mouse and monkey challenge models [161]. Such an immune enhancement effect of ISCOMATRIX $(50 \mu \mathrm{g})$ on recombinant HIV gp120 vaccine can be significantly greater than that aluminum hydroxide [162]. Similarly, immunization of patients with a mixture of HPV16 E6E7 fusion protein and ISCOMATRIX adjuvant induced antigen specific cell mediated immunity in terms of antibody formation, delayed type hypersensitivity, in vitro cytokine release, and CD8 T cell responses [163]. To mitigate the potential safety issues related to ISCOMATRIX, Matrix M, the particles made of two selected and purified fractions of saponin, was developed and found to be effective to initiate strong immediate and long-term humoral immune response for influenza H5N1 vaccine with a balanced Th1/Th2 cytokine profile and high crossreactivity against drifted $\mathrm{H} 5 \mathrm{~N} 1$ viruses in mice [164].

The lipophilic nature of the ISCOMATRIX also makes it an effective mucosal adjuvants. It was shown to induce more effective pulmonary protection (10-100 fold dose sparing) against viral challenge when it is used intranasally with split influenza vaccines in mice [165]. Deep pulmonary delivery of several ISCOMATRIX-based vaccines has been shown to induce antigen-specific mucosal and systemic immunity [166,167]. It was also shown to induce local and systemic immune responses against orally delivered protein antigens, partly due to the enhancement of antigen absorption in mice [159].

The ISCOMATRIXes are promising vaccine adjuvants. Due to the side effects of component saponins (see below), their uses as vaccine adjuvants would be limited for serious indications. Further modification of this system is expected to reduce its side effect while maintain or improve its adjuvatation effect.

\subsection{Liposomes/Proteoliposome/Virosomes}

Liposomes have been shown to up-regulate several chemokine genes, including CCL2, CCL3 and CCL4, in dendritic cells [168]. Liposomes can facilitate in vivo migration of antigens [169] and deliver encapsulated antigen into cytosol of the antigen presenting cells for both cell mediated as well as humoral immune responses $[170,171]$. It is believed that uptake of liposomes is generally through a passive phagocytic or endocytic process, not by fusing with cellular membranes [172]. Charged liposomes can bind to antigen readily and enhance the uptake of antigen and the efficiency of antigen presentation [173]. Liposome- antigen complexes could induce significantly higher cellular immune responses that antigen carried by aluminum hydroxide after subcutaneous administration in mice [174]. Other additives, such as vitamine $\mathrm{E}$, can be included to improve the adjuvant ef- 
fect (novasomes) [175].

Liposomes can induce different types and levels of immune response for a variety of vaccines/antigens, such as cytosolic proteins $(\mathrm{sAg})$ of Plasmodium yoelii nigeriensis [170], tuberculosis vaccine candidate Ag85BESAT-6 [176], flu vaccine [169,177], leishmanial antigen vaccine [178], and DNA vaccine [179]. Liposomes can generate more efficient immune response [180] and less side effect (limited IgE levels) than aluminum-adjuvanted vaccines [171]. Greater effectiveness was observed in mice for a leishmaniasis vaccine adjuvanted with cationic liposomes than those adjuvanted with BCG or MPL plus trehalose dicorynomycolate [178]. Vaxfectin, a cationic lipid-based adjuvant, was shown to increase the immune response for a seasonal influenza vaccine with $a \geq 10$-fold dose sparing effect in mice and the type of effect (Th1 or Th2) could be directed simply by varying the ratio of adjuvant to antigen $[181,182]$. Similar effect could also be obtained by adding/varying other liposome components such as lipid A [183] or an immunomodulator $\alpha, \alpha^{\prime}$-trehalose 6,6'-dibehenate (TDB) [184].

The type and degree of immunogenicity enhancement by liposomes depends on liposome's composition, size, the type of antigens [185], and interestingly, the chirality of lipids [186] Liposomes made of S. cerevisiae membrane lipids are more effective than egg PC liposomes in inducing IgG2a, IFN- $\gamma$, and IL-4 cytokine [170]. Cationic lipid vesicles (comprising a cationic cholesterol derivative, DC-Chol) bind strongly split influenza vaccine antigens and induced robust anti-influenza immune responses while neutral cholesterol/DOPC liposomes displayed virtually no stable antigen binding and no adjuvant effect in mice [187]. Replacing the polyalkylamine head group spermine with spermidine (with one less secondary amine) in a polycationic liposome reduced the enhancement of the immune response to a flu vaccine by $\sim 50 \%$ in mice [177]. Saturated phospholipids are more effective than unsaturated phospholipids in the enhancement of allergen-specific IgG response upon immunization in mice [171]. Increasing the amount of fusogenic lipids (DOPE) could further enhance the Th1 response to model OVA antigen in mice [188]. Bile salt-incorporated lipid vesicles (bilosomes) of $980 \mathrm{~nm}$ in size containing influenza A antigen generated significantly more Th1 biased response than vesicles of $250 \mathrm{~nm}$ in mice [189].

More complexed lipid-based vesicles were also developed as potential adjuvants, including proteoliposomes (PL), cochleate structures (CS), and virosomes. Proteoliposomes in different sizes contain bacterial membrane components (e.g. the outer membrane of $\mathrm{N}$. meningitidis B), including LPS, phospholipids, and traces of bacterial DNA to improve immunogenicity
[190,191]. Cochleate structures (AFCo1) are made through interaction of divalent cations with anionic lipids in proteoliposomes. Virosomes mimics the structure of a virus. Proteoliposomes can up-regulate MHC-II, CD40, CD80, and CD86 expression and production of TNF $\alpha$ and IL12(p70) in dendritic cells [192]. They were found to be effective in inducing a Th1-type immune response (production of IgG2a and IFN- $\gamma$ ) to allergens even in the presence of alum in mice [193]. Proteoliposomes can also be used as effective mucosal adjuvants. Intranasal administration of proteoliposomes containing LPS into mice led to high anti-LPS IgG titers [194]. Similarly, intranasal administration of proteoliposomes (AFPL1; 70 $\mathrm{nm}$ in size) containing glycoprotein $\mathrm{D}(\mathrm{gD})$ of herpes simplex virus type 2 (HSV-2) induced gD-specific IgG antibody formation, leading to partial protection against genital herpes infection in mice [190]. In comparison, intranasal administration of AFPL1-derived cochleate structures (AFCo1) containing the same protein elicited a complete protection in the study [190]. Indeed, the cochleate structures can be more potent than aluminum salts in inducing high levels of both IgG1 and IgG2a for a variety of pathogen-derived antigens in mice [195]. Virosomes have been successfully used in three commercial products [196]. The representative product is Inflexal V, a virosomal adjuvanted influenza vaccine, which is made of phosphatidylcholine bilayer liposomes, containing neuraminidase and hemagglutinin. By mimicking natural infection, the vaccine has shown to have good efficacy for people of all age groups [197]. The entire virosome has a diameter of $150 \mathrm{~nm}$ and have been proven safe with mostly mild to moderate symptoms resolvable within a few days [198].

The effect of liposomes on DNA vaccines has not been consistent. Intramuscular injection of Vaxfectin ${ }^{\circledR}$ - adjuvanted vaccines containing five $P$. falciparum proteinencoding plasmids enhanced both antibody and cellular immune responses to each component of the multi-antigen vaccine with no apparent antigenic competition in mice [199]. In human trials, intramuscular injections of Vaxfectin ${ }^{\circledR}$-adjuvanted H5 hemagglutinin- encoding DNA vaccine led to 4-fold rises in hemagglutination inhibition (HI) titers in $47 \%-67 \%$ of subjects [200]. However, $\leq 20 \%$ of subjects showed such a response after immunization with a trivalent Vaxfectin $\AA$ - adjuvanted DNA vaccine [200]. While liposomes, made of phosphatidyl choline (PC), dioleoyl phosphatidyl ethanolamine (DOPE), and dioleoyloxy trimethyl ammonium propane (DOTAP) in a molar ratio of 4:2:1, is a good adjuvant for DNA vaccination against hepatitis infection in Rhesus monkeys [201], subcutaneous administration of hepatitis E virus neutralizing epitope-encoding or hepatitis B virus surface antigen-encoding DNAs entrapped 
in liposomes consisting of the same types of lipids does not elicit antibody response in mice [202]. In fact, lipid-DNA complexes actually appear to inhibit the expression of the complexed DNA comparing with naked DNA after IM injection [172].

The above results show that lipid-based systems are effective and promising vaccine adjuvants with exceptions, especially for DNA vaccines. The versatility of these adjuvant systems resides in the availability of a variety of lipids and other additives to accommodate different types of antigens $[4,172,184,185]$.

\subsection{Polymeric Solutions or Particulates}

Polymeric solutions, micro-or nano-particulates can be used as effective adjuvants either alone [203] or in a complexed form with antigens [204] and/or other adjuvants [205]. Various polymers have been demonstrated to have such properties, such as polylactic acid (PLA), poly (lactide- co-glycolide) acid (PLGA) [206,207], chitosan [208-211] or modified chitosan [207], poly $(\gamma$-glutamic acid) ( $\gamma$-PGA) [212,213], polypeptides [204], starch [214,215], polystyrene [35,205], polyphosphazene [216], poly (prolylene sulfide) [217], polyethylene glycol [218], alginate [219], and their copolymers [220,221]. They enhance immunogenicity through several mechanisms, including enhancement of antigen uptake by dendritic cells (in vitro) [212], maturation of dendritic cells [212], promotion of proliferation of antigen-specific $\mathrm{T}$ cells [212], stimulation of both $\mathrm{B}$ and $\mathrm{T}$ lymphocytes [208], facilitation of activation of dendritic cells [222], viscosity-induced retention of antigens in the vaccination site [210] and controlled release of antigen by particles $[223,224]$. Uptake of such nanoparticulates could take place by DCs through both clathrin and pinocytic pathwasys [217]. The event leads to activation of the NALP3 inflammasome, promoting innate and antigen-specific cellular immunity [77]. Such particulate adjuvants could be as effective as aluminum hydroxide [221] or even the potent complete Freund's adjuvant (CFA) [212].

A widely studied polymer is polylactic acid (PLA) or poly (lactide-co-glycolide) acid (PLGA). Antigens can either be adsorbed on the surface or encapsulated inside the polymeric particles. Intramuscular administration of adsorbed antigen - Neisseria meningitidis serotype B (Men B) (99\% adsorption efficiency) on PLGA particulates with $\mathrm{CpG}$ significantly increased the anti-Men B serum antibody titers and serum bactericidal titer in mice [206]. The immunogenicity enhancement can be comparable to that by traditional aluminum hydroxide-adju-

vanted vaccine [225]; or even better than that by more advanced adjuvant such as Montanide ISA 720 [226]. Using poly (lactide-co-glycolide) as a model polymer and Neisseria meningitidis serotype B (Men B) as a model antigen, encapsulating CpG within PLG microparticles induced statistically significant higher antibody, bactericidal activity and $\mathrm{T}$ cell responses when compared to the soluble form of $\mathrm{CpG}$ [206].

Another widely studied polymer is chitosan. Addition of $0.5 \%$ of a chitosan derivative to an inactivated influenza vaccine resulted in a four or six to tenfold increase in antibody titers after intramuscular injection of a single or two doses in mice, respectively [227]. Their effect of immune enhancement can be better than the traditional aluminum adjuvants. Intramuscular administration of chitosan nanoparticle (160 - $200 \mathrm{~nm})$-encapsulated recombinant hepatitis B surface antigen (rHBsAg; $10 \mu \mathrm{g}$ ) induced a 9-fold higher anti-HBsAg IgG levels compared to the conventional alum-adsorbed vaccine in mice [223]. It was also shown to be more effective than PLGA or PLA for HBsAg vaccine [224]. Chitosan as a mucosal adjuvant enabled a M2 flu vaccine against heterologous virus challenge after intranasal administration in mice [209]. Mannosylation of chitosan can further enhance its activity as a mucosal adjuvant [228].

The degree and types of immunogenicity enhancement may be dependent on the types of polymers and preparation methods. While immunization with zinc-chitosan particles bound to histidine-tagged recombinant protein antigen promoted an IgG1 response in mice, subcutaneous immunization with a simple mixture of an influenza hemagglutinin (HA) vaccine and amphiphilic poly $(\gamma-$ glutamic acid)-graft-l-phenylalanine copolymers $(\gamma$-PGA -NPs) led to a more balanced immune response than aluminum-adjuvanted vaccines in mice [229]. Some polymer particulates may also exert their immune enhancement activity through conjugation with antigens, such as starch microparticles for protein antigens in mice $[214,215]$, and polystyrene beads for protein antigens in sheeps [35]. A more recent study suggests that a reducible linker (-S-S-) could be effective than non-reducible linkers in immunogenicity enhancement [217].

Other physical properties of particulates such as size and charge can have a significant effect on the immunogenicity. While no significant difference was found in the immune response after intramuscular administration of MenB antigen adsorbed on PLGA nanoparticles $(110 \mathrm{~nm})$ or microparticles (800-900 nm) in mice [225], PLGACTAB particles of $0.3 \mu$ were more effective than larger particles $(1$ and $30 \mu)$ in the elicitation of transgene- specific serum IgG responses [230]. The greater effect with smaller particles could be related to two factors-higher adsorption capacity of smaller particles and greater efficiency of particle uptake by dendritic cells. It has been shown that the antigens adsorbed on aluminum particles of $3 \mu$ are internalized more effectively than those of 17 $\mu$ [28]. Charged nanoparticles could present antigens 
effectively thorough electrostatic interactions with antigens. Immunization of HIV-1 Tat (1-72) protein $(1 \mu \mathrm{g}$ antigen dose) coated on anionic nanoparticles generated higher antibody titers than alum-adjuvanted vaccine [231]. Polyphosphazene (ionic, cross-linkable water soluble polymers) has been shown to have synergistic effect on enhancement of the secretion of cytokines in vitro when used with $\mathrm{CpG}$ and indolicidin, likely due to formation of antigen-adjuvant complexes [87]. Cationic block co-polymers and DNA can easily form complex structures via electrostatic interaction and were shown to elicit broad and long-lasting antigen-specific humoral and cellular responses after intramuscular administration in mice [232].

Polymeric particles are also effective mucosal adjuvants. Examples include oral administration of PLGA microsphere-encapsulated concentrated rabies virus (CRV) in mice [233], or polyacryl starch microparticle- conjugated diphtheria toxin in mice [234]. The oral uptake of particulate antigens is presumably through the Peyer's patches in the GI tract [215]. Nasal administration has not resulted in consistent results. No immune response was seen after intranasal immunization with a mixture of $\gamma$-PGA-NPs and influenza virus hemagglutinin (HA) in mice [235]. While PLGA-encapsulated OVA did not initiate induce detectable antibody titers after nasal administration in mice, high titers were observed when positively charged N- trimethyl chitosan was used [207]. This could be due to a difference in the binding strength between the antigen and polymeric particles.

The above examples demonstrated effectiveness of polymers as vaccine adjuvants. Similar to lipid-based adjuvant systems, polymeric systems appear also versatile, due to the availability of a variety of polymers and their processability for surface modification and direct conjugation with antigens. It is expected that such adjuvant systems would be further explored and optimized for enhancement of vaccine efficacy.

\subsection{Saponins and QS21}

Saponins are natural glycosides of steroids or triterpenes. They possess certain adjuvant activities, due to their structural features of sugar chain(s), its length, and hydrophilic and lipophilic properties [236]. Therefore, their adjuvant activity can be further modified by structural modifications such as GPI-0100 [237]. The widely used saponin-based adjuvants are Quil A, isolated from the bark of Quillaja saponaria (QS) Molina, and QS21, a more purified form, is the 21 st of 22 fractions in RPHPLC trace of semipurified QS bark extracts [238].

These adjuvants have been evaluated in numerous preclinical and clinical trials [239]. They have been proven to be very effective in enhancing the immunogenicity of various vaccines, including $A \beta(1-15)$ in mice [240]; foot-and -mouth disease virus (FMDV) antigen in mice [241]; L1 and A33 proteins in mice [242]; vaccinia virus proteins in monkeys [242]; parasitic antigens in sheeps [243]; keyhole limpet hemocyanin (KLH) conjugate antigens $[238,244,245]$. The effect is often toward a Th1type response in comparison with aluminum-based vaccine such as $A \beta(1-15)$, PADRE-A $\beta(1-15)-M A P)$ [240], L1 and A33 proteins in mice[242], parasitic antigen (Fasciola hepatica) in sheeps [243].

Quil A or QS21 is often much more effective than aluminum salts in immunogenicity enhancement for many antigens, such as $A \beta$ (1-15) in mice [240], and SPf66 (a synthetic malaria peptide vaccine) [246]. Exceptions do exist. QS21 did not exert any significant effect on either binding or neutralizing antibody titers after IM immunization of gp120 HIV-1(MN) protein (rsgp120) at doses of 100,300 , and $600 \mu \mathrm{g}$, even though it is effective at a lower antigen dose [247]. Similarly, QS21 adjuvant was not effective in enhancing the immunogenicity of an inactivated influenza vaccine in healthy young adults, in terms of serum titers, $\mathrm{T}$ cell cytotoxicity, and IFN- $\gamma$ levels [248].

A key issue of saponins is their induction of red blood cell hemolysis, and they are painful to inject with high local reactogenicity [30,239]. The more purified form QS21 is much better tolerated but the side effects still prevent its use as an effective adjuvant. These side effects include moderate to severe pain for a recombinant HIV protein vaccine [247], site pain and postvaccination myalgias for inactivated influenza vaccine in healthy young adults [248], malaise, headache, fever, and nausea [247]. Two out of 89 subjects developed severe vaccine allergy following the third dose of 1/3 QS21/SPf66 formulations (a synthetic malaria peptide vaccine) [246].

Because of these potential toxicities, alternative sources or structural modifications of saponins were then sought. Platycodin D (PD), a saponin from the root of Platycodon grandiflorum without the acyl domain, is less hemolytic, very stable in aqueous solution, and enhanced the immunogenicity of hepatitis $\mathrm{B}$ surface antigen (HBsAg) in mice [249]. This led to deacylation of QS21 but the deacylated QS21 was less effective as an adjuvant for ovulbumin in inducing $\operatorname{IgG} 1$ responses and inactive in inducing $\mathrm{IgG} 2 \mathrm{a}$ or CTL responses at any doses in mice [250]. A semi-synthetic saponin (GPI-0100) was found to enhance the immunogenicity of a single tandem fusion protein in mice [251] and enhance antibody titers against the glycolipid Globo $\mathrm{H}$ and the glycosylated mucin MUC2 with only occasional grade II local toxicity at a dose of $5000 \mu \mathrm{g}$ in cancer patients [252]. Less haemolytic saponins were also found in Chinese herbs [253]. Some are effective, such as Achyranthes bidentata (herb) 
saponins [254], Glycyrrhiza uralensis (herb) saponins (GLS) [255], Bupleurum chinense (herb) saponins [256], and Panax ginseng (root) saponins [257].

The side effects of QS21 is a clear disadvantage for this adjuvant. Additional structural modifications could potentially overcome this deficiency but may lose adjuvantation effect at the same time. It is expected that future use of this adjuvant would be limited to serious indications.

\subsection{Virus-Like Particles (VLPs)}

Virus-like particles (VLPs) has been widely used for vaccination against the corresponding virus such as influenza virus $[175,258]$. VLPs possess key immunologic features of viruses-repetitive surfaces, particulate structures and induction of innate immunity through activation of pathogen-associated molecular-pattern recognition receptors. Therefore, they can facilitate presentation of a foreign antigen or hapten to the immune system through chemical conjugation or genetic fusion.

Most VLP-conjugate vaccines seem to be effective. Examples include CCR5 peptide-VLP conjugates for HIV [259], M2 peptide-VLP conjugate for influenza [260], nicotine-VLP conjugates via succinimate linkers for nicotine addiction [261]. It should be noted that VLPs may not be very stable in an aqueous solution and could be responsible for lower-than-expected immunogenicity [262]. Conjugation of VLPs with haptens may improve the stability of VPLs [260]. DNA vaccines containing proper antigens can be designed to form VLPs in vivo, inducing strong cellular immune responses [263]. Multiple tandem copies of antigens can be incorporated in such a vector for enhanced immunogenicity [264].

Virus replicon particles (VRP) can also be used as an effective systemic, cellular or mucosal adjuvant. Intramuscular delivery of equine encephalitis VRP-conjugated OVA induced dose-dependent immune response in mice [265]. Alphavirus replicon particles have been shown to enhance the immunogenicity and effectiveness of Fluzone ${ }^{\circledR}$ vaccine in rhesus macaques [266] and to induce high antibody titers to the influenza hemagglutinin (HA) protein in pigs [267].

VLPs hold great promise as effective vaccine adjuvants, and particularly as effective carriers for non-immunogenic haptens. A clear disadvantage is the complexity of expression, production, and purification of VLPs, adding significant manufacturing cost to the final vaccine product. Additional chemical conjugation steps would further reduce the final yield and incur additional production cost.

\subsection{Carrier Proteins}

Small-molecule drugs or even protein antigens may not initiate any or adequate immune response. They can be conjugated or fused to an effective protein antigen to generate adequate immune response. Such carrier proteins have been recently reviewed, such as keyhole limpet hemocyanin (KLH), and bacterial proteins [268]. KLH belongs to the largest oxygen-transporting proteins in nature and the glycoprotein moiety is critical for the antigenicity of the molecule. Yet, use of KLH conjugate alone may or may not initiate adequate immune response and another adjuvant often has to be used. Such combinations include KLH conjugates with QS21 for cancer antigen (GD3; ganglioside) [238], with Freund's adjuvant for influenza virus A M2 peptide [269], and with other adjuvants for cancer antigens (MUC1 and GD3) $[237,244]$. The structure of linkers between hapten/antigen and KLH carrier protein may have a significant effect on the immunogenicity and selectivity of the conjugated vaccine [270].

Conjugation or fusion of a hapten or antigen with a bacterial or parasitic protein is frequently used. A class of such proteins is the bacterial heat shock proteins (HSPs). Success examples include HSP70 conjugates with viral MHC Class I-restricted epitope (for Herpes Simplex Virus Type-1) [271], and HSP65 conjugates with a protein containing linear repeats of the gonadotropinreleasing hormone (GnRH3), the hinge region of human IgG1 (hinge),or a T-helper epitope from the measles virus protein (MVP) [272]. The immunogenicity enhancement can be comparable to that with Freund's adjuvant. Because HSPs can effectively induce partial maturation of DCs in vitro [273], such proteins, as free forms, can also enhance immune responses of antigens but the effect may not be as strong as other adjuvants such as CFA or LPS in mice [273]. Plasmid expressing heat shock proteins (HSPs) could achieve the same effect [274].

Other bacterial proteins can also be effective. Fusion of the Brucella spp. lumazine synthase (BLS), a highly immunogenic (decameric) protein, with a model virus protein domain (C486 bovine rotavirus VP8 core protein (VP8d)) led to almost $100 \%$ protection against homologous challenge with $\mathrm{C} 486$ bovine rotavirus [275]. Conjugation of synthetic peptides of influenza virus A M2 extracellular domain with Neisseria meningitidis outer membrane protein complex (OMPC) was able to confer protection against lethal challenge of either H1N1 or $\mathrm{H} 3 \mathrm{~N} 1$ virus in the presence of Freund's adjuvants in mice [269].

In general, carrier proteins as vaccine adjuvants seem to have limited adjuvantation effects, as the protein itself may have limited immunogenicity. Therefore, additional adjuvants may have to be used to initiate adequate immune response. 


\subsection{Toxins}

Toxins represent one of the most potent adjuvants, especially for mucosal vaccines. Bacterial toxins are considered the most potent mucosal adjuvants such as heatabile enterotoxin and cholera toxin [34]. Intranasal delivery of ovalbumin with a recombinant bacterial enterotoxin Zonula occludens toxin (Zot; 45kD single polypeptide chain) induced high Ag-specific serum IgG titers over a year and is effective also through other mucosal routes in mice [276]. It can increase reversibly the intestinal mucosa permeability by affecting the structure of tight junctions. Several mutant heat-labile enterotoxins were found to be effective as adjuvants for nasal administration of pneumococcal vaccine [277], deglycosylated chain A ricin (DGCA) [278], or influenza vaccine [279], and for vaginal administration of inactivated caprine herpes virus 1 vaccine [280].

Different toxins may offer different degrees of effect. Zonula occludens toxin (a bacterial enterotoxin; $45 \mathrm{kD}$ single polypeptide chain) is highly efficacious when compared to the mucosal adjuvant Escherichia coli heat-labile enterotoxin (LT) [276]. However, two major issues prevent them from use as vaccine adjuvants-their toxicities and the residual bacterial endotoxins. Options to bypass their toxicities include use of subunits of toxins, toxoids, or structurally modified versions [281]. The toxin subunits could be still effective [282,283] but a less adjuvantation effect would be expected relative to the complete toxin [284]. Several non-toxic LT mutants have been recently reviewed [285]. A successful one is the nontoxic mutant of diphtheria toxin CRM197 [286].

Conjugation of these less effective toxin subunits or toxoids to antigens could potentially restore the original efficiency in immunogenicity enhancement. Successful examples include fusion of subunit B of LT to a viral protein [287], conjugation of toxoids to capsular polysaccharides of many invasive bacteria such as Streptococcus pneumoniae, $H$. influenzae type $b$, meningococci, pneumococci $[2,288,289]$, and conjugation of LT subunits with $\mathrm{CpG}[111,290]$. It should be noted that the bacterial toxins can initiate a strong humoral immune response, which may overshadow the response to the conjugate antigen [7]. Adjuvants could also potentially enhance antibody formation against both the conjugate antigen and the toxins [244].

The above examples demonstrated that toxins or their derivatives are effective antigen carriers for immunogenicity enhancement, especially for mucosal vaccinations. The potential immune response against both the original antigens and toxins need to be evaluated for possible mutual interferences.

\subsection{Lipopolysaccharides/Polysaccharides}

Lipopolysaccharides (LPS) are proven to be effective adjuvants in many studies. Mechanistically, LPS activates TLR4 and directs DCs for a Th1 response [11,29]. LPS can facilitate internalization of particles by dendritic cells [291], stimulate significantly expression of CD40, CD80, CD86 and CD275 in dendritic cells, and also stimulate release of IL-6, IL-12p40, and IL-12p70 [29]. Generation of a Th1 response can also be induced by LPS fused with calreticulin/peptide complex in mice [292]. If bound to proteins, bacterial polysaccharides could induce both $\mathrm{T}$ and $\mathrm{B}$ cell arms of an immune response [268].

The potential toxicities of these compounds, especially those from Gram-negative bacteria are the barrier for human use [293]. The purified Neisseria meningitidis serogroup B lipopolysaccharide (LPS) has high endotoxic activity but can be detoxified through structural modifications. LPS analog LpxL1 from Neisseria meningitidis is non-toxic and incorporation of this analog LpxL1 in influenza H5N1 virosomes induced significantly enhanced H5N1-specific total IgG titers as compared to non-adjuvanted virosomes in mice [294]. Conjugation with tetanus toxoid (TT) reduced the endotoxic activity of LPS by 2400 times and the conjugated LPS-TT elicited higher anti-TT IgG2a and IgG1 levels than unconjugated TT in mice [295]. In addition, high levels of anti-LPS IgG and IgG subclasses were also detected in sera.

Many polysaccharides have been shown to potentiate immune response, such as $\gamma$-inulin, a human polysaccharide for HBsAg [293], Advax, a inulin-based polysaccharide for Japanese encephalitis vaccine in mice [296], PAP, a water-soluble polysaccharide from the mycelium of Polyporus albicans (edible fungus) for subcutaneous immunization of mice with ovalbumin [297], BOS 2000 (polysaccharides from Boswellia serrata) for hepatitis B in mice [298], lentinan (a (1-3)-beta-D-glucan from the mushroom Lentinus edodes) or its sulfated form for Newcastle disease (ND) vaccine [299]. Their effects can be more effective than alum-based vaccine [296,298]. Intradermal administration of bovine serum albumin conjugated to microparticulate $\beta$-glucan (MG) from yeast Saccharomyces cerevisiae enhanced the primary $\operatorname{IgG}$ antibody response to BSA in a manner comparable to the prototypic complete Freund's adjuvant in mice [300].

It seems that the endotoxic activity of LPS needs to be reduced before it can be used safely as a vaccine adjuvant. Detoxification could be done through purification, structural modification, or conjugation to another toxoid. In comparison, polysaccharides seem to be much safer but their adjuvantation effect may not be adequate. As 
for toxins, the simultaneous immune response to both the original antigen and LPS needs to be evaluated for mutual interferences.

\subsection{Monophosphoryl Lpid A/Lipids}

Monophosphoryl lipid A (MPL or MPLA) is a detoxified (chemically modified) form of the endotoxin lipopolysaccharide (from Salmonella minnosota). Its properties and applications have been reviewed recently [301]. Similar to LPS, it exerts its action through toll-like receptor 4. OM-174, a lipid A analog when injected intravenously or subcutaneously in mice, induces the migration of DCs from the periphery to the $\mathrm{T}$ cell areas of lymphoid organs, and their maturation into cells expressing high levels of MHC class II and co-stimulatory molecules, with its potency close to that of Escherichia coli lipopolysaccharide (LPS) [302].

Both Th1- or Th2-biased response was observed with MPL-adjuvanted vaccines. Administration of the full length recombinant Toxoplasma GRA2 or GRA6 protein antigen in combination with MPL adjuvant led to a Th1 response in mice [303]. Similar Th1 effects were also observed with vaccine Fluzone [304] or recombinant antigens [305], both adjuvanted with synthesized hesaacylated lipid A derivatives in mice and Leishmania sterol 24-c-methyltransferase antigen with MPL-SE [306]. In contract, subcutaneous immunization of MPL-adjuvanted ovalbumin or glutaraldehyde-modified ragweed pollen extract enhanced IgG1 titer (barely increased IgG2a) in mice [307].

Many other lipids have been shown to have immunomodulating effect, certainly for those from microorganisms [308,309]. Lysophosphatidylcholine (LPC) mixed with various antigens induced cytotoxic $\mathrm{T}$ cell responses and production of antigen-specific antibodies with an efficiency similar to Alum in mice [310]. Synthetic alkylglycerol analogues in a mixture with ovulbumin have been shown to increase anti-Ova IgG antibody production in sera of immunized mice and the relative levels of IgG1 and IgG2a depended on the carbon chain length [311]. Immunization of mice with an HBV vaccine with various doses of $\beta$-glucosylceramide ( $\beta$-GC), $\beta$-lactosylceramide $(\beta$-LC), or a combination of both augmented both the anti-HBV titers and the percentage of mice exhibiting high titers [312]. A similar lipid, $\alpha$-galactosylceramide $(\alpha$-GalCer) increased the immune response after repeated intranasal or oral delivery of HIV peptide antigens [313]. This compound was able to stimulate repeatedly NKT cells without inducing anergy of NKT cells [314]. More recently, step-wise screening of 25 $\alpha$-GalCer analogues led to the identification of a glycolipid 7DW8-5, which is a more potent adjuvant than $\alpha$ GalCer on HIV and malaria vaccines in mice [315,316].
Mucosal applications of lipids can also be effective. Several studies have shown that intranasal delivery of a HIV-1 genetic vaccine (plasmids) in the presence of a cationic lipid adjuvant, the Eurocine N3, resulted in vaginal and rectal IgA responses as well as systemic humoral and cellular responses in mice [317,318]. Initial immunization can be boosted intranasally with a gp41 peptide in an anionic L3 adjuvant for a lower dose of DNA [317].

Although MPL is currently a component of a licensed cancer vaccine (Melacine), its potential toxicity led to synthesis of MPL analogues. Three such analogues, synthesized by different substitutions at 3-O-position of the reducing sugar, were all found as effective as the natural compound in inducing antigen specific T-cell proliferation and interferon- $\gamma$ production with a liposome vaccine [319]. A hexaacylated lipid A derivative was recently found to be more potent than MPL on DC maturation and expression of cytokines/chemokines [305]. The exploration of MPL derivatives or other glycolipids would continue in the development of future vaccines.

\subsection{Cytokines}

Cytokines have been tried as valuable adjuvants. They can be used either systemically and mucosally, such as mutant TNF- $\alpha$ [320,321]. The majority of tested cytokines are briefly summarized below.

\subsubsection{Interferons}

Type I interferons (IFN- $\alpha$, IFN- $\beta$ and IFN- $\omega$ ) are cytokines with multiple biological activities in innate immunity, dendritic cell maturation/differentiation, etc. IM vaccination of mice with a flu vaccine with IFN- $\alpha$ generated clear-cut $\mathrm{IgG}$ production (IgG2a rather than $\mathrm{IgG} 1$ and also $\operatorname{Ig} \mathrm{A}$ ) and complete survival to infection with flu virus [322]. In a similar study, intramuscular injection of flu vaccine Vaxigrip ad-mixed with IFN- $\alpha$ markedly increased the serum levels of all four classes of flu-specific IgGs (IgG, IgG1, IgG2a, and IgA) in a dose-dependent manner in mice [323]. Coadministration of interferon- $\alpha 2 b$ (Intron A) with hepatis B vaccine (Egerix B) by IM initiated earlier and higher seroprotection with improved Th1 response in haemodialysis patients [324]. Plasmid encoding IFN- $\alpha$ can also be an effective adjuvant for protein antigens [325].

IFNs can be effective in mucosal vaccinations. A single intranasal administration of IFN $\alpha \beta$-adjuvanted vaccine resulted in a full protection of $100 \%$ of mice against virus challenge while vaccine alone was only partially effective (40\%) [326]. However, the efficacy seen in animals has not translated into efficacy in humans. Addition of IFN- $\alpha$ to a trivalent flu vaccine did not change significantly the serum neutralizing antibody response 
nor the IgA antibody response in respiratory secretions of humans after nasal administration [327].

\subsubsection{Granulocyte-Macrophage Colony Stimulating Factor}

Granulocyte-macrophage colony stimulating factor (GMCSF) can attract and stimulate macrophages, leading to increased antigen presentation [328]. It increased the rate of immune response (earlier seroconversion) and antiHBs titers in human subjects relative to hepatitis B virus vaccination alone [329]. Administration of plasmids encoding GM-CSF can also be effective for DNA vaccines, such as HIV-1 Gag DNA vaccine [330-332] and murine vaccinia env pDNA vaccine [331,332].

On the other hand, results from human trials have not been consistent. In some studies, GM-CSF appeared to have minimal effect or even a suppressive effect, apparently related to the dose level and frequency [328]. In a recent clinical trial, use of GM-CSF as adjuvant in a novel multiepitope peptide vaccine was minimally immunogenic (6 of 80 volunteers) in developing transient HIV-specific responses [333]. In addition, the vaccine induced formation of anti-GM-CSF antibody in the majority of GM-CSF recipients333. In another example, subcutaneous administration of GM-CSF as an adjuvant for a tetanus toxoid-adjuvanted influenza or hepatitis A vaccine did not augment the antibody responses in normal volunteers relative to vaccination alone [334]. In fact, subjects who received GM-CSF had statistically significant lower increases in anti-tetanus antibodies.

\subsubsection{Interleukins}

Several interleukins have been tried as vaccine adjuvants and proven to be effective. IL-12 has been extensively tested for its adjuvant activity not only systemically but mucosally [335]. IL-12 promotes differentiation of CD4+ cells towards a Th1 immune response. Its effect seems due at least partially to its inflammatory properties. S. C. injection of recombinant human IL-12 (rhIL-12) in patients with renal cell cancer induced dose-dependent systemic activation of multiple inflammatory mediator systems [336]. Increasing the dose of rhIL-12 in a human cytomegalovirus (CMV) vaccine gradually increased the peak anti-CMV gB IgG titers and CMV viral lysate- specific CD4+T cell proliferation [337]. DNA expressing IL-12 was also shown to be an effective adjuvant for SIVmac239 gag pDNA vaccine in rhesus macaques [338], VSG antigens expressed by Trypanosoma brucei, and pneumonic plague after both systemic or nasal administration in mice [339,340].

However, use of IL-12 as an adjuvant should be limited to severe diseases as it increases incidence of local and systemic side effects. Such side effects include injection site pain, fever, headache, myalgia, general pain, chills, and increased cough side effects observed when used concurrently with a pneumococcal polysaccharide vaccine in healthy volunteers [341]. Therefore, the amount of IL-12 as an adjuvant was suggested not to exceed a dose of $0.1 \mu \mathrm{g} / \mathrm{kg}$, in order to avoid severe systemic inflammatory responses [336].

IL-15 is a powerful immune stimulatory cytokine with a wide range of biological activities. It plays critical roles in the activation, proliferation and differentiation of CD8 + T-cells and NK-cells. SC vaccination of mice with a multi-valent TB vaccine with IL-15 induced comparable $\mathrm{CD} 4+\mathrm{T}$ cell and greater CD8+T cell and antibody responses against Mycobacterium tuberculosis compared with the standard BCG vaccine [342]. Insertion of IL-15 in a recombinant $\mathrm{TB}$ virus make it an effective vaccine for generation of consistent anti-TB responses in mice and equal protection as BCG vaccine against $\mathrm{M}$. tuberculosis challenge after heterologous prime/boost regimen (priming with a fusion TB antigen adjuvanted with dimethyldiotacylammonium bromide/monophosphoryl lipid A and boosting with the recombinant TB virus) [343]. Combining IL-15 with $\mathrm{CpG}$ generated synergistic effect on the immunogenicity of a SIV mucosal vaccine [344]. Similarly, plasmids encoding IL-15 could also be effective for a variety of vaccines tested in mice, such as a tumor antigen-derived peptide vaccine [345], HIV-1 DermaVir vaccine formulated with HIV-1 Gag plasmid (more potent than IL-7) [346] and flaviviruse DNA vaccine [347].

Recombinant IL-2 has been shown to increase the immune response (Th1) of $78 \mathrm{kDa}$ antigen of Leishmania donovani in mice and provided better protection against challenge than other adjuvants, including monophosphoryl lipid A, liposomal encapsulation, and even Freund's adjuvant [348]. Metronomic low dose of IL-2 as a biological adjuvant has been applied in combination with a recombinant vaccinia virus vaccine encoding prostate-specific antigen (PSA) can induce prostate-specific immune responses with markedly reduced toxicities [349].

Other interleukins that have been tested for adjuvantation effect, include IL- $1 \alpha$ and IL1 $\beta$. Intranasal immunization with pneumococcal surface protein A or tetanus toxoid with IL- $1 \beta$ induced immune protection equivalent to that induced by parenteral immunization with alumbased vaccines in mice [350].

The above results show that cytokines can be used as potential adjuvants with a variety of vaccines. Combination of cytokines can be more effective than a single one, either as a co-expressing plasmid or a mixture of proteins [351,352]. Nonetheless, their positive effects as adjuvants have not been consistent in many cases. Further studies are needed to understand their different behav- 
iors.

\subsection{Specific Peptides/Proteins}

Generally, peptides are too small to change the immunogenicity of an antigen. However, peptides of special structures do have such an effect. Among all peptides studied, IC31 seems to be among the most widely reported. Actually, it is a vehicle made of both cationic antimicrobial peptide KLKL(5)KLK and ODN and therefore, one component can affect the effect of the other [353]. It generally promotes efficient Th1 responses $[88,353]$. This adjuvant was found to increase the immunogenicity of a mycobacterial vaccine antigen, and offered a comparable protective efficacy to the standard BCG vaccine in mice [354]. In a different study, IC31 was shown to increase the $\mathrm{HI}$ titers and induction of IFN- $\gamma$ producing $\mathrm{CD} 4+\mathrm{T}$ cells after single vaccination with influenza vaccine in both young and aged mice [355].

Several other small peptides were found to be effective as adjuvants. Co-administration of WKYMVm (a synthetic peptide) with HIV, HBV or Influenza DNA vaccines selectively enhanced the vaccine-induced CD8 $(+)$ $\mathrm{T}$ cell responses in a dose-dependent manner in mice [356]. Another one is complement component C5a YSFKPMPLaR (EP54). B and T cell epitopes attached to EP54 $(0.2 \mu \mathrm{M})$ were easily internalized by human DCs, which induced activation of genes specific for the Th1 and Th2 cytokines [357]. Another complement component C5a65-74 (EP67) was also shown to induce Th1 (inflammatory) cytokines from C5a receptor-bearing antigen presenting cells and immunization of EP67-valbumin resulted in higher OVA-specific antibody titers (IgG1, IgG2a and IgG2b) in mice [358]. Its adjuvantation effect seems to be better alum or $\mathrm{CpG}$, as shown in a recent study [359].

Host defense peptides (HDPs) are small and positively charged peptides. Indolicidin (a bovine host defense peptide; cationic;13-mer), CpG1826 (20-mer) and polyphosphazene can form a complex, enhancing antibody formation and cell-mediated response in mice88. Substitution of the proline residues in indolicidin with arginine increased the synergistic adjuvant effect of the peptide. Similarly, a synthetic cationic defense peptide (HH2; 12 mer) forms a complex with CpG 10101 and significantly increases the immunogenicity of pertussis toxoid in terms of toxoid-specific antibody formation (both $\operatorname{IgG}$ and $\operatorname{IgA}$ ) relative to toxoid alone in mice [360]. A modified (Arg and IsoLeu replaced) HDP - Bac2A (11 aa) was also shown to increase the immune response (Th2) to subcutaneous OVA and enhance the adjuvant activity of $\mathrm{CpG}$ to OVA in mice [361]. A hypothesis for the improved adjuvant activity of the modified peptides is the en- hanced stability.

Peptides derived from microorganisms can be used as effective adjuvants, such as muramyl glycopeptides, analogs of muramyl dipeptide (MDP), glucosaminylmuramyl dipeptide (GMDP), and desmuramyl peptides. Changes in both the sugar and the peptide structures can improve the immunostimulating and adjuvant activity and suppress adverse side effects [362]. Coadministration of GK1 (19-mer from Taenia crassiceps cysticerci) with an influenza vaccine increased levels of anti-influenza antibodies (higher IgG levels than that with aluminum hydroxide), reduced the local inflammation that accompanied influenza vaccination itself, and favored virus clearance after infection in mice [363].

CEL-1000 (18-mer) is an analogue of peptide G (a peptide from human MHCII beta chain, aa 135-149), which is known to enhance immune responses of other immunogenic peptides. They can be conjugated to HIV (HGP-30) and malaria peptides as potential vaccines. SC administration of the conjugate CEL-1000-HGP-30 led to a 4-10-fold higher titer in antibody response than seen with several other peptide conjugates (such as KLH) in mice [364]. Improved adjuvant activity of CEL-1000 for the peptide conjugates was also demonstrated by a shift in the antibody isotypes toward a Th1 response (IgG2a). CEL-1000 did not induce detectable self-directed or cross reactive antibodies [364].

These peptides can also be used as mucosal vaccine adjuvants. Macrophage-activating lipopeptide (MALP; $2 \mathrm{kD}$; a TLR2/6 agonist) has been proven to be an effective adjuvant in several studies. Intranasal vaccination with HIV-1 matrix protein p17 and immunomodulator MALP-2 (a synthetic derivative of the MALP) stimulated strong humoral and cellular immune responses both at systemic and mucosal levels [365]. Similar results were reported in heterologous prime/boost vaccination- intradermal priming with the HIV-1 Tat protein and intranasal boosting with the Tat protein co-administered with the mucosal adjuvant MALP-2 in mice [366]. The pegylated form of MALP-2 was also effective in inducing strong humoral and cellular immune responses after intranasal vaccination in mice [367].

Lactoferrin is a natural immune modulator and has been shown to decrease pro-inflammatory cytokines and chemokines, increase regulatory cytokines, enhance the ability of BCG-infected BMDCs to respond to IFN- $\gamma$ activation through up-regulation of DC maturation markers, increase IFN- $\gamma$ production, promote generation of antigen-specific T cells, etc [368,369]. Indeed, it was shown that co-administration of lactoferrin with a BCG vaccine increased host protection against Mycobacterium tuberculosis (MTB) infection in terms of organ bacterial load, lung histopathology, and significant reduction in 
tissue CFUs compared with BCG alone in mice [370]. In addition, it was shown that the sialylated form of lactoferrin was more effective in increasing the immune response in terms of IFN- $\gamma$, IL- 6 and IL-12 production in mice and in protecting the animals against infection in challenge studies [371].

CD40 is a co-stimulatory receptor on B lymphocytes. Agonistic antibodies against CD40 have great potential as immunological adjuvants to induce strong antibody responses against conjugated antigen [372,373]. It is believed that the adjuvant effect is mediated at least in part through enhanced antigen presentation by specific B cells [373]. Such immune enhancement activity of CD40 antibody is similar to that of CD40 ligand, which has been shown to enhance cellular immune activity in mice [374]. Conjugation of anti-CD-40 to antigen (HSV glycoprotein D) enhanced the immunogenicity of the antigen [375]. Similarly, CCR5 agonists could also be used as potential adjuvants [376].

Another similar concept is the use of immune complex to enhance the immunogenicity of antigens. It has been shown that interaction of anti-CD4-binding site (CD4bs) Abs with HIV-1 gp120 induces conformation changes that lead to enhanced antigenicity and immunogenicity of neutralizing epitopes in the V3 loop and $\mathrm{C} 1$ regions of gp120 of several subtypes and the immune complexes as immunogens induced serum Abs to gp120 and V3 at significantly higher titers than those induced by the respective uncomplexed gp120s [377]. Fusion of the c-terminal domain of gp96 to transmembrane and extracellular domain of rat Her2/neu enhanced the immunogenicity of Her2/neuIt DNA vaccine [378]. It is possible that such an immunogenicity enhancement is due to increased rigidity of the protein antigen. Such a rigidity concept may explain why administration of plasmids encoding aggregation-prone103Q-GFP generated significantly higher antiGFP antibody titer than plasmid encoding control or soluble 25Q-GFP [379].

The above results demonstrated availability of a variety of peptides and proteins as potential vaccine adjuvants for different kinds of vaccines. The concept of using small but immunogenic peptides is plausible, as they are easy to synthesize and can be further modified for optimization of their adjuvantatioun effect. Development of a peptide vaccine adjuvant could be one of the focus areas in the future.

\subsection{RNA-Like Compounds}

Foreign RNAs and RNA-like compounds can initiate immune stimulatory effects [380,381]. Such effects include activation of TLR3, recruitment of mature APCs, and induction of proinflammatory cytokines [381]. A synthetic and seemingly popular dsRNA is poly(I:C) (polyinosine- polycytidylic acid). The immune stimulatory effect of poly (I:C) is likely through activation of TLR3 [382,383], and possibly other receptors as well [380]. Stimulation of bone marrow-derived murine dendritic cell populations with poly(I:C) results in Th1- polarized maturation of dendritic cells in mice [92]. Indeed, poly (I:C) treatment in mice was associated with a rapid induction of inflammatory cytokines in the serum, including IL-6, IL-10, MCP-1, TNF- $\alpha$, IFN- $\alpha$, and IFN- $\gamma$, and selective increases in the numbers of NK $(\mathrm{NK} 1.1(+) \mathrm{CD} 11 \mathrm{~b}(+))$ cells [382]. These effects make it an effective adjuvant for pneumococcal surface protein A vaccine against secondary pneumococcal pneumonia in mice [384].

The immunostimulation of poly (I:C) can be more effective than other adjuvants. Poly (I:C) complex with a peptide epitope - E749-57 (derived from the HPV 16 E7 protein) was shown to induce strong E749-57-specific CTL responses, leading to significant regressions of model human cervical cancer tumors - an effect much better than E749-57 conjugated with CpG1826 in mice [118]. Combination of poly (I:C) with other adjuvants could further enhance the adjuvantation effect. Inclusion of poly(I:C) $(100 \mu \mathrm{g})$ in a Montanide-ISA51/GP33 (50 $\mu \mathrm{g}$, peptide 33-41 of LCMV glycoprotein) vaccine significantly enhanced the proliferation of antigen-specific $\mathrm{CD} 8+\mathrm{T}$ cells, greater than $\mathrm{CpG} 1826(50 \mu \mathrm{g})$-adjuvanted vaccine after SC administration in mice [383]. Another example is the combination with zymosan, a cell wall extract from Saccharomyces cervisiae for a flu vaccine for intranasal administration [385].

Recently, another similar adjuvant, polyI:polyC12U (Ampligen ${ }^{\circledR}$ ), a toll-like receptor 3 agonist, has been shown to be more effective as a mucosal adjuvant for intranasal H5N1 influenza vaccination (formalin- inactivated A/Vietnam/1194/2004 strain) than for subcutaneous administration, and nasal vaccination provided protection against both homologous and heterologous viral challenges in mice [386] and against homologous viral challenge in monkeys [387]. Poly-ICLC, a stabilized poly (I:C) by polylysine and carboxymethylcellulose, is also effective adjuvant for a malaria vaccine in primates [388].

It seems that these RNA-like compounds can be effective as vaccine adjuvants. Their relative adjuvantation and potential side effects will need to be compared with other types of adjuvants. The future of these compounds as vaccine adjuvants remains to be seen.

\subsection{Surfactant-Like Compounds}

Surfactants can be used as potential adjuvants, such as fatty acid derivatives, dimethyl dioctadecyl ammonium bromide (DDAB), and poloxamers. Mannide monoo- 
leates induced both $\operatorname{IgG} 1$ and $\operatorname{IgG} 2 \mathrm{a}$ antibody responses in mice in a dispersed form without base oil [389]. On the other hand, injection of certain surfactants can produce local irritation reactions [390]. Therefore, such surfactants are usually used in an emulsion. CoVaccine HT is a microemulsion of squalene-in-water (squalene droplets of $130 \mathrm{~nm}$ ) containing the key sucrose derivatives with seven lauric acid esters and one sulphate ester immobilized on the oil droplets. This adjuvant system enhanced both humoral and cell-mediated responses against a wide range of antigens, e.g. inactivated viruses, bacterial subunits, recombinant proteins, virus-like particles and peptide-protein conjugates in large non-rodent animal models and showed significantly lower reactogenicity than simple mineral oil emulsions $(\mathrm{W} / \mathrm{O}$ or $\mathrm{O} / \mathrm{W})$ [391].

Other surfactant-like compounds may have similar effects. Addition of a nonionic surfactant-like block copolymer CRL1005 (95:5=polyoxypropylene: polyoxyethylene) to an inactivated whole influenza virus vaccine significantly enhanced virus-specific IgG and hemagglutination-inhibition (HI) antibody responses in mice following subcutaneous vaccination [392]. Addition of a cationic surfactant-like preservative, benzalkonium chloride (BAK) in a plasmid DNA vaccine formulation (human immunodeficiency virus-1 gag) containing a nonionic triblock copolymer adjuvant (CRL1005) leads to an enhancement in the gag-specific cellular immune response [393]. Use of a lipopeptide (P3CSK4) in a respiratory syncytial virus (RSV) vaccine led to a balanced Th1/Th2 response and immunity to virus challenge in mice and cotton rats [394].

Surfactants as adjuvants have also been used in mucosal vaccines. Nasal administration of antigens diphtheria toxoid, tetanus toxoid and BBG2Na (recombinant fragment of the G protein of respiratory syncytial virus) with dimethyldioctadecylammonium bromide (DDA) induced both mucosal and systemic immune responses [395]. DDA was found equally effective as Adju-Phos when used with $\mathrm{BBG} 2 \mathrm{Na}$ for protection against viral challenge in mice and rats [395,396]. Intranasal administration of influenza hemagglutinin (HA) vaccine with Surfacten, a modified pulmonary surfactant, induced higher protective mucosal immunity in the airway without inducing a systemic response in mice [283].

\subsection{Bacteria and Other Related Components}

Bacteria or their components represent natural foreign antigens and may enhance immune response of other antigens. Lactobacillus GG has been shown to have certain adjuvantation effect for live-attenuated flu vaccine in healthy adults [397]. Gram-positive enhancer matrix (GEM) particles derived from Lactococcus lactis was effective for intranasal vaccination with subunit flu vaccine in mice [398]. Other examples include a mixture from heat-killed Mycobacterium vaccae preparation [399] or a particular component, such as Neisseria meningitidis outer membrane [262] or mycobacterial binding protein 1 [400].

\subsubsection{Peptidoglycans}

Peptidoglycans are bacterial origin and have certain immunostimulant activity. These compounds activate cells primarily via the cytosolic NLR family member NOD2 and therefore lead to enhancement of antibody production [401]. Peptidoglycan monomer (PGM), a natural compound of bacterial origin (Brevibacterium divaricatum), is a non-toxic, non-pyrogenic, water-soluble immunostimulator. Immunization of mice (twice) with OVA + PGM induced significantly higher anti-OVA IgG levels than OVA alone $[402,403]$. In comparison, the individual PGM components - the pentapeptide or the disaccharide, are not effective [402]. Addition of peptidoglycan monomer into OVA-containing liposomes switched the response from Th1 to Th2 type after subcutaneous injection in mice [188].

Other peptidoglycan fragments, known as muramyl peptides, are also effective. A series of di, tetrasaccharide peptides and their stearoyl derivatives were found to activate NF-kB pathway through NOD2 [404]. While muramyl peptides preferentially stimulate $\mathrm{IgG} 1$ production, the tetrasaccharide containing muramyl peptide induces additional production of IgG2b subclasses [404]. However, muramyl dipeptide (MDP), a component of the peptidoglycan polymer, has minimal adjuvant properties for antibody production compared to the TLR agonist lipopolysaccharide under a variety of immunization conditions [401].

\subsection{2. cdiGMP}

Cyclic dimeric guanosine monophosphate (cdiGMP) is a bacterial intracellular signaling molecule capable of stimulating protective innate immunity against various bacterial infections [405]. Its application as a systemic or mucosal vaccine adjuvant has been recently reviewed [406]. Subcutaneous co-administration of $\beta$-galactosidase $\left(\beta\right.$-al) and bis- $\left(3^{\prime}, 5^{\prime}\right)$-cyclic dimeric guanosine monophosphate (cdiGMP) elicited strong cellular immune responses, characterized by a balanced $\mathrm{Th} 1 / \mathrm{Th} 2$ pattern, and significantly higher antigen-specific serum IgG titers than $\beta$ - al alone in mice [407]. In a different study, it was found that intraperitoneal coadministration of cdiGMP with pneumolysin toxoid (PdB) or pneumococcal surface protein A (PspA) resulted in significantly higher antigen-specific antibody titers and increased survival of mice, compared to alum adjuvant [405]. 


\subsubsection{Spores}

The negatively charged and hydrophobic surface of bacterial spores can adsorb protein antigens for enhanced immunogenicity [408]. It was found that mice immunized intranasally or intragastrically can be protected against challenge with different kinds of toxins [408]. Killed or inactivated spores appear equally effective as live spores in these studies. Intranasal administration of two model antigens, tetanus toxoid fragment $\mathrm{C}$ (TT) and ovalbumin (OVA), with Bacillus subtilis spores (safe and fully tolerated by ingestion in man) increased $\mathrm{T}$ cell response and specific IgA both in the local respiratory and distal vaginal mucosa, as well as increased antigen-specific IgG antibody in draining $\mathrm{LN}$ and blood in mice [409].

\subsubsection{Flagellin}

IM administration of influenza virus epitope peptides carried by recombinant flagellin (originated from nonvirulent salmonella bacteria) induced both humoral and cellular responses and conferred some protection against lethal challenge (H5N1) [410]. The intensive response to flagellin is mediated by toll-like receptor 5 , linking innate and adaptive immunity 11 . Because of this, a powerful vaccine can be created by fusion of flagellin with an antigen [411].

In general, bacterial components can be effective adjuvants, as they are natural antigens. If these components are not synthetically obtained, a key issue in using such components is to control the level of potential bacterial contaminants. Therefore, purification of such components could be intensive during production, adding additional cost to the vaccine products.

\subsection{Miscellaneous Compounds/Means as Adjuvants}

Many other compounds have been shown to provide immunogenicity enhancement. Topical application of Imiquimod (5\% cream) over the site of subcutaneous injection with ovalbumin enhanced anti-OVA antibody responses 100 -fold and markedly increased cellular responses in mice [412]. So is Resiquimod for the same model antigen [413]. These are TLR 7/8 agonists, which can be more effective adjuvants than alum for HBsAg [414]. Naloxone, an opioid receptor antagonist, improved the immunogenicity of heat-killed Listeria monocytogenes vaccine [415]. Broystatin 1, a protein kinase $\mathrm{C}$ modulator, could stimulate chemokine release from dendritic cells and be used for cancer vaccines [416]. Tomatine, a glycoalkaloid (rod-like structures under microscope), was shown to be capable of stimulating potent antigen- specific humoral and cellular immune responses leading to protection against malaria, Francisella tularen- sis and regression of experimental tumors [417]. Other plant isolates were found to promote both Th1 and Th2 effects in mice such as paclitaxel (a diterpenoid) for ovalbumin [418], RLJ-NE-299A, a mixture of iridoid glycosides for hepatitis B surface antigen (HBsAg) [419], and acylated derivatives of iridoid glycosides for ovalbumin [420]. Other compounds as potential adjuvants include anti-viral drugs such as Ribavirin [421], the active form of vitamin D3 $(1,25(\mathrm{OH}) 2 \mathrm{D} 3)[422,423]$, calcium phosphate [293,424], and herbs such as Astragalus membranaceus and Scutellaria baicalensis [425,426], or herbal extract [427] and tumor cell components [428, 429].

A recent report shows that green laser $(520 \mathrm{~nm})$ can mobilize APCs and facilitate antigen uptake at the vaccine injection site, leading to increased humoral and cell-me- diated immune responses to OVA after im administration in mice [430]. Such a novel concept needs to be verified, regarding its relative adjuvantation and side effects.

\section{Adjuvant Combinations}

The above adjutants may enhance immunogenicity through different mechanisms. Therefore, combining two or more adjuvants may further enhance the degree of immune response due to simultaneous, multiple mechanisms of actions [385]. In several studies, combination of aluminum salts and deacylated MPL was shown to induce a robust and persistent immune response with HPV16/18 protein VLP vaccine in women (Cervarix, GSK Biologicals) [431] and more effective with a hepatitis B vaccine than the commercial product Engerix-B in humans [432]. Another reason for combing adjuvants is to change the type of immune response. For example, combining emulsion and a synthetic lipid A in Fluzone vaccine significantly and synergistically increased Th1 type response in mice [304]. Use of $\mathrm{CpG}$ often changes a Th2-type immune response of aluminum-based adjuvants to a Th1-type immune response $[107,242,433]$.

A variety of adjuvant combinations have been tried. Aluminum salts are often used with CpG ODNs to enhance and/or balance the immunogenicity of many different types of antigens [264,434,435]. Naloxone (an opioid receptor antagonist) has been recently evaluated with aluminum salts with use [436,437]. Liposomes can easily accommodate another adjuvant for enhanced immunogenicity, such as CpG ODNs [119,438-440], TLR7 ligand-3M-019 [441], Quil-A [442], MPL [443], and DNA [444]. Liposomes have been shown to enhance the uptake of CpG ODN (16-mer) by immune cells in spleen and lymph nodes [440] and DC maturation by these adjuvants [438]. Other combinations include MPA/trehalose dicorynomycolate for a protein vaccine [445], chi- 
tosan/LTK63 (a nontoxic E. coli enterotoxin mutant) for DT-conjugated group $\mathrm{C}$ meningococcal polysaccharide antigen [446], chitosan/muramyl di-peptide (MDP) for Helicobacter pylori urease [230], PLG microparticles/ MF59 for recombinant protein antigens [447], PLGA particles/LPS for West Nile encephalitis [291], proteosome/LPS for influenza virus [448], QS-21 combinations with a variety of adjuvants for KLH-conjugated peptide vaccine [237], and FML (a glycoprotein complex) combinations with a variety of adjuvants for visceral leishmaniasis (VL) [449]. More complex adjuvant systems ( $\geq 3$ adjuvant components) have also been tried. These include, GM-CSF/IL-2/emulsion for HPV16 E7 peptide antigen [352], liposome/polycation/DNA (LPD) particles for HPV 16 E7 protein antigen [450], CpG (1826)/indolicidin/ olyphosphazene for OVA[88], QS21/ GM-CSF/MPL/emulsion system for KLH-conjugated peptide antigens [244]. Although some of these combinations have been compared, the results are difficult to interpret as their doses and preparations are different $[237,449]$.

A widely investigated adjuvant combinations containing $\geq 2$ adjuvant components are the AS series of adjuvants, such as AS01 (liposomes containing deacylated MPL and QS21) [451], AS02 (an oil-in-water emulsion containing deacylated MPL and QS21) [452,453], and AS05 (liposomes containing aluminum hydroxide, deacylated MPL and QS21 in a weight ratio of 10:1:1) [454]. These systems seem to be effective in enhancing both humoral and cellular immunogenicity of different types of antigens in human subjects $[452,455]$ and can be more effective than commercial vaccines for certain patient populations 453. In a comparative study on these systems, AS01B offered the best enhancement in cellular immunity for a malaria vaccine relative to AS02A, and AS05 both in Rhesus macaques [454] and human subjects [456]. The superiority of AS01B was confirmed in a recent study with recombinant hepatitis B surface antigen in terms of cellular immune responses among several AS series of adjuvants and all the AS adjuvants (MPL/QS21) are more effective than $\mathrm{CpG}$ (dosed at $0.5 \mathrm{mg}$ ) in healthy adults [457]. These studies clearly indicate that liposomes are superior to emulsions, suggesting that more rigid particulates might be more immunogenic.

It should be noted that even combinations of adjuvants may have limited effect, such as use of AS systems in a malaria vaccine [458]. Such combinations could further enhance the side effects of individual adjuvants and potentially lead to greater and perhaps different types of effects from those generated by individual adjuvants. On the other hand, infinite enhancement of vaccine immunity may not the best choice for developing vaccines against certain viruses. This is because vaccines can ac- tually enhance the susceptibility of the host to virus infection, such as certain flavi-, corona-, paramyxo-, immunodeficiency-, and lentivirus vaccines, likely due to antibody-dependent enhancement of viral entry [459].

\section{Summary}

Development of the first-generation human vaccines has been largely semi-empirical. Aluminum salts are the only type of adjuvants used in these vaccines. Although the efficacy and safety of aluminum salts have been well established through the long history of use, a minimum quantity is recommended for use in a vaccine, as we continue to gather new evidence for their potential side effect.

Due to the limited adjuvantation effect of aluminum salts, constant mutation of existing microbes, and ever identification of new disease-causing microbes, extensive search of more effective adjuvants has been the focus of many scientists for many years. Although many novel adjuvants have been identified, few have been commercialized in limited market regions. This is partly due to the difficulty in elucidating the exact mechanisms of adjuvantation, especially for multi- component adjuvant systems, and lack of long-term safety data. Another fact is that none of these novel adjuvants seem to work well with different kinds of vaccines. Therefore, further investigations would continue to address these issues.

Among all adjuvants examined, it seems difficult to pinpoint the most effective one, as these adjuvants are evaluated in different laboratories, with different animal models, and for different indications. Even some adjuvants were compared side-by-side by the same investigators, the amount of adjuvant may still be different and thus, conclusions from these studies are still debatable. It is expected that future comparative studies would be designed such that data could support selection of the right adjuvant. Novel adjuvants will be continually searched and evaluated, but their successes will be based on our further understanding of the interactions between human body and foreign microorganisms on a molecular level [460-463]. Ideally, such adjuvants would offer earlier, robust and durable immunity with less adverse events.

A clear trend in the development of effective adjuvant is to use an adjuvant system consisting of two or more adjuvants. Good examples are the AS systems, as discussed above. Most adjuvant systems seem to be more effective than individual adjuvants due to additive or frequently synergistic effect, which may result from combining the same or different classes of adjuvants [344,352]. One the other hand, use of such systems should not be first choice, unless no individual adjuvant would be able to provide adequate immunogenicity enhancement. If an adjuvant system is to be used, it should 
ideally comprise no more than two adjutants. Any adjuvant system consisting of three or more adjuvant would need much more studies to understand the interactions among all the adjuvants, and between adjuvants and antigens. It would be very difficult to decipher the contribution of individual adjuvants, and their mechanisms of actions. In addition, preparation of such a system with antigen and subsequent characterization would be more laborious and batch-to-atch consistency would not be easy to control.

The human society is still facing many uncurable diseases today. Given the high cost of drug product development, the high pressure of reducing health care cost, and the public desire for a better quality of life, the development of both prophylactic and therapeutic vaccines would remain a top focus of many pharmaceutical companies and public health leaders.

\section{REFERENCES}

[1] G. A. Poland and D. Morse, "Improving the Public Health: The U. S. Recommendation for Universal Influenza Immunization," Vaccine, Vol. 28, No. 16, 2010, pp. 2799-2800. doi:10.1016/j.vaccine.2010.03.002

[2] L. Danzig, "Reverse Vaccinology-in Search of a Genome-Derived Meningococcal Vaccine," Vaccine, Vol. 24, Suppl 2, April 12, 2006, pp. S2-11-2.

[3] A. M. Harandi, D. Medaglini and R. J. Shattock, "Vaccine Adjuvants: A Priority for Vaccine Research," Vaccine, Vol. 28, No. 12, 2010, pp. 2363-2366. doi:10.1016/j.vaccine.2009.12.084

[4] Y. Perrie, A. R. Mohammed, D. J. Kirby, S. E. McNeil and V. W. Bramwell, "Vaccine Adjuvant Systems: Enhancing the Efficacy of Sub-Unit Protein Antigens," Int J Pharm, Vol. 364, No. 2, December 2008, pp. 272-280. doi:10.1016/j.ijpharm.2008.04.036

[5] D. T. O'Hagan and E. De Gregorio, "The Path to a Successful Vaccine Adjuvant-'The Long and Winding Road," Drug Discov Today, Vol. 14, No. 11-12, June 2009, pp. 541-551.

[6] Y. van Kooyk, A. Engering, A. N. Lekkerkerker, I. S. Ludwig and T. B. Geijtenbeek, "Pathogens Use Carbohydrates to Escape Immunity Induced by Dendritic Cells," Current Opinion in Immunology, Vol. 16, No. 4, August 2004, pp. 488-493. doi:10.1016/j.coi.2004.05.010

[7] J. H. Wilson-Welder, M. P. Torres, M. J. Kipper, S. K. Mallapragada, M. J. Wannemuehler, and B. Narasimhan, "Vaccine Adjuvants: Current Challenges and Future Approaches," Journal of Pharmaceutical Sciences, Vol. 14, August 2008

[8] J. Rajcani, T. Mosko and I. Rezuchova, "Current Developments in Viral DNA Vaccines: Shall They Solve the Unsolved?" Rev Med Virol, Vol. 15, No. 5, September-October 2005, pp. 303-325.

doi: $10.1002 /$ rmv.467
[9] M. Majewska and M. Szczepanik, "The Role of Toll-Like Receptors (TLR) in Innate and Adaptive Immune Responses and Their Function in Immune Response Regulation," Postepy Hig Med Dosw (Online), Vol. 60, 2006, pp. 52-63.

[10] A. Lahiri, P. Das, and D. Chakravortty, "Engagement of TLR Signaling as Adjuvant: Towards Smarter Vaccine and Beyond," Vaccine, Vol. 26, No. 52, December 2008, pp. 6777-6783. doi:10.1016/j.vaccine.2008.09.045

[11] S. Agrawal, A. Agrawal, B. Doughty, A. Gerwitz, J. Blenis, T. Van Dyke and B. Pulendran, "Cutting Edge: Different Toll-Like Receptor Agonists Instruct Dendritic Cells to Induce Distinct Th Responses via Differential Modulation of Extracellular Signal-Regulated KinaseMitogen-Activated Protein Kinase And c-Fos," J Immunol, Vol. 171, No. 10, November 2003, pp. 49844989.

[12] Q.-E. Yang, "IgM, not IgG, a Key for HIV Vaccine," Vaccine, Vol. 27, No. 9, 2009, pp. 1287-1288. doi:10.1016/j.vaccine.2008.12.030

[13] M. S. Sinyakov and R. R. Avtalion, "Vaccines and Natural Antibodies: A Link to be Considered," Vaccine, Vol. 27, No. 14, 2009, pp. 1985-1986. doi:10.1016/j.vaccine.2009.01.121

[14] D. C. Gondek, N. R. Roan and M. N. Starnbach, "T Cell Responses in the Absence of IFN-Gamma Exacerbate Uterine Infection with Chlamydia Trachomatis," The Journal of Immunology, Vol. 183, No. 2, July 2009, pp. 1313-1319. doi:10.4049/jimmunol.0900295

[15] H. L. Davis, "Novel Vaccines and Adjuvant Systems: The Utility of Animal Models for Predicting Immunogenicity in Humans," Human Vaccines, Vol. 4, No. 3, November 2007, pp. 246-250.

[16] C. L. Cooper, H. L. Davis, M. L. Morris, S. M. Efler, A. M. Krieg, Y. Li, C. Laframboise, M. J. Al Adhami, Y. Khaliq, I. Seguin and D. W. Cameron, "Safety and Immunogenicity of CPG 7909 Injection as an Adjuvant to Fluarix Influenza Vaccine," Vaccine, Vol. 22, No. 23-24, August 2004, pp. 3136-3143. doi:10.1016/j.vaccine.2004.01.058

[17] J. M. Taylor, M. E. Ziman, D. R. Canfield, M. Vajdy and J. V. Solnick, "Effects of a Th1-versus a Th2-Biased Immune Response in Protection against Helicobacter Pylori Challenge in Mice," Microbial Pathogenesis, Vol. 44, No. 1, 2008, pp. 20-27. doi:10.1016/j.micpath.2007.06.006

[18] J. Klingstrom, I. Maljkovic, B. Zuber, E. Rollman, A. Kjerrstrom and A. Lundkvist, "Vaccination of C57/BL6 Mice with Dobrava Hantavirus Nucleocapsid Protein in Freund's Adjuvant Induced Partial Protection against Challenge," Vaccine, Vol. 22, No. 29-30, September 2004, pp. 4029-4034. doi:10.1016/j.vaccine.2004.03.045

[19] N. W. Baylor, W. Egan and P. Richman, "Aluminum Salts in Vaccines-US Perspective," Vaccine, Vol. 20, Suppl 3, May 2002, pp. S18-23. doi:10.1016/S0264-410X(02)00166-4 
[20] E. B. Lindblad, "Aluminium Adjuvants - in Retrospect and Prospect," Vaccine, Vol. 22, No. 27-28, September 2004, pp. 3658-3668. doi:10.1016/j.vaccine.2004.03.032

[21] L. Franchi and G. Nunez, "The Nlrp3 Inflammasome is Critical for Aluminium Hydroxide-Mediated IL-1beta Secretion but Dispensable for Adjuvant Activity," European Journal of Immunology, Vol. 38, No. 8, August 2008, pp. 2085-2089. doi:10.1002/eji.200838549

[22] C. A. Shaw and M. S. Petrik, "Aluminum Hydroxide Injections Lead to Motor Deficits and Motor Neuron Degeneration," Journal of Inorganic Biochemistry, Vol. 103, No. 11, 2009, pp. 1555-1562. doi:10.1016/j.jinorgbio.2009.05.019

[23] M. Chang, Y. Shi, S. L. Nail, H. HogenEsch, S. B. Adams, J. L. White and S. L. Hem, "Degree of Antigen Adsorption in the Vaccine or Interstitial Fluid and Its Effect on the Antibody Response in Rabbits," Vaccine, Vol. 19, No. 20-22, April 2001, pp. 2884-2889. doi:10.1016/S0264-410X(00)00559-4

[24] X. Wang, M. Bao, M. Wan, H. Wei, L. Wang, H. Yu, X. Zhang and Y. Yu, "A CpG Oligodeoxynucleotide Acts as a Potent Adjuvant for Inactivated Rabies Virus Vaccine," Vaccine, Vol. 26, No. 15, March 2008, pp. 1893-1901. doi:10.1016/j.vaccine.2008.01.043

[25] E. Tritto, F. Mosca and E. De Gregorio, "Mechanism of Action of Licensed Vaccine Adjuvants," Vaccine, Vol. 27, No. 25-26, May 2009, pp. 3331-3334. doi:10.1016/j.vaccine.2009.01.084

[26] S. L. Hem and H. Hogenesch, "Relationship between Physical and Chemical Properties of AluminumContaining Adjuvants and Immunopotentiation," Expert Rev Vaccines, Vol. 6, No. 5, October 2007, pp. 685-698. doi:10.1586/14760584.6.5.685

[27] S. Iyer, H. HogenEsch and S. L. Hem, "Relationship between the Degree of Antigen Adsorption to Aluminum Hydroxide Adjuvant in Interstitial Fluid and Antibody Production," Vaccine, Vol. 21, No. 11-12, March 2003, pp. 1219-1223. doi:10.1016/S0264-410X(02)00556-X

[28] G. L. Morefield, D. Jiang, I. Z. Romero-Mendez, R. L. Geahlen, H. Hogenesch and S. L. Hem, "Effect of Phosphorylation of Ovalbumin on Adsorption by Aluminum-Containing Adjuvants and Elution upon exposUre to Interstitial Fluid," Vaccine, Vol. 23, No. 12, February 2005, pp. 1502-1506. doi:10.1016/j.vaccine.2004.08.048

[29] A. Sokolovska, S. L. Hem and H. HogenEsch, "Activation of Dendritic Cells and Induction of CD4(+) T Cell Differentiation by Aluminum-Containing Adjuvants," Vaccine, Vol. 25, No. 23, June 2007, pp. 4575-4585. doi:10.1016/j.vaccine.2007.03.045

[30] IDdb. com. "Adjuvants and Adjuvanted Preventive and Therapeutic Vaccines for Infectious Disease Indications," (Online).

[31] M. Kool, V. Petrilli, T. De Smedt, A. Rolaz, H. Hammad, M. van Nimwegen, I. M. Bergen, R. Castillo, B. N. Lambrecht and J. Tschopp, "Cutting Edge: Alum Adjuvant
Stimulates Inflammatory Dendritic Cells through Activation of the NALP3 Inflammasome," The Journal of Immunology, Vol. 181, No. 6, September 2008, pp. 37553759 .

[32] S. C. Eisenbarth, O. R. Colegio, W. O'Connor, F. S. Sutterwala and R. A. Flavell, "Crucial Role for the Nalp3 Inflammasome in the Immunostimulatory Properties of Aluminium Adjuvants," Nature, Vol. 453, No. 7198, June 2008, pp. 1122-1126. doi:10.1038/nature06939

[33] H. Li, S. B. Willingham, J. P. Ting and F. Re, "Cutting Edge: Inflammasome Activation by Alum and Alum's Adjuvant Effect are Mediated by NLRP3," The Journal of Immunology, Vol. 181, No. 1, July 2008, pp. 17-21.

[34] D. T. O'Hagan and R. Rappuoli, "Novel Approaches to Vaccine Delivery," Pharmaceutical Research, Vol. 21, No. 9, 2004, pp. 1519-1530. doi:10.1023/B:PHAM.0000041443.17935.33

[35] J. P. Scheerlinck, S. Gloster, A. Gamvrellis, P. L. Mottram and M. Plebanski, "Systemic Immune Responses in Sheep, Induced by a Novel Nano-Bead Adjuvant," Vaccine, Vol. 24, No. 8, February 2006, pp. 1124 1131.doi:10.1016/j.vaccine.2005.09.009

[36] S. F. Little, B. E. Ivins, W. M. Webster, S. L. Norris and G. P. Andrews, "Effect of Aluminum Hydroxide Adjuvant and Formaldehyde in the Formulation of $\mathrm{rPA}$ Anthrax Vaccine," Vaccine, Vol. 25, No. 15, April 2007, pp. 2771-2777. doi:10.1016/j.vaccine.2006.12.043

[37] R. C. Brady, J. J. Treanor, R. L. Atmar, W. A. Keitel, R. Edelman, W. H. Chen, P. Winokur, R. Belshe, I. L. Graham, D. L. Noah, K. Guo and H. Hill, "Safety and Immunogenicity of a Subvirion Inactivated Influenza A/H5N1 Vaccine with or without Aluminum Hydroxide among Healthy Elderly Adults," Vaccine, Vol. 27, No. 37, August 2009, pp. 5091-5095. doi:10.1016/j.vaccine.2009.06.057

[38] D. Ikeno, K. Kimachi, Y. Kudo, S. Goto, S. Itamura, T. Odagiri, M. Tashiro and Y. Kino, "A Prime-Boost Vaccination of Mice with Heterologous H5N1 Strains," Vaccine, Vol. 27, No. 23, May 2009, pp. 3121-3125. doi:10.1016/j.vaccine. 2009.01 .007

[39] C. Vessely, T. Estey, T. W. Randolph, I. Henderson, R. Nayar and J. F. Carpenter, "Effects of Solution Conditions and Surface Chemistry on the Adsorption of Three Recombinant Botulinum Neurotoxin Antigens to Aluminum Salt Adjuvants," Journal of Pharmaceutical Sciences, Vol. 96, No. 9, September 2007, pp. 2375-2389. doi:10.1002/jps.20880

[40] L. Wolff, J. Flemming, R. Schmitz, K. Gröger, C. Goso and C. Müller-Goymann, "Forces Determining the Adsorption of a Monoclonal Antibody onto an Aluminium Hydroxide Adjuvant: Influence of Interstitial Fluid Components," Vaccine, Vol. 27, No. 12, 2009, pp. 1834-1840. doi:10.1016/j.vaccine.2009.01.037

[41] R. A. DePaz, I. Henderson and S. J. Advant, "Formulation of Botulinum Neurotoxin Heavy Chain Fragments for Vaccine Development: Mechanisms of Adsorption to an Aluminum-Containing Adjuvant," Vac- 
cine, Vol. 23, No. 31, July 2005, pp. 4029-4035. doi:10.1016/j.vaccine.2005.03.028

[42] S. Iyer, H. HogenEsch and S. L. Hem, "Effect of the Degree of Phosphate Substitution in Aluminum Hydroxide Adjuvant on the Adsorption of Phosphorylated Proteins," Pharmaceutical Development and Technology, Vol. 8, No. 1, 2003, pp. 81-86. doi:10.1081/PDT-120017526

[43] K. Singh and S. Mohan, "Adsorption Behavior of Selected Monosaccharides onto an Alumina Interface," Journal of Colloid Interface Science, Vol. 270, No. 1, Febuary 2004, pp. 21-28. doi:10.1016/j.jcis.2003.05.002

[44] G. L. Morefield, H. HogenEsch, J. P. Robinson and S. L. Hem, "Distribution of Adsorbed Antigen in Mono-Valent and Combination Vaccines," Vaccine, Vol. 22, No. 15-16, May 2004, pp. 1973-1984. doi:10.1016/j.vaccine.2003.10.040

[45] S. Jendrek, S. F. Little, S. Hem, G. Mitra and S. Giardina, "Evaluation of the Compatibility of a Second Generation Recombinant Anthrax Vaccine with Aluminum-Containing Adjuvants," Vaccine, Vol. 21, No. 21-22, June 2003, pp. 3011-3018. doi:10.1016/S0264-410X(03)00109-9

[46] S. L. Hem, H. HogenEsch, C. R. Middaugh and D. B. Volkin, "Preformulation Studies: The Next Advance in Aluminum Adjuvant-Containing Vaccines," Vaccine, Vol. 28, No. 31, 2010, pp. 4868-4870. doi:10.1016/j.vaccine.2010.05.007

[47] S. Iyer, R. S. Robinett, H. HogenEsch and S. L. Hem, "Mechanism of Adsorption of Hepatitis B Surface Antigen by Aluminum Hydroxide Adjuvant," Vaccine, Vol. 22, No. 11-12, March 2004, pp. 1475-1479. doi:10.1016/j.vaccine.2003.10.023

[48] L. S. Jones, L. J. Peek, J. Power, A. Markham, B. Yazzie and C. R. Middaugh, "Effects of Adsorption to Aluminum Salt Adjuvants on the Structure and Stability of Model Protein Antigens," The Journal of Biological Chemistry, Vol. 280, No. 14, April 2005, pp. 13406- 13414. doi:10.1074/jbc.M500687200

[49] Y. Shi, H. HogenEsch, F. E. Regnier and S. L. Hem, "Detoxification of Endotoxin by Aluminum Hydroxide Adjuvant," Vaccine, Vol. 19, No. 13-14, Febuary 2001, pp. 1747-1752. doi:10.1016/S0264-410X(00)00394-7

[50] K. P. Yau, D. G. Schulze, C. T. Johnston and S. L. Hem, "Aluminum Hydroxide Adjuvant Produced under Constant Reactant Concentration," Journal of Pharmaceutical Sciences, Vol. 95, No. 8, August 2006, pp. 18221833. doi:10.1002/jps. 20692

[51] C. Vessely, T. Estey, T. W. Randolph, I. Henderson, J. Cooper, R. Nayar, L. J. Braun and J. F. Carpenter, "Stability of a Trivalent Recombinant Protein Vaccine Formulation against Botulinum Neurotoxin during Storage in Aqueous Solution," Journal of Pharmaceutical Sciences, August 2008.

[52] D. Jiang, C. T. Johnston and S. L. Hem, "Using Rate of Acid Neutralization to Characterize Aluminum Phosphate Adjuvant," Pharmaceutical Development and Technology,
Vol. 8, No. 4, 2003, pp. 349-356. doi:10.1081/PDT-120024688

[53] B. Hansen, M. Belfast, G. Soung, L. Song, P. M. Egan, R. Capen, H. Hogenesch, R. Mancinelli and S. L. Hem, "Effect of the Strength of Adsorption of Hepatitis B Surface Antigen to Aluminum Hydroxide Adjuvant on the Immune Response," Vaccine, Vol. 27, No. 6, February 2009, pp. 888-892. doi:10.1016/j.vaccine.2008.11.078

[54] L. S. Burrell, C. T. Johnston, D. Schulze, J. Klein, J. L. White and S. L. Hem, "Aluminium Phosphate Adjuvants Prepared by Precipitation at Constant $\mathrm{pH}$. Part II: Physicochemical Properties," Vaccine, Vol. 19, No. 2-3, September 2000, pp. 282-287.

[55] J. V. Rinella, J. L. White and S. L. Hem, "Effect of pH on the Elution of Model Antigens from AluminumContaining Adjuvants," Journal of Colloid and Interface Science, Vol. 205, No. 1, September 1998, pp. 161-165. doi:10.1006/jicis. 1998.5648

[56] I. Z. Romero Mendez, Y. Shi, H. HogenEsch and S. L. Hem, "Potentiation of the Immune Response to NonAdsorbed Antigens by Aluminum-Containing Adjuvants," Vaccine, Vol. 25, No. 5, January 2007, pp. 825-33. doi:10.1016/j.vaccine.2006.09.039

[57] L. Lin, A. S. Ibrahim, V. Avanesian, J. E. Edwards, Jr., Y. Fu, B. Baquir, R. Taub and B. Spellberg, "Considerable Differences in Vaccine Immunogenicities and Efficacies Related to the Diluent Used for Aluminum Hydroxide Adjuvant," Clinical and Vaccine Immunology, Vol. 15, No. 3, March 2008, pp. 582-584. doi:10.1128/CVI.00427-07

[58] B. Hansen, A. Sokolovska, H. HogenEsch and S. L. Hem, "Relationship between the Strength of Antigen Adsorption to an Aluminum-Containing Adjuvant and the Immune Response," Vaccine, Vol. 25, No. 36, September 2007, pp. 6618-24. doi:10.1016/j.vaccine.2007.06.049

[59] P. M. Egan, M. T. Belfast, J. A. Gimenez, R. D. Sitrin and R. J. Mancinelli, "Relationship between Tightness of Binding and Immunogenicity in an Aluminum-Containing Adjuvant-Adsorbed Hepatitis B Vaccine," Vaccine, Vol. 27, No. 24, May 2009, pp. 3175-3180. doi:10.1016/j.vaccine.2009.03.054

[60] L. S. Burrell, E. B. Lindblad, J. L. White and S. L. Hem, "Stability of Aluminium-Containing Adjuvants to Autoclaving," Vaccine, Vol. 17, No. 20-21, June 1999, pp. 2599-2603. doi:10.1016/S0264-410X(99)00051-1

[61] A. L. Clausi, S. A. Merkley, J. F. Carpenter and T. W. Randolph, "Inhibition of Aggregation of Aluminum Hydroxide Adjuvant during Freezing and Drying," Journal of Pharmaceutical Sciences, Vol. 97, No. 6, June 2008, pp. 2049-61. doi:10.1002/jps.21143

[62] M. I. Zapata, J. R. Feldkamp, G. E. Peck, J. L. White and S. L. Hem, "Mechanism of Freeze-Thaw Instability of Aluminum Hydroxycarbonate and Magnesium Hydroxide Gels," Journal of Pharmaceutical Sciences, Vol. 73, No. 1, January 1984, pp. 3-8. doi:10.1002/jps.2600730103 
[63] D. Chen, A. Tyagi, J. Carpenter, S. Perkins, D. Sylvester, M. Guy, D. D. Kristensen and L. J. Braun, "Characterization of the Freeze Sensitivity of a Hepatitis B Vaccine," Human Vaccines, Vol. 5, No. 1, January 2009, pp. 26-32. doi:10.4161/hv.5.1.6494

[64] L. J. Braun, A. Tyagi, S. Perkins, J. Carpenter, D. Sylvester, M. Guy, D. Kristensen and D. Chen, "Development of a Freeze-Stable Formulation for Vaccines Containing Aluminum Salt Adjuvants," Vaccine, Vol. 27, No. 1, January 2009, pp. 72-79. doi:10.1016/j.vaccine.2008.10.027

[65] A. L. Clausi, A. Morin, J. F. Carpenter and T. W. Randolph, "Influence of Protein Conformation and Adjuvant Aggregation on the Effectiveness of Aluminum Hydroxide Adjuvant in a Model Alkaline Phosphatase Vaccine," Journal of Pharmaceutical Sciences, Vol. 98, No. 1, January 2009, pp. 114-121. doi:10.1002/jps.21433

[66] V. A. Conforti, D. M. de Avila, N. S. Cummings, K. J. Wells, H. Ulker and J. J. Reeves, "The Effectiveness of a CpG Motif-Based Adjuvant (CpG ODN 2006) for LHRH Immunization," Vaccine, Vol. 25, No. 35, August 2007, pp. 6537-6543. doi:10.1016/j.vaccine.2007.05.056

[67] D. Chen, S. Kapre, A. Goel, K. Suresh, S. Beri, J. Hickling, J. Jensen, M. Lal, J. M. Preaud, M. LaForce and D. Kristensen, "Thermostable Formulations of a Hepatitis B Vaccine and a Meningitis A Polysaccharide Conjugate Vaccine Produced by a Spray drying Method," Vaccine, Vol. 28, No. 31, 2010, pp. 5093-5099. doi:10.1016/i.vaccine.2010.04.112

[68] C. J. Hutcheon, J. O. Becker, B. A. Russell, P. A. Bariola, G. J. Peterson and S. D. Stroop, "Physiochemical and Functional Characterization of Antigen Proteins Eluted from Aluminum Hydroxide Adjuvant," Vaccine, Vol. 24, No. 49-50, November 2006, pp. 7214-7225. doi:10.1016/j.vaccine.2006.06.043

[69] A. Wittayanukulluk, D. Jiang, F. E. Regnier and S. L. Hem, "Effect of Microenvironment $\mathrm{pH}$ of Aluminum Hydroxide Adjuvant on the Chemical Stability of Adsorbed Antigen," Vaccine, Vol. 22, No. 9-10, March 2004, pp. 1172-1176. doi:10.1016/j.vaccine.2003.09.037

[70] L. J. Braun, J. Jezek, S. Peterson, A. Tyagi, S. Perkins, D. Sylvester, M. Guy, M. Lal, S. Priddy, H. Plzak, D. Kristensen and D. Chen, "Characterization of a Thermostable Hepatitis B Vaccine Formulation," Vaccine, Vol. 27, No. 34, July 2009, pp. 4609-4614. doi:10.1016/j.vaccine.2009.05.069

[71] J. M. Langley, V. Sales, A. McGeer, R. Guasparini, G. Predy, W. Meekison, M. Li, J. Capellan and E. Wang, "A Dose-Ranging Study of a Subunit Respiratory Syncytial Virus Subtype A Vaccine with and without Aluminum Phosphate Adjuvantation in Adults $>$ or $=65$ Years of Age," Vaccine, Vol. 27, No. 42, September 2009, pp. 5913-5919. doi:10.1016/j.vaccine.2009.07.038

[72] M. Kwissa, S. P. Kasturi and B. Pulendran, "The Science of Adjuvants," Expert Review of Vaccines, Vol. 6, No. 5, October 2007, pp. 673-684. doi: $10.1586 / 14760584.6 .5 .673$
[73] M. Singh and D. T. O'Hagan, "Recent Advances in Vaccine Adjuvants," Pharmaceutical Research, Vol. 19, No. 6, 2002, pp. 715-728. doi:10.1023/A:1016104910582

[74] J. Vollmer and A. M. Krieg, "Immunotherapeutic Applications of CpG Oligodeoxynucleotide TLR9 Agonists," Advanced Drug Delivery Review, Vol. 61, No. 3, March 2009, pp. 195-204.

doi:10.1016/j.addr.2008.12.008

[75] G. Mutwiri, S. van Drunen Littel-van den Hurk and L. A. Babiuk, "Approaches to Enhancing Immune Responses Stimulated by CpG Oligodeoxynucleotides," Advanced Drug Delivery Review, Vol. 61, No. 3, March 2009, pp. 226-232. doi:10.1016/j.addr.2008.12.004

[76] P. Malyala, D. T. O'Hagan and M. Singh, "Enhancing the Therapeutic Efficacy of $\mathrm{CpG}$ Oligonucleotides Using Biodegradable Microparticles," Advanced Drug Delivery Review, Vol. 61, No. 3, March 2009, pp. 218-225. doi:10.1016/j.addr.2008.12.009

[77] F. A. Sharp, D. Ruane, B. Claass, E. Creagh, J. Harris, P. Malyala, M. Singh, D. T. O'Hagan, V. Petrilli, J. Tschopp, L. A. O'Neill and E. C. Lavelle, "Uptake of Particulate Vaccine Adjuvants by Dendritic Cells Activates the NALP3 Inflammasome," Proceedings of the National Academy of Sciences USA, Vol. 106, No. 3, January 2009, pp. 870-875. doi:10.1073/pnas.0804897106

[78] D. M. Lubaroff and D. Karan, "CpG Oligonucleotide as an Adjuvant for the Treatment of Prostate Cancer," Advanced Drug Delivery Review, Vol. 61, No. 3, March 2009, pp. 268-274. doi:10.1016/j.addr.2008.12.005

[79] Y. Krishnamachari and A. K. Salem, "Innovative Strategies for Co-Delivering Antigens and CpG Oligonucleotides," Advanced Drug Delivery Review, Vol. 61, No. 3, March 2009, pp. 205-217. doi:10.1016/j.addr.2008.12.013

[80] K. D. Wilson, S. D. de Jong and Y. K. Tam, "LipidBased Delivery of $\mathrm{CpG}$ Oligonucleotides Enhances Immunotherapeutic Efficacy," Advanced Drug Delivery Review, Vol. 61, No. 3, March 2009, pp. 233-242. doi:10.1016/j.addr.2008.12.014

[81] H. Wagner, "The Immunogenicity of CpG-Antigen Conjugates," Advanced Drug Delivery Review, Vol. 61, No. 3, March 2009, pp. 243-247. doi:10.1016/j.addr.2008.12.010

[82] J. Vollmer, R. D. Weeratna, M. Jurk, U. Samulowitz, M. J. McCluskie, P. Payette, H. L. Davis, C. Schetter and A. M. Krieg, "Oligodeoxynucleotides Lacking CpG Dinucleotides Mediate Toll-Like Receptor 9 Dependent T Helper Type 2 Biased Immune Stimulation," Immunology, Vol. 113, No. 2, October 2004, pp. 212-223. doi:10.1111/j.1365-2567.2004.01962.x

[83] A. Conforti, B. Cipriani, D. Peruzzi, S. Dharmapuri, E. R. Kandimalla, S. Agrawal, F. Mori, G. Ciliberto, N. La Monica and L. Aurisicchio, "A TLR9 Agonist Enhances Therapeutic Effects of Telomerase Genetic Vaccine," Vaccine, Vol. 28, No. 20, 2010, pp. 3522-3530. doi:10.1016/j.vaccine.2010.03.020

[84] M. W. Hornef, B. Henriques-Normark and S. Normark, "The Function and Biological Role of Toll-Like 
Receptors in Infectious Diseases: An Update," Current Opinion in Infectious Diseases, Vol. 21, No. 3, June 2008, pp. 304-312. doi:10.1097/QCO.0b013e3282f88ba3

[85] D. Tudor, C. Dubuquoy, V. Gaboriau, F. Lefevre, B. Charley and S. Riffault, "TLR9 Pathway is Involved in Adjuvant Effects of Plasmid DNA-Based Vaccines," Vaccine, Vol. 23, No. 10, January 2005, pp. 1258-1264. doi:10.1016/j.vaccine.2004.09.001

[86] D. M. Klinman, S. Klaschik, K. Tomaru, H. Shirota, D. Tross and H. Ikeuchi, "Immunostimulatory $\mathrm{CpG}$ Oligonucleotides: Effect on Gene Expression and Utility as Vaccine Adjuvants," Vaccine, Vol. 28, No. 8, 2010, pp. 1919-1923. doi:10.1016/j.vaccine.2009.10.094

[87] J. Kovacs-Nolan, J. W. Mapletoft, L. Latimer, L. A. Babiuk and S. v. D. L.-V. D. Hurk, "CpG Oligonucleotide, Host Defense Peptide and Polyphosphazene act Synergistically, inducing Long-Lasting, Balanced Immune Responses in Cattle," Vaccine, Vol. 27, No. 14, 2009, pp. 2048-2054. doi:10.1016/j.vaccine.2009.01.117

[88] J. Kovacs-Nolan, L. Latimer, A. Landi, H. Jenssen, R. E. W. Hancock, L. A. Babiuk and S. van Drunen Littel-van den Hurk, "The Novel Adjuvant Combination of $\mathrm{CpG}$ ODN, Indolicidin and Polyphosphazene Induces Potent Antibody- and cell-Mediated Immune Responses in Mice," Vaccine, Vol. 27, No. 14, 2009, pp. 2055-2064. doi:10.1016/j.vaccine.2009.01.118

[89] M. Gautam, S. Gairola, S. Jadhav and B. Patwardhan, "Ethnopharmacology in Vaccine Adjuvant Discovery," Vaccine, Vol. 26, No. 41, Septtember 2008, pp. 52395340. doi:10.1016/j.vaccine.2008.07.045

[90] J. Vollmer, R. Weeratna, P. Payette, M. Jurk, C. Schetter, M. Laucht, T. Wader, S. Tluk, M. Liu, H. L. Davis and A. M. Krieg, "Characterization of Three $\mathrm{CpG}$ OligodEoxynucleotide Classes with Distinct Immunostimulatory Activities," The European Journal of Immunology, Vol. 34, No. 1, January 2004, pp. 251-262. doi:10.1002/eji.200324032

[91] C. L. Cooper, N. K. Ahluwalia, S. M. Efler, J. Vollmer, A. M. Krieg and H. L. Davis, "Immunostimulatory Effects of Three Classes of $\mathrm{CpG}$ Oligodeoxynucleotides on PBMC from HCV Chronic Carriers," Journal of Immune Based Therapies and Vaccines, Vol. 6, 2008, p. 3. doi:10.1186/1476-8518-6-3

[92] D. A. Hokey, A. T. Larregina, G. Erdos, S. C. Watkins and L. D. Falo, "Tumor Cell Loaded Type-1 Polarized Dendritic Cells Induce Th1-Mediated Tumor Immunity," Cancer Research, Vol. 65, No. 21, November 2005, pp. 10059-10067. doi:10.1158/0008-5472.CAN-05-1692

[93] R. S. Corral and P. B. Petray, "CpG DNA as a Th1Promoting Adjuvant in Immunization against Trypanosoma Cruzi," Vaccine, Vol. 19, No. 2-3, September 2000, pp. 234-242. doi:10.1016/S0264-410X(00)00172-9

[94] F. M. Frank, S. I. Cazorla, M. J. Sartori and R. S. Corral, "Elicitation of Specific, Th1-Biased Immune Response Precludes Skeletal Muscle Damage in CruzipainVaccinated Mice," Experimental and Molecular Pathology, Vol. 84, No. 1, February 2008, pp. 64-70. doi:10.1016/j.yexmp.2007.10.004
[95] D. Pokorna, I. Polakova, M. Kindlova, M. Duskova, V. Ludvikova, P. Gabriel, L. Kutinova, M. Muller and M. Smahel, "Vaccination with Human Papillomavirus Type 16-Derived Peptides Using a Tattoo Device," Vaccine, Vol. 27, No. 27, June 2009, pp. 3519-3529. doi:10.1016/j.vaccine.2009.03.073

[96] C. Yang, H. Shi, J. Zhou, Y. Liang and H. Xu, "CpG Oligodeoxynucleotides Are a Potent Adjuvant for an Inactivated Polio Vaccine Produced from Sabin Strains of Poliovirus," Vaccine, Vol. 27, No. 47, 2009, pp. 65586563. doi:10.1016/j.vaccine.2009.08.047

[97] J. B. Angel, C. L. Cooper, J. Clinch, C. D. Young, A. Chenier, K. G. Parato, M. Lautru, H. Davis and D. W. Cameron, "CpG Increases Vaccine Antigen-Specific CellMediated Immunity When Administered with Hepatitis B Vaccine in HIV Infection," Journal of Immune Based Therapies and Vaccines, Vol. 6, 2008, p. 4. doi:10.1186/1476-8518-6-4

[98] O. S. Sogaard, N. Lohse, Z. B. Harboe, R. Offersen, A. R. Bukh, H. L. Davis, H. C. Schonheyder and L. Ostergaard, "Improving the Immunogenicity of Pneumococcal Conjugate Vaccine in HIV-Infected Adults with a TollLike Receptor 9 Agonist Adjuvant: A Randomized, Controlled Trial," Clinical Infectious Diseases, Vol. 51, No. 1, July 2010, pp. 42-50. doi:10.1086/653112

[99] P. Silvera, J. R. Savary, V. Livingston, J. White, K. H. Manson, M. H. Wyand, P. L. Salk, R. B. Moss and M. G. Lewis, "Vaccination with gp120-depleted HIV-1 plus Immunostimulatory $\mathrm{CpG}$ Oligodeoxynucleotides in Incomplete Freund's Adjuvant Stimulates Cellular and Humoral Immunity in Rhesus Macaques," Vaccine, Vol. 23, No. 6, December 2004, pp. 827-839. doi:10.1016/j.vaccine.2004.06.045

[100] B. D. Silva, E. B. da Silva, I. P. do Nascimento, M. C. Dos Reis, A. Kipnis and A. P. Junqueira-Kipnis, "MPT-51/CpG DNA Vaccine Protects Mice against Mycobacterium Tuberculosis," Vaccine, Vol. 27, No. 33, July 2009, pp. 4402-4407.

doi:10.1016/j.vaccine.2009.05.049

[101] Y. Kojima, K. Q. Xin, T. Ooki, K. Hamajima, T. Oikawa, K. Shinoda, T. Ozaki, Y. Hoshino, N. Jounai, M. Nakazawa, D. Klinman and K. Okuda, "Adjuvant Effect of Multi-CpG Motifs on an HIV-1 DNA Vaccine," Vaccine, Vol. 20, No. 23-24, July 2002, pp. 2857-2865. doi:10.1016/S0264-410X(02)00238-4

[102] S. A. Halperin, G. Van Nest, B. Smith, S. Abtahi, H. Whiley and J. J. Eiden, "A Phase I Study of the Safety and Immunogenicity of Recombinant Hepatitis B Surface Antigen Co-Administered with an Immunostimulatory Phosphorothioate Oligonucleotide Adjuvant," Vaccine, Vol. 21, No. 19-20, June 2003, pp. 2461-2467. doi:10.1016/S0264-410X(03)00045-8

[103] S. S. Martin, R. R. Bakken, C. M. Lind, P. Garcia, E. Jenkins, P. J. Glass, M. D. Parker, M. K. Hart and D. L. Fine, "Comparison of the Immunological Responses and Efficacy of Gamma-Irradiated V3526 Vaccine Formulations against Subcutaneous and Aerosol Challenge with Venezuelan Equine Encephalitis Virus Subtype IAB," 
Vaccine, Vol. 28, No. 4, 2010, pp. 1031-1040. doi:10.1016/j.vaccine.2009.10.126

[104] M. Gu, P. M. Hine, W. James Jackson, L. Giri and G. S. Nabors, "Increased Potency of BioThrax Anthrax Vaccine with the Addition of the C-Class CpG Oligonucleotide Adjuvant CPG 10109," Vaccine, Vol. 25, No. 3, January 2007, pp. 526-534. doi:10.1016/j.vaccine.2006.07.056

[105] P. J. Payette, X. Ma, R. D. Weeratna, M. J. McCluskie, M. Shapiro, R. E. Engle, H. L. Davis and R. H. Purcell, "Testing of CpG-Optimized Protein and DNA Vaccines against the Hepatitis B Virus in Chimpanzees for Immunogenicity and Protection from Challenge," Intervirology, Vol. 49, No. 3, 2006, pp. 144-151. doi: $10.1159 / 000089375$

[106] I. Sagara, R. D. Ellis, A. Dicko, M. B. Niambele, B. Kamate, O. Guindo, M. S. Sissoko, M. P. Fay, M. A. Guindo, O. Kante, R. Saye, K. Miura, C. Long, G. E. D. Mullen, M. Pierce, L. B. Martin, K. Rausch, A. Dolo, D. A. Diallo, L. H. Miller and O. K. Doumbo, "A Randomized and Controlled Phase 1 Study of the Safety and Immunogenicity of the AMA1-C1/Alhydrogel $\mathbb{R}+$ CPG 7909 Vaccine for Plasmodium Falciparum Malaria in Semi-Immune Malian Adults," Vaccine, Vol. 27, No. 52, 2009, pp. 7292-7298. doi:10.1016/j.vaccine.2009.10.087

[107] F. Elias, J. Flo, J. M. Rodriguez, A. De Nichilo, R. A. Lopez, J. Zorzopulos, C. Nagle, M. Lahoz and A. Montaner, "PyNTTTTGT Prototype Oligonucleotide IMT504 is a Potent Adjuvant for the Recombinant Hepatitis B Vaccine That Enhances the Th1 Response," Vaccine, Vol. 23, No. 27, May 2005, pp. 3597-3603. doi:10.1016/j.vaccine.2004.12.030

[108] J. A. Aebig, G. E. Mullen, G. Dobrescu, K. Rausch, L. Lambert, O. Ajose-Popoola, C. A. Long, A. Saul and A. P. Miles, "Formulation of Vaccines Containing $\mathrm{CpG}$ Oligonucleotides and Alum," Journal of Immunological Methods, Vol. 323, No. 2, June 2007, pp. 139-146. doi:10.1016/j.jim.2007.04.003

[109] G. E. Mullen, J. A. Aebig, G. Dobrescu, K. Rausch, L. Lambert, C. A. Long, A. P. Miles and A. Saul, "Enhanced Antibody Production in Mice to the Malaria Antigen AMA1 by CPG 7909 Requires Physical Association of CpG and Antigen," Vaccine, Vol. 25, No. 29, July 2007, pp. 5343-5347. doi:10.1016/j.vaccine.2007.05.007

[110] R. D. Ellis, G. E. Mullen, M. Pierce, L. B. Martin, K. Miura, M. P. Fay, C. A. Long, D. Shaffer, A. Saul, L. H. Miller and A. P. Durbin, "A Phase 1 Study of the Blood-Stage Malaria Vaccine Candidate AMA1-C1/ Alhydrogel with CPG 7909, Using Two Different Formulations and Dosing Intervals," Vaccine, Vol. 27, No. 31, June 2009, pp. 4104-4109. doi:10.1016/j.vaccine.2009.04.077

[111] A. M. Harandi and J. Holmgren, "CpG OligodEoxynucleotides and Mobilization of Innate Mucosal Immunity: Tasks and Tactics," Vaccine, Vol. 24, Suppl 2, April 2006, pp. S2-48-9.
[112] S. Tengvall, A. Lundqvist, R. J. Eisenberg, G. H. Cohen and A. M. Harandi, "Mucosal Administration of $\mathrm{CpG}$ Oligodeoxynucleotide Elicits Strong CC and CXC Chemokine Responses in the Vagina and Serves as a Potent Th1-Tilting Adjuvant for Recombinant gD2 Protein Vaccination against Genital Herpes," Journal of Virology, Vol. 80, No. 11, June 2006, pp. 5283-5291. doi:10.1128/JVI.02013-05

[113]L. Zhang, X. Tian and F. Zhou, "Intranasal Administration of $\mathrm{CpG}$ Oligonucleotides Induces Mucosal and Systemic Type 1 Immune Responses and Adjuvant Activity to Porcine Reproductive and Respiratory Syndrome Killed Virus Vaccine in Piglets in Vivo," International Immunopharmacology, Vol. 7, No. 13, December 2007, pp. 1732-1740. doi:10.1016/j.intimp.2007.09.012

[114] S. Zimmermann, A. Dalpke and K. Heeg, "CpG Oligonucleotides as Adjuvant in Therapeutic Vaccines against Parasitic Infections," International Journal of Medical Microbiology, Vol. 298, No. 1-2, January 2008, pp. 39-44. doi:10.1016/j.ijmm.2007.07.011

[115] M. J. McCluskie and H. L. Davis, "Oral, Intrarectal and Intranasal Immunizations Using $\mathrm{CpG}$ and Non-CpG Oligodeoxynucleotides as Adjuvants," Vaccine, Vol. 19, No. 4-5, October 2000, pp. 413-422. doi:10.1016/S0264-410X(00)00208-5

[116] D. Wang, E. R. Kandimalla, D. Yu, J. X. Tang and S. Agrawal, "Oral Administration of Second-Generation Immunomodulatory Oligonucleotides Induces Mucosal Th1 Immune Responses and Adjuvant Activity," Vaccine, Vol. 23, No. 20, April 2005, pp. 2614-2622. doi:10.1016/j.vaccine.2004.11.028

[117] D. T. O'Hagan, M. Singh, J. Kazzaz, M. Ugozzoli, M. Briones, J. Donnelly and G. Ott, "Synergistic Adjuvant Activity of Immunostimulatory DNA and Oil/Water Emulsions for Immunization with HIV p55 Gag Antigen," Vaccine, Vol. 20, No. 27-28, September 2002, pp. 3389-3398. doi:10.1016/S0264-410X(02)00272-4

[118] Z. Cui and F. Qiu, "Synthetic Double-Stranded RNA Poly (I:C) as a Potent Peptide Vaccine Adjuvant: Therapeutic Activity against Human Cervical Cancer in a Rodent Model," Cancer Immunology, Immunotherapy, Vol. 55, No. 10, October 2006, pp. 1267-1279. doi:10.1007/s00262-005-0114-6

[119] M. Ringvall, E. J. M. Huijbers, P. Ahooghalandari, L. Alekseeva, T. Andronova, A.-K. Olsson and L. Hellman, "Identification of Potent Biodegradable Adjuvants That Efficiently Break Self-Tolerance: A Key Issue in the Development of Therapeutic Vaccines," Vaccine, Vol. 28, No. 1, 2009, pp. 48-52. doi:10.1016/j.vaccine.2009.09.122

[120] T. R. Johnson, S. Rao, R. A. Seder, M. Chen and B. S. Graham, "TLR9 Agonist, but not TLR7/8, Functions as an Adjuvant to Diminish FI-RSV Vaccine-Enhanced Disease, While Either Agonist Used as Therapy during Primary RSV Infection Increases Disease Severity," Vaccine, Vol. 27, No. 23, May 2009, pp. 3045-3052. doi:10.1016/j.vaccine.2009.03.026 
[121] M. Chennaoui, C. Drogou, A. F. Carpentier, C.-Y. Guezennec and D. Gomez-Merino, "Cytokine Content in Lymphoid and White Adipose Tissues after Repeated CpG Oligodeoxynucleotide Administration in Trained Rats," Vaccine, Vol. 28, No. 7, 2010, pp. 1814-1818. doi:10.1016/j.vaccine.2009.12.003

[122] B. Traore, Y. Koné, S. Doumbo, D. Doumtabé, A. Traoré, P. D. Crompton, M. Mircetic, C.-Y. Huang, K. Kayentao, A. Dicko, I. Sagara, R. D. Ellis, K. Miura, A. Guindo, L. H. Miller, O. K. Doumbo and S. K. Pierce, "The TLR9 Agonist $\mathrm{CpG}$ Fails to Enhance the Acquisition of Plasmodium Falciparum-Specific Memory B Cells in Semi-Immune Adults in Mali," Vaccine, Vol. 27, No. 52, 2009, pp. 7299-7303. doi:10.1016/j.vaccine.2009.08.023

[123] J. Aucouturier, S. Ascarateil and L. Dupuis, "The Use of Oil Adjuvants in Therapeutic Vaccines," Vaccine, Vol. 24 Suppl 2, April 2006, pp. S2-44-5.

[124] J. Oscherwitz, F. C. Hankenson, F. Yu and K. B. Cease, "Low-Dose Intraperitoneal Freund's Adjuvant: Toxicity and Immunogenicity in Mice Using an Immunogen Targeting Amyloid-Beta Peptide," Vaccine, Vol. 24, No. 15, April 2006, pp. 3018-3025. doi:10.1016/j.vaccine.2005.10.046

[125] S. A. Rosenberg, J. C. Yang, U. S. Kammula, M. S. Hughes, N. P. Restifo, S. L. Schwarz, K. E. Morton, C. M. Laurencot and R. M. Sherry, "Different Adjuvanticity of Incomplete Freund's Adjuvant Derived from Beef or Vegetable Components in Melanoma Patients Immunized with a Peptide Vaccine," Journal of Immunotherapy, Vol. 33, No. 6, July-August 2010, pp. 626-629. doi:10.1097/CJI.0b013e3181dac9de

[126] J. A. Langermans, A. Schmidt, R. A. Vervenne, A. J. Birkett, J. M. Calvo-Calle, M. Hensmann, G. B. Thornton, F. Dubovsky, H. Weiler, E. Nardin and A. W. Thomas, "Effect of Adjuvant on Reactogenicity and Long-Term Immunogenicity of the Malaria Vaccine ICC-1132 in Macaques," Vaccine, Vol. 23, No. 41, September 2005, pp. 4935-4943. doi:10.1016/j.vaccine.2005.05.036

[127] A. Saul, G. Lawrence, A. Allworth, S. Elliott, K. Anderson, C. Rzepczyk, L. B. Martin, D. Taylor, D. P. Eisen, D. O. Irving, D. Pye, P. E. Crewther, A. N. Hodder, V. J. Murphy and R. F. Anders, "A Human Phase 1 Vaccine Clinical Trial of the Plasmodium Falciparum Malaria Vaccine Candidate Apical Membrane Antigen 1 in Montanide ISA720 Adjuvant," Vaccine, Vol. 23, No. 23, April 2005, pp. 3076-3083. doi:10.1016/j.vaccine.2004.09.040

[128]D. O'Hagan, "The Role of Adjuvants in Vaccine Development: The Example of MF59," Novel Vaccines: Adjuvants and Delivery Systems Providence, RI, USA, 2009.

[129] M. Dupuis, D. M. McDonald and G. Ott, "Distribution of Adjuvant MF59 and Antigen gD2 after Intramuscular Injection in Mice," Vaccine, Vol. 18, No. 5-6, October 1999, pp. 434-439. doi:10.1016/S0264-410X(99)00263-7

[130] C. B. Fox, R. C. Anderson, T. S. Dutill, Y. Goto, S. G. Reed and T. S. Vedvick, "Monitoring the Effects of Component Structure and Source on Formulation Stabi- lity and Adjuvant Activity of Oil-in-Water Emulsions," Colloids Surf B Biointerfaces, Vol. 65, No. 1, August 2008, pp. 98-105. doi:10.1016/j.colsurfb.2008.03.003

[131]D. T. O'Hagan, "MF59 is a Safe and Potent Vaccine Adjuvant that Enhances Protection against Influenza Virus Infection," Expert Review of Vaccines, Vol. 6, No. 5, October 2007, pp. 699-710. doi: $10.1586 / 14760584.6 .5 .699$

[132] V. Schultze, V. D'Agosto, A. Wack, D. Novicki, J. Zorn and R. Hennig, "Safety of MF59 Adjuvant," Vaccine, Vol. 26, No. 26, June 2008, pp. 3209-3222. doi:10.1016/j.vaccine.2008.03.093

[133] S. E. Frey, M. Houghton, S. Coates, S. Abrignani, D. Chien, D. Rosa, P. Pileri, R. Ray, A. M. Di Bisceglie, P. Rinella, H. Hill, M. C. Wolff, V. Schultze, J. H. Han, B. Scharschmidt and R. B. Belshe, "Safety and Immunogenicity of HCV E1E2 Vaccine Adjuvanted with MF59 Administered to Healthy Adults," Vaccine, Vol. 28, No. 38,2010 , pp. 6367-6373 doi:10.1016/j.vaccine.2010.06.084

[134] T. Vesikari, M. Pellegrini, A. Karvonen, N. Groth, A. Borkowski, T. O'Hagan D and A. Podda, "Enhanced Immunogenicity of Seasonal Influenza Vaccines in Young Children Using MF59 Adjuvant," The Pediatric Infectious Disease Journal, Vol. 28, No. 7, July 2009, pp. 563-571. doi:10.1097/INF.0b013e31819d6394

[135] T. Vesikari, N. Groth, A. Karvonen, A. Borkowski and M. Pellegrini, "MF59®-Adjuvanted Influenza Vaccine (FLUAD ${ }^{\circledR}$ ) in Children: Safety and Immunogenicity Following a Second Year Seasonal Vaccination," Vaccine, Vol. 27, No. 45, 2009, pp. 6291-6295. doi:10.1016/j.vaccine.2009.02.004

[136] W. Keitel, N. Groth, M. Lattanzi, M. Praus, A. K. Hilbert, A. Borkowski and T. F. Tsai, "Dose Ranging of Adjuvant and Antigen in a Cell Culture H5N1 Influenza Vaccine: Safety and Immunogenicity of a Phase $1 / 2$ Clinical Trial," Vaccine, Vol. 28, No. 3, 2010, pp. 840-848. doi:10.1016/j.vaccine.2009.10.019

[137] T. C. Heineman, M. L. Clements-Mann, G. A. Poland, R. M. Jacobson, A. E. Izu, D. Sakamoto, J. Eiden, G. A. Van Nest and H. H. Hsu, "A Randomized, Controlled Study in Adults of the Immunogenicity of a Novel Hepatitis B Vaccine Containing MF59 Adjuvant," Vaccine, Vol. 17, No. 22, July 1999, pp. 2769-2778. doi:10.1016/S0264-410X(99)00088-2

[138] H. El Sahly, "MF59\&\#x2122; as a Vaccine Adjuvant: A Review of Safety and Immunogenicity," Expert Review of Vaccine, Vol. 9, No. 10, October 2010, pp. 1135-1141. doi:10.1586/erv.10.111

[139] G. Del Giudice, E. Fragapane, R. Bugarini, M. Hora, T. Henriksson, E. Palla, D. O'Hagan, J. Donnelly, R. Rappuoli and A. Podda, "Vaccines with the MF59 Adjuvant do not Stimulate Antibody Responses against Squalene," Clinical and Vaccine Immunology, Vol. 13, No. 9, September 2006, pp. 1010-1013. doi:10.1128/CVI.00191-06 
[140] A. Arguedas, C. Soley, A. Abdelnour, V. Sales, K. Lindert, G. D. Cioppa and R. Clemens, "Assessment of the Safety, Tolerability and Kinetics of the Immune Response to A/H1N1v Vaccine Formulations with and without Adjuvant in Healthy Pediatric Subjects from 3 through 17 Years of Age," Human Vaccines, Vol. 7, No. 1, January 2011, pp. 33-78. doi:10.4161/hv.7.1.13411

[141] S. Black, G. Della Cioppa, A. Malfroot, P. Nacci, U. Nicolay, M. Pellegrini, E. Sokal and A. Vertruyen, "Safety of MF59-Adjuvanted Versus Non-Adjuvanted Influenza Vaccines in Children and Adolescents: An Integrated Analysis," Vaccine, Vol. 28, No. 45, October 2010, pp. 7331-7336. doi:10.1016/j.vaccine.2010.08.075

[142] S. L. Baldwin, C. B. Fox, M. A. Pallansch, R. N. Coler, S. G. Reed and M. Friede, "Increased Potency of an Inactivated Trivalent Polio Vaccine with Oil-in-Water Emulsions," Vaccine, Vol. 29, No. 4, 2011, pp. 644-649. doi:10.1016/j.vaccine.2010.11.043

[143] J. Suli, Z. Benisek, D. Elias, S. Svrcek, A. Ondrejkova, R. Ondrejka and V. Bajova, "Experimental Squalene Adjuvant. I. Preparation and Testing of Its Effectiveness," Vaccine, Vol. 22, No. 25-26, September 2004, pp. 34643469. doi:10.1016/j.vaccine.2004.02.023

[144] R. Bodewes, M. M. Geelhoed-Mieras, J. G. M. Heldens, J. Glover, B. N. Lambrecht, R. A. M. Fouchier, A. D. M. E. Osterhaus and G. F. Rimmelzwaan, "The Novel Adjuvant CoVaccineHT(TM) Increases the Immunogenicity of Cell-Culture Derived Influenza A/H5N1 Vaccine and Induces the Maturation of Murine and Human Dendritic Cells in Vitro," Vaccine, Vol. 27, No. 49, 2009, pp. 68336839. doi:10.1016/j.vaccine.2009.09.015

[145] C. Caillet, F. Piras, M.-C. Bernard, A. de Montfort, F. Boudet, F. R. Vogel, A. Hoffenbach, C. Moste and I. Kusters, "AF03-Adjuvanted and Non-Adjuvanted Pandemic Influenza A (H1N1) 2009 Vaccines Induce Strong Antibody Responses in Seasonal Influenza Vaccine-Primed and Unprimed Mice," Vaccine, Vol. 28, No. 18,2010 , pp. 3076-3079. doi:10.1016/j.vaccine.2010.02.050

[146] W. R. J. Ballou and E. J. Hanon, "Vaccine Comprising an Oil in Water Emulsion Adjuvant," 2008.

[147] N. J. Carter and G. L. Plosker, "Prepandemic Influenza Vaccine H5N1 (Split Virion, Inactivated, Adjuvanted) [Prepandrix]: A Review of Its Use as an Active Immunization against Influenza A Subtype H5N1 Virus," BioDrugs, Vol. 22, No. 5, 2008, pp. 279-292. doi:10.2165/00063030-200822050-00001

[148] O. Berger, "Novel approaches for vaccine adjuvants," In" Novel Vaccines: Adjuvants and Delivery Systems Providence, RI, USA, 2009.

[149] D. W.-S. Chu, S.-J. Hwang, F. S. Lim, H. M. L. Oh, P. Thongcharoen, P.-C. Yang, H. L. Bock, M. Dramé, P. Gillard, Y. Hutagalung, H. Tang, Y. L. Teoh and R. W. Ballou, "Immunogenicity and Tolerability of an AS03AAdjuvanted Prepandemic Influenza Vaccine: A Phase III Study in a Large Population of Asian Adults," Vaccine, Vol. 27, No. 52, 2009, pp. 7428-7435. doi:10.1016/j.vaccine.2009.07.102
[150] I. Leroux-Roels, M. Van der Wielen, F. Kafeja, C. Vandermeulen, R. Lazarus, M. D. Snape, T. John, C. Carre, N. Nougarede, S. Pepin, G. Leroux-Roels, K. Hoppenbrouwers, A. J. Pollard and P. Van Damme, "Humoral and Cellular Immune Responses to SplitVirion H5N1 Influenza Vaccine in Young and Elderly Adults," Vaccine, Vol. 27, No. 49, November 2009, pp. 6918-6925. doi:10.1016/j.vaccine.2009.08.110

[151]F. Roman, T. Vaman, B. Gerlach, A. Markendorf, P. Gillard and J.-M. Devaster, "Immunogenicity and Safety in Adults of One Dose of Influenza A H1N1v 2009 Vaccine Formulated with and without AS03A-Adjuvant: Preliminary Report of an Observer-Blind, Randomised Trial," Vaccine, Vol. 28, No. 7, 2010, pp. 1740-1745. doi:10.1016/j.vaccine.2009.12.014

[152] A. S. Madhun, P. E. Akselsen, H. Sjursen, G. Pedersen, S. Svindland, J. K. Nøstbakken, M. Nilsen, K. Mohn, A. Jul-Larsen, I. Smith, D. Major, J. Wood and R. J. Cox, "An Adjuvanted Pandemic Influenza H1N1 Vaccine Provides Early and Long Term Protection in Health Care Workers," Vaccine, Vol. 29, No. 2, 2011, pp. 266-273. doi:10.1016/j.vaccine.2010.10.038

[153] D. Engelhard, Z. Zakay-Rones, M. Y. Shapira, I. Resnick, D. Averbuch, S. Grisariu, L. Dray, E. Djian, N. StraussLiviatan, I. Grotto, D. G. Wolf and R. Or, "The Humoral Immune Response of Hematopoietic Stem Cell Transplantation Recipients to AS03-Adjuvanted A/California/ 7/2009 (H1N1)v-Like Virus Vaccine during the 2009 Pandemic," Vaccine, Vol. 29, No. 9, 2011, pp. 1777-1782. doi:10.1016/j.vaccine.2010.12.113

[154] A. Carmona, F. Omeñaca, J. C. Tejedor, J. M. Merino, T. Vaman, I. Dieussaert, P. Gillard and J. Arístegui, "Immunogenicity and Safety of AS03-Adjuvanted 2009 influenza A H1N1 Vaccine in Children 6-35 Months," Vaccine, Vol. 28, No. 36, 2010, pp. 5837-5844. doi:10.1016/j.vaccine.2010.06.065

[155] E. Javelle, B. Soulier, C. Brosset, S. Lorcy and F. Simon, "Delayed Focal Lipoatrophy after AS03-Adjuvanted Influenza A (H1N1) 2009 Vaccine," Vaccine, Vol. 29, No. 6, 2011, pp. 1123-1125. doi:10.1016/j.vaccine.2010.12.018

[156] M. J. Pearse and D. Drane, "Iscomatrix Adjuvant: A Potent Inducer of Humoral and Cellular Immune Responses," Vaccine, Vol. 22, No. 19, June 2004, pp. 2391-2395. doi:10.1016/j.vaccine.2003.12.031

[157] M. J. Pearse and D. Drane, "Iscomatrix Adjuvant for Antigen Delivery," Advanced Drug Delivery Review, Vol. 57, No. 3, January 2005, pp. 465-474. doi:10.1016/j.addr.2004.09.006

[158]H. X. Sun, Y. Xie and Y. P. Ye, "ISCOMs and ISCOMATRIX," Vaccine, Vol. 27, No. 33, July 2009, pp. 4388-4401. doi:10.1016/j.vaccine.2009.05.032

[159] E. Furrie, R. E. Smith, M. W. Turner, S. Strobel and A. M. Mowat, "Induction of Local Innate Immune Responses and Modulation of Antigen Uptake as Mechanisms Underlying the Mucosal Adjuvant Properties of Immune Stimulating Complexes (ISCOMS)," Vaccine, Vol. 20, No. 17-18, May 2002, pp. 2254-2262. doi:10.1016/S0264-410X(02)00106-8 
[160] J. Malliaros, C. Quinn, F. H. Arnold, M. J. Pearse, D. P. Drane, T. J. Stewart and R. I. Macfarlan, "Association of Antigens to Iscomatrix Adjuvant Using Metal Chelation Leads to Improved CTL Responses," Vaccine, Vol. 22, No. 29-30, September 2004, pp. 3968-3975. doi:10.1016/j.vaccine.2004.03.054

[161] D. E. Clements, B.-A. G. Coller, M. M. Lieberman, S. Ogata, G. Wang, K. E. Harada, J. R. Putnak, J. M. Ivy, M. McDonell, G. S. Bignami, I. D. Peters, J. Leung, C. Weeks-Levy, E. T. Nakano and T. Humphreys, "Development of a Recombinant Tetravalent Dengue Virus Vaccine: Immunogenicity and Efficacy Studies in Mice and Monkeys," Vaccine, Vol. 28, No. 15, 2010, pp. 2705-2715. doi:10.1016/j.vaccine.2010.01.022

[162] J. Boyle, D. Eastman, C. Millar, S. Camuglia, J. Cox, M. Pearse, J. Good and D. Drane, "The Utility of Iscomatrix Adjuvant for Dose Reduction of Antigen for Vaccines Requiring Antibody Responses," Vaccine, Vol. 25, No. 14, March 2007, pp. 2541-2544. doi:10.1016/j.vaccine.2006.12.018

[163] I. H. Frazer, M. Quinn, J. L. Nicklin, J. Tan, L. C. Perrin, P. Ng, V. M. O'Connor, O. White, N. Wendt, J. Martin, J. M. Crowley, S. J. Edwards, A. W. McKenzie, S. V. Mitchell, D. W. Maher, M. J. Pearse and R. L. Basser, "Phase 1 Study of HPV16-Specific Immunotherapy with E6E7 Fusion Protein and Iscomatrix Adjuvant in Women with Cervical Intraepithelial Neoplasia," Vaccine, Vol. 23, No. 2, November 2004, pp. 172-181. doi:10.1016/j.vaccine.2004.05.013

[164] A. S. Madhun, L. R. Haaheim, M. V. Nilsen and R. J. Cox, "Intramuscular Matrix-M-Adjuvanted Virosomal H5N1 Vaccine Induces High Frequencies of Multifunctional Th1 CD4+Cells and Strong Antibody Responses in Mice," Vaccine, Vol. 27, No. 52, 2009, pp. 7367-7376. doi:10.1016/j.vaccine.2009.09.044

[165] M. T. Sanders, G. Deliyannis, M. J. Pearse, M. K. McNamara and L. E. Brown, "Single Dose Intranasal Immunization with Iscomatrix Vaccines to Elicit Antibody-Mediated Clearance of Influenza Virus Requires Delivery to the Lower Respiratory Tract," Vaccine, Vol. 27, No. 18, April 2009, pp. 2475-2482. doi:10.1016/j.vaccine.2009.02.054

[166] A. Vujanic, J. L. K. Wee, K. J. Snibson, S. Edwards, M. Pearse, C. Quinn, M. Moloney, S. Taylor, J.-P. Y. Scheerlinck and P. Sutton, "Combined Mucosal and Systemic Immunity Following Pulmonary Delivery of Iscomatrix(TM) Adjuvanted Recombinant Antigens," Vaccine, Vol. 28, No. 14, 2010, pp. 2593-2597. doi:10.1016/j.vaccine.2010.01.018

[167] J. L. Wee, J. P. Scheerlinck, K. J. Snibson, S. Edwards, M. Pearse, C. Quinn and P. Sutton, "Pulmonary Delivery of Iscomatrix Influenza Vaccine Induces Both Systemic and Mucosal Immunity with Antigen Dose Sparing," Mucosal Immunology, Vol. 1, No. 6, November 2008, pp. 489-496. doi:10.1038/mi.2008.59

[168] W. Yan, W. Chen and L. Huang, "Mechanism of Adjuvant Activity of Cationic Liposome: Phosphorylation of a MAP Kinase, ERK and Induction of Chemokines,"
Molecular Immunology, Vol. 44, No. 15, July 2007, pp. 3672-3681. doi:10.1016/j.molimm.2007.04.009

[169] D. Christensen, C. Foged, I. Rosenkrands, C. V. Lundberg, P. Andersen, E. M. Agger and H. M. Nielsen, "CAF01 Liposomes as a Mucosal Vaccine Adjuvant: In Vitro and in Vivo Investigations," International Journal of Pharmaceutics, Vol. 390, No. 1, May 2010, pp. 19-24.

doi:10.1016/j.ijpharm.2009.10.043

[170] V. Dwivedi, A. Vasco, S. Vedi, A. Dangi, K. Arif, S. M. Bhattacharya and M. Owais, "Adjuvanticity and Protective Immunity of Plasmodium Yoelii Nigeriensis Blood-Stage Soluble Antigens Encapsulated in Fusogenic Liposome," Vaccine, Vol. 27, No. 3, January 2009, pp. 473-482. doi:10.1016/i.vaccine.2008.10.054

[171] L. Calderon, E. Facenda, L. Machado, K. Uyema, D. Rodriguez, E. Gomez, Y. Martinez, B. Gonzalez, V. Bourg, C. Alvarez, A. Otero, M. Russo, A. Labrada and M. E. Lanio, "Modulation of the Specific Allergic Response by Mite Allergens Encapsulated into Liposomes," Vaccine, Vol. 24, Suppl 2, April 2006, pp. S2-38-9.

[172] C. J. Pachuk, D. E. McCallus, D. B. Weiner and C. Satishchandran, "DNA Vaccines: Challenges in Delivery," Current Opinion in Molecular Therapeutics, Vol. 2, No. 2, April 2000, pp. 188-198.

[173] K. S. Korsholm, E. M. Agger, C. Foged, D. Christensen, J. Dietrich, C. S. Andersen, C. Geisler and P. Andersen, "The Adjuvant Mechanism of Ationic Imethyldioctadecylammonium Liposomes," Immunology, Vol. 121, No. 2, June 2007, pp. 216-226. doi:10.1111/j.1365-2567.2007.02560.x

[174] N. Lincopan, N. M. Espíndola, A. J. Vaz, M. H. B. d. Costa, E. Faquim-Mauro and A. M. Carmona-Ribeiro, "Novel Immunoadjuvants Based on Cationic Lipid: Preparation, Characterization and Activity in Vivo," Vaccine, Vol. 27, No. 42, 2009, pp. 5760-5771. doi:10.1016/j.vaccine.2009.07.066

[175] P. Pushko, T. M. Tumpey, N. Van Hoeven, J. A. Belser, R. Robinson, M. Nathan, G. Smith, D. C. Wright and R. A. Bright, "Evaluation of Influenza Virus-Like Particles and Novasome Adjuvant as Candidate Vaccine for Avian Influenza," Vaccine, Vol. 25, No. 21, May 2007, pp. 4283-4290. doi:10.1016/j.vaccine.2007.02.059

[176] D. Christensen, C. Foged, I. Rosenkrands, H. M. Nielsen, P. Andersen and E. M. Agger, "Trehalose Preserves DDA/TDB Liposomes and Their Adjuvant Effect during Freeze-Drying," Biochimica et Biophysica Acta, Vol. 1768, No. 9, September 2007, pp. 2120-2129. doi:10.1016/j.bbamem.2007.05.009

[177] O. Even-Or, S. Samira, E. Rochlin, S. Balasingam, A. J. Mann, R. Lambkin-Williams, J. Spira, I. Goldwaser, R. Ellis and Y. Barenholz, "Immunogenicity, Protective Efficacy and Mechanism of Novel CCS Adjuvanted Influenza Vaccine," Vaccine, Vol. 28, No. 39, 2010, pp. 6527-6541. doi:10.1016/j.vaccine.2010.04.011

[178] R. Ravindran, S. Bhowmick, A. Das and N. Ali, "Comparison of BCG, MPL and Cationic Liposome Adjuvant Systems in Leishmanial Antigen Vaccine 
Formulations against Murine Visceral Leishmaniasis," BMC Microbiology, Vol. 10, 2010, p. 181.

[179] M. Karkada, G. M. Weir, T. Quinton, A. Fuentes-Ortega and M. Mansour, "A Liposome-Based Platform, VacciMax ${ }^{\circledR}$, and Its Modified Water-Free Platform DepoVax(TM) Enhance Efficacy of in Vivo Nucleic Acid Delivery," Vaccine, Vol. 28, No. 38, 2010, pp. 6176-6182. doi:10.1016/j.vaccine.2010.07.025

[180] M. E. Lanio, M. C. Luzardo, C. Alvarez, Y. Martinez, L. Calderon, M. E. Alonso, B. Zadi, G. Gregoriadis, D. Q. Craig and A. Disalvo, "Humoral Immune Response against Epidermal Growth Factor Encapsulated in Dehydration Rehydration Vesicles of Different Phospholipid Composition," Journal of Liposome Research, Vol. 18, No. 1, 2008, pp. 1-19. doi:10.1080/08982100801893887

[181] J. Hartikka, V. Bozoukova, C. K. Yang, M. Ye, D. Rusalov, M. Shlapobersky, A. Vilalta, Q. Wei, A. Rolland and L. R. Smith, "Vaxfectin ${ }^{\circledR}$, a Cationic LipidBased Adjuvant for Protein-Based Influenza Vaccines," Vaccine, Vol. 27, No. 46, 2009, pp. 6399-6403. doi:10.1016/j.vaccine.2009.06.014

[182] M. Shlapobersky, Q. Wei, S. Sullivan and A. Vilalta, "Vaxfectin ${ }^{\circledR}$-Adjuvanted Seasonal Influenza Protein Vaccine: Correlation of Systemic and Local Immunological Markers with Formulation Parameters," Vaccine, Vol. 27, No. 46, 2009, pp. 6404-6410. doi:10.1016/j.vaccine.2009.06.087

[183] N. J. Steers, K. K. Peachman, S. McClain, C. R. Alving and M. Rao, "Liposome-Encapsulated HIV-1 Gag p24 Containing Lipid A Induces Effector CD4+ T-Cells, Memory CD8+ T-Cells, and Pro-Inflammatory Cytokines," Vaccine, Vol. 27, No. 49, 2009, pp. 6939-6949. doi:10.1016/j.vaccine.2009.08.105

[184] D. Christensen, M. Alleso, I. Rosenkrands, J. Rantanen, C. Foged, E. M. Agger, P. Andersen and H. M. Nielsen, "NIR Transmission Spectroscopy for Rapid Determination of Lipid and Lyoprotector Content in Liposomal Vaccine Adjuvant System CAF01," European Journal of Pharmaceutical Sciences, Vol. 70, No. 3, November 2008, pp. 914-920. doi:10.1016/j.ejpb.2008.07.007

[185] A. Pattani, R. K. Malcolm and R. M. Curran, "Retrongineering of Liposomal Vaccine Adjuvants: Role of a Microarray-Based Screen," Vaccine, Vol. 28, No. 6, 2010, pp. 1438-1439. doi:10.1016/j.vaccine.2009.11.070

[186] E. A. Vasievich, W. Chen and L. Huang, "Enantiospecific Adjuvant Activity of Cationic Lipid DOTAP in Cancer Vaccine," Cancer Immunology, Immunotherapy, Vol. 60. No. 5, January 2011, pp. 629-638.

[187] B. Guy, N. Pascal, A. Francon, A. Bonnin, S. Gimenez, E. Lafay-Vialon, E. Trannoy and J. Haensler, "Design, Characterization and Preclinical Efficacy of a Cationic Lipid Adjuvant for Influenza Split Vaccine," Vaccine, Vol. 19, No. 13-14, February 2001, pp. 1794-1805. doi:10.1016/S0264-410X(00)00386-8

[188] M. Brgles, L. Habjanec, B. Halassy and J. Tomasic, "Liposome Fusogenicity and Entrapment Efficiency of Antigen Determine the Th1/Th2 Bias of Antigen-Specific
Immune Response," Vaccine, Vol. 27, No. 40, September 2009, pp. 5435-5442. doi:10.1016/j.vaccine.2009.07.012

[189] J. F. Mann, E. Shakir, K. C. Carter, A. B. Mullen, J. Alexander and V. A. Ferro, "Lipid Vesicle Size of an Oral Influenza Vaccine Delivery Vehicle Influences the Th1/Th2 Bias in the Immune Response and Protection against Infection," Vaccine, Vol. 27, No. 27, June 2009, pp. 3643-3649. doi:10.1016/j.vaccine.2009.03.040

[190] J. Del Campo, M. Lindqvist, M. Cuello, M. Bäckström, O. Cabrerra, J. Persson, O. Perez and A. M. Harandi, "Intranasal Immunization with a Proteoliposome-Derived Cochleate Containing Recombinant gD Protein Confers Protective Immunity against Genital Herpes in Mice," Vaccine, Vol. 28, No. 5, 2010, pp. 1193-1200. doi:10.1016/j.vaccine.2009.11.035

[191] C. Mesa, J. de Leon and L. E. Fernandez, "Very Small Size Proteoliposomes Derived from Neisseria Meningitidis: An Effective Adjuvant for Generation of CTL Responses to Peptide and Protein Antigens," Vaccine, Vol. 24, No. 14, March 2006, pp. 2692-2699. doi:10.1016/j.vaccine.2005.08.111

[192] T. Rodriguez, O. Perez, S. Ugrinovic, G. Bracho and P. Mastroeni, "Bacterial Derived Proteoliposome as Ideal Delivery System and Cellular Adjuvant," Vaccine, Vol. 24, Suppl 2, April 2006, pp. S2-24-5.

[193] M. Lastre, O. Perez, A. Labrada, I. Bidot, J. Perez, G. Bracho, J. del Campo, D. Perez, E. Facenda, C. Zayas, C. Rodriguez and G. Sierra, "Bacterial Derived Proteoliposome for Allergy Vaccines," Vaccine, Vol. 24, Suppl 2, April 2006, pp. S2-34-5.

[194] J. L. Perez, R. Acevedo, A. Callico, Y. Fernandez, B. Cedre, G. Ano, L. Gonzalez, G. Falero, A. Talavera, O. Perez and L. Garcia, "A Proteoliposome Based Formulation administered by the Nasal Route Produces Vibriocidal Antibodies against El for Ogawa Vibrio Cholerae O1 in BALB/c Mice," Vaccine, Vol. 27, No. 2, January 2009, pp. 205-212. doi:10.1016/j.vaccine.2008.10.052

[195] G. Bracho, M. Lastre, J. del Campo, C. Zayas, D. Gonzalez, D. Gil, R. Acevedo, C. Taboada, R. L. Solis and O. Perez, "Proteoliposome Derived Cochleate as Novel Adjuvant," Vaccine, Vol. 24, Suppl 2, April 2006, pp. S2-30-1.

[196] T. Stauffer, "Virosome-Based Vaccine Design," In: Novel Vaccines: Adjuvants and Delivery Systems Providence, RI, USA, 2009.

[197] C. Herzog, K. Hartmann, V. Kunzi, O. Kursteiner, R. Mischler, H. Lazar and R. Gluck, "Eleven Years of Inflexal V-a Virosomal Adjuvanted Influenza Vaccine," Vaccine, Vol. 27, No. 33, July 2009, pp. 4381-4387. doi:10.1016/j.vaccine.2009.05.029

[198] V. Kunzi, M. Dornseiff, J. Horwath and K. Hartmann, "Safe Vaccination of Children with a Virosomal Adjuvanted Influenza Vaccine," Vaccine, Vol. 27, No. 8, February 2009, pp. 1261-1265. doi:10.1016/j.vaccine.2008.12.008

[199] M. Sedegah, W. O. Rogers, M. Belmonte, A. Belmonte, G. Banania, N. B. Patterson, D. Rusalov, M. Ferrari, T. L. Richie and D. L. Doolan, "Vaxfectin ${ }^{\circledR}$ Enhances Both 
Antibody and in Vitro $\mathrm{T}$ Cell Responses to Each Component of a 5-Gene Plasmodium Falciparum Plasmid DNA Vaccine Mixture Administered at Low Doses," Vaccine, Vol. 28, No. 17, 2010, pp. 3055-3065. doi:10.1016/i.vaccine.2009.10.044

[200] L. R. Smith, M. K. Wloch, M. Ye, L. R. Reyes, S. Boutsaboualoy, C. E. Dunne, J. A. Chaplin, D. Rusalov, A. P. Rolland, C. L. Fisher, M. S. Al-Ibrahim, M. L. Kabongo, R. Steigbigel, R. B. Belshe, E. R. Kitt, A. H. $\mathrm{Chu}$ and R. B. Moss, "Phase 1 Clinical Trials of the Safety and Immunogenicity of Adjuvanted Plasmid DNA Vaccines Encoding Influenza A Virus H5 Hemagglutinin," Vaccine, Vol. 28, No. 13, 2010, pp. 2565-2572. doi:10.1016/j.vaccine.2010.01.029

[201] V. A. Arankalle, K. S. Lole, T. M. Deshmukh, S. Srivastava and U. S. Shaligram, "Challenge Studies in Rhesus Monkeys Immunized with Candidate Hepatitis E Vaccines: DNA, DNA-Prime-Protein-Boost and DNARotein Encapsulated in Liposomes," Vaccine, Vol. 27, No. 7, February 2009, pp. 1032-1039. doi:10.1016/j.vaccine.2008.11.097

[202] S. Shrivastava, K. S. Lole, A. S. Tripathy, U. S. Shaligram and V. A. Arankalle, "Development of Candidate Combination Vaccine for Hepatitis E and Hepatitis B: A Liposome Encapsulation Approach," Vaccine, Vol. 27, No. 47, 2009, pp. 6582-6588. doi:10.1016/j.vaccine.2009.08.033

[203] T. M. Fahmy, S. L. Demento, M. J. Caplan, I. Mellman and W. M. Saltzman, "Design Opportunities for Actively Targeted Nanoparticle Vaccines," Nanomedicine, Vol. 3, No. 3, June 2008, pp. 343-355. doi:10.2217/17435889.3.3.343

[204] T. J. Powell, N. Palath, M. E. DeRome, J. Tang, A. Jacobs and J. G. Boyd, "Synthetic Nanoparticle Vaccines Produced by Layer-by-Layer Assembly of Artificial Biofilms Induce Potent Protective T-Cell and Antibody Responses in Vivo," Vaccine, Vol. 29, No. 3, 2011, pp. 558-569. doi:10.1016/j.vaccine.2010.10.001

[205] E. Shahar, R. Gorodetsky, E. Gaberman, E. Aizenshtein and J. Pitcovski, "Targeted Microbeads for Attraction and Induction of Specific Innate Immune Response in the Tumor Microenvironment," Vaccine, Vol. 28, No. 45, October 2010, pp. 7279-7287. doi:10.1016/j.vaccine.2010.08.083

[206] P. Malyala, J. Chesko, M. Ugozzoli, A. Goodsell, F. Zhou, M. Vajdy, D. T. O'Hagan and M. Singh, "The Potency of the Adjuvant, CpG Oligos, is Enhanced by Encapsulation in PLG Microparticles," Journal of Pharmaceutical Sciences, Vol. 97, No. 3, March 2008, pp. 1155-1164. doi:10.1002/jps.21065

[207] B. Slütter, S. Bal, C. Keijzer, R. Mallants, N. Hagenaars, I. Que, E. Kaijzel, W. van Eden, P. Augustijns, C. Löwik, J. Bouwstra, F. Broere and W. Jiskoot, "Nasal Vaccination with N-Trimethyl Chitosan and PLGA Based Nanoparticles: Nanoparticle Characteristics Determine Quality and Strength of the Antibody Response in Mice against the Encapsulated Antigen," Vaccine, Vol. 28, No. 38,2010 , pp. 6282-6291. doi:10.1016/j.vaccine.2010.06.121
[208] P. G. Seferian and M. L. Martinez, "Immune Stimulating Activity of Two New Chitosan Containing Adjuvant Formulations," Vaccine, Vol. 19, No. 6, November 2000, pp. 661-668. doi:10.1016/S0264-410X(00)00248-6

[209] Z. Sui, Q. Chen, R. Wu, H. Zhang, M. Zheng, H. Wang and Z. Chen, "Cross-Protection against Influenza Virus Infection by Intranasal Administration of M2-Based Vaccine with Chitosan as an Adjuvant," Archives of Virology, Vol. 155, No. 4, April 2010, pp. 535-544. doi:10.1007/s00705-010-0621-4

[210] S. G. Markushin, Z. Gendon Iu, G. G. Krivtsov, Akopova, II, A. S. Sukhno and A. D. Pereverzev, "Increase of Immunogenicity of Cold-Adapted Influenza Vaccine by Using Adjuvant," Zh Mikrobiol Epidemiol Immunobiol, No. 5, September-October 2010, pp. 29-34.

[211] H. Chang, X. Li, Y. Teng, Y. Liang, B. Peng, F. Fang and Z. Chen, "Comparison of Adjuvant Efficacy of Chitosan and Aluminum Hydroxide for Intraperitoneally Administered Inactivated Influenza H5N1 Vaccine," DNA and Cell Biology, Vol. 29, No. 9, September 2010, pp. 563-568. doi:10.1089/dna.2009.0977

[212] X. Wang, T. Uto, T. Akagi, M. Akashi and M. Baba, "Poly(Gamma-Glutamic Acid) Nanoparticles as an Efficient Antigen Delivery and Adjuvant System: Potential for an AIDS Vaccine," Journal of Medical Virology, Vol. 80, No. 1, January 2008, pp. 11-19. doi:10.1002/jmv.21029

[213] S. Broos, K. Lundberg, T. Akagi, K. Kadowaki, M. Akashi, L. Greiff, C. A. K. Borrebaeck and M. Lindstedt, "Immunomodulatory Nanoparticles as Adjuvants and Allergen-Delivery System to Human Dendritic Cells: Implications for Specific Immunotherapy," Vaccine, Vol. 28, No. 31, 2010, pp. 5075-5085. doi:10.1016/j.vaccine.2010.05.004

[214] L. Stertman, L. Strindelius and I. Sjoholm, "Starch Microparticles as an Adjuvant in Immunisation: Effect of Route of Administration on the Immune Response in Mice," Vaccine, Vol. 22, No. 21-22, July 2004, pp. $2863-$ 2872. doi:10.1016/j.vaccine.2003.12.019

[215] L. Stertman, E. Lundgren and I. Sjoholm, "Starch Microparticles as a Vaccine Adjuvant: Only Uptake in Peyer's Patches Decides the Profile of the Immune Response," Vaccine, Vol. 24, No. 17, April 2006, pp. 3661-3668. doi:10.1016/j.vaccine.2005.10.059

[216] L. El-Attar, S. L. Oliver, A. Mackie, A. Charpilienne, D. Poncet, J. Cohen and J. C. Bridger, "Comparison of the Efficacy of Rotavirus VLP Vaccines to a Live Homologous Rotavirus Vaccine in a Pig Model of Rotavirus Disease," Vaccine, Vol. 27, No. 24, May 2009, pp. 32013208. doi:10.1016/j.vaccine.2009.03.043

[217] S. Hirosue, I. C. Kourtis, A. J. van der Vlies, J. A. Hubbell and M. A. Swartz, "Antigen Delivery to Dendritic Cells by Poly(Propylene Sulfide) Nanoparticles with Disulfide Conjugated Peptides: Cross-Presentation and T Cell Activation," Vaccine, Vol. 28, No. 50, 2010, pp. 7897-7906. doi:10.1016/j.vaccine.2010.09.077

[218] J. Wang, L. Lu, H. Song, Y. Yang and Y. Ma, "Effect of Polyethylene Glycol as Adjuvant on Hepatitis B Virus 
DNA Vaccine in Vitro," Wei Sheng Wu Xue Bao, Vol. 50, No. 7, July 2010, pp. 949-954.

[219] A. C. Boesteanu, N. S. Babu, M. Wheatley, E. S. Papazoglou and P. D. Katsikis, "Biopolymer Encapsulated Live Influenza Virus as a Universal CD8+ T Cell Vaccine against Influenza Virus," Vaccine, Vol. 29, No. 2, 2010, pp. 314-322. doi:10.1016/j.vaccine.2010.10.036

[220] S. Garlapati, N. F. Eng, H. L. Wilson, R. Buchanan, G. K. Mutwiri, L. A. Babiuk and V. Gerdts, "PCPP (Poly[Di (Carboxylatophenoxy)-Phosphazene]) Microparticles CoEncapsulating Ovalbumin and $\mathrm{CpG}$ Oligo-Deoxynucleotides Are Potent Enhancers of Antigen Specific Th1 Immune Responses in Mice," Vaccine, Vol. 28, No. 52, 2010, pp. 8306-8314.

doi:10.1016/j.vaccine.2010.09.080

[221] L. V. Carvalho, R. d. C. Ruiz, K. Scaramuzzi, E. B. Marengo, J. R. Matos, D. V. Tambourgi, M. C. A. Fantini and O. A. Sant'Anna, "Immunological Parameters Related to the Adjuvant Effect of the Ordered Mesoporous Silica SBA-15," Vaccine, Vol. 28, No. 50, 2010, pp. 7829-7836. doi:10.1016/j.vaccine.2010.09.087

[222] F. Aline, D. Brand, J. Pierre, P. Roingeard, M. Severine, B. Verrier and I. Dimier-Poisson, "Dendritic Cells Loaded with HIV-1 p24 Proteins Adsorbed on Surfactant-Free Anionic PLA Nanoparticles Induce Enhanced Cellular Immune Responses against HIV-1 after Vaccination," Vaccine, Vol. 27, No. 38, August 2009, pp. 5284-5291. doi:10.1016/j.vaccine.2009.05.028

[223] C. Prego, P. Paolicelli, B. Díaz, S. Vicente, A. Sánchez, Á. González-Fernández and M. J. Alonso, "ChitosanBased Nanoparticles for Improving Immunization against Hepatitis B Infection," Vaccine, Vol. 28, No. 14, 2010, pp. 2607-2614. doi:10.1016/j.vaccine.2010.01.011

[224] S. M. Sivakumar, N. Sukumaran, L. Nirmala, R. Swarnalakshmi, B. Anilbabu, L. Siva, J. Anbu, T. S. Shanmugarajan and V. Ravichandran, "Immunopotentiation of Hepatitis B Vaccine Using Biodegradable Polymers as an Adjuvant," J Microbiol Immunol Infect, Vol. 43, No. 4, August 2010, pp. 265-270. doi:10.1016/S1684-1182(10)60042-4

[225] J. Wendorf, J. Chesko, J. Kazzaz, M. Ugozzoli, M. Vajdy, D. O'Hagan and M. Singh, "A Comparison of Anionic Nanoparticles and Microparticles as Vaccine Delivery systems," Human Vaccine, Vol. 4, No. 1, January-February 2008, pp. 44-49. doi:10.4161/hv.4.1.4886

[226] E. Mata, A. M. Carcaboso, R. M. Hernandez, M. Igartua, G. Corradin and J. L. Pedraz, "Adjuvant Activity of Polymer Microparticles and Montanide ISA 720 on Immune Responses to Plasmodium Falciparum MSP2 Long Synthetic Peptides in Mice," Vaccine, Vol. 25, No. 5, January 2007, pp. 877-885. doi:10.1016/j.vaccine.2006.09.036

[227] Y. Ghendon, S. Markushin, G. Krivtsov and I. Akopova, "Chitosan as an Adjuvant for Parenterally Administered Inactivated Influenza Vaccines," Archives of Virology, Vol. 153, No. 5, 2008, pp. 831-837. doi:10.1007/s00705-008-0047-4

[228] H. L. Jiang, M. L. Kang, J. S. Quan, S. G. Kang, T. Akaike, H. S. Yoo and C. S. Cho, "The Potential of
Mannosylated Chitosan Microspheres to Target Macrophage Mannose Receptors in an Adjuvant-Delivery System for Intranasal Immunization," Biomaterials, Vol. 29, No. 12, April 2008, pp. 1931-1939. doi:10.1016/j.biomaterials.2007.12.025

[229] S. Okamoto, H. Yoshii, T. Akagi, M. Akashi, T. Ishikawa, Y. Okuno, M. Takahashi, K. Yamanishi and Y. Mori, "Influenza Hemagglutinin Vaccine with Poly(GammaGlutamic Acid) Nanoparticles Enhances the Protection against Influenza Virus Infection through Both Humoral and Cell-Mediated Immunity," Vaccine, Vol. 25, No. 49, November 2007, pp. 8270-8278.

doi:10.1016/j.vaccine.2007.09.051

[230] S. A. Moschos, V. W. Bramwell, S. Somavarapu and H. O. Alpar, "Comparative Immunomodulatory Properties of a Chitosan-MDP Adjuvant Combination Following Intranasal or Intramuscular Immunisation," Vaccine, Vol. 23, No. 16, March 2005, pp. 1923-1930. doi:10.1016/j.vaccine.2004.10.016

[231] J. Patel, D. Galey, J. Jones, P. Ray, J. G. Woodward, A. Nath and R. J. Mumper, "HIV-1 Tat-Coated Nanoparticles Result in Enhanced Humoral Immune Responses and Neutralizing Antibodies Compared to Alum Adjuvant," Vaccine, Vol. 24, No. 17, April 2006, pp. 35643573. doi:10.1016/j.vaccine.2006.01.065

[232] R. Voltan, A. Castaldello, E. Brocca-Cofano, R. De Michele, C. Triulzi, G. Altavilla, L. Tondelli, M. Laus, K. Sparnacci, E. Reali, R. Gavioli, B. Ensoli and A. Caputo, "Priming with a Very Low Dose of DNA Complexed with Cationic Block Copolymers Followed by Protein Boost Elicits Broad and Long-Lasting Antigen-Specific Humoral and Cellular Responses in Mice," Vaccine, Vol. 27, No. 33, July 2009, pp. 4498-4507. doi:10.1016/j.vaccine.2009.05.031

[233] R. Ramya, P. C. Verma, V. K. Chaturvedi, P. K. Gupta, K. D. Pandey, M. Madhanmohan, T. R. Kannaki, R. Sridevi and B. Anukumar, "Poly(Lactide-Co-Glycolide) Microspheres: A Potent Oral Delivery System to Elicit Systemic Immune Response against Inactivated Rabies Virus," Vaccine, Vol. 27, No. 15, 2009, pp. 2138-2143. doi:10.1016/j.vaccine.2009.01.129

[234] N. Rydell and I. Sjoholm, "Mucosal Vaccination against Diphtheria Using Starch Microparticles as Adjuvant for Cross-Reacting Material (CRM197) of Diphtheria Toxin," Vaccine, Vol. 23, No. 21, April 2005, pp. 27752783. doi:10.1016/j.vaccine.2004.11.049

[235] S. Okamoto, M. Matsuura, T. Akagi, M. Akashi, T. Tanimoto, T. Ishikawa, M. Takahashi, K. Yamanishi and Y. Mori, "Poly([Gamma]-Glutamic Acid) Nano-Particles Combined with Mucosal Influenza Virus Hemagglutinin Vaccine Protects against Influenza Virus Infection in Mice," Vaccine, Vol. 27, No. 42, 2009, pp. 5896-5905. doi:10.1016/j.vaccine.2009.07.037

[236] K. Oda, H. Matsuda, T. Murakami, S. Katayama, T. Ohgitani and M. Yoshikawa, "Relationship between Adjuvant Activity and Amphipathic Structure of Soyasaponins," Vaccine, Vol. 21, No. 17-18, May 2003, pp. 2145-2151. doi:10.1016/S0264-410X(02)00739-9 
[237] S. K. Kim, G. Ragupathi, S. Cappello, E. Kagan and P. O. Livingston, "Effect of Immunological Adjuvant Combinations on the Antibody and T-Cell Response to Vaccination with MUC1-KLH and GD3-KLH Conjugates," Vaccine, Vol. 19, No. 4-5, October 2000, pp. 530-537. doi:10.1016/S0264-410X(00)00195-X

[238] K. Deng, M. M. Adams, P. Damani, P. O. Livingston, G. Ragupathi and D. Y. Gin, "Synthesis of QS-21-Xylose: Establishment of the Immunopotentiating Activity of Synthetic QS-21 Adjuvant with a Melanoma Vaccine," Angewandte Chemie International Edition, Vol. 47, No. 34, 2008, pp. 6395-6398. doi:10.1002/anie.200801885

[239] H.-X. Sun, Y. Xie and Y.-P. Ye, "Advances in Saponin-Based Adjuvants," Vaccine, Vol. 27, No. 12, 2009, pp. 1787-1796. doi:10.1016/j.vaccine.2009.01.091

[240] A. Ghochikyan, M. Mkrtichyan, I. Petrushina, N. Movsesyan, A. Karapetyan, D. H. Cribbs and M. G. Agadjanyan, "Prototype Alzheimer's Disease Epitope Vaccine Induced Strong Th2-Type Anti-Abeta Antibody Response with Alum to Quil A Adjuvant Switch," Vaccine, Vol. 24, No. 13, March 2006, pp. 2275-2282. doi:10.1016/j.vaccine.2005.11.039

[241] X. Song, S. Bao, L. Wu and S. Hu, "Ginseng Stem-Leaf Saponins (GSLS) and Mineral Oil Act Synergistically to Enhance the Immune Responses to Vaccination against Foot-and-Mouth Disease in Mice," Vaccine, Vol. 27, No. 1, January 2009, pp. 51-55. doi:10.1016/j.vaccine.2008.10.030

[242] C. N. Fogg, J. L. Americo, S. Lustig, J. W. Huggins, S. K. Smith, I. Damon, W. Resch, P. L. Earl, D. M. Klinman and B. Moss, “Adjuvant-Enhanced Antibody Responses to Recombinant Proteins Correlates with Protection of Mice and Monkeys to Orthopoxvirus Challenges," Vaccine, Vol. 25, No. 15, April 2007, pp. 2787-2799. doi:10.1016/j.vaccine.2006.12.037

[243] O. Hacariz, G. Sayers, M. McCullough, M. Garrett, J. O'Donovan and G. Mulcahy, "The Effect of Quil A Adjuvant on the Course of Experimental Fasciola Hepatica Infection in Sheep," Vaccine, Vol. 27, No. 1, January 2009, pp. 45-50. doi:10.1016/j.vaccine.2008.10.035

[244] S. K. Kim, G. Ragupathi, C. Musselli, S. J. Choi, Y. S. Park and P. O. Livingston, "Comparison of the Effect of Different Immunological Adjuvants on the Antibody and T-Cell Response to Immunization with MUC1-KLH and GD3-KLH Conjugate Cancer Vaccines," Vaccine, Vol. 18, No. 7-8, November 1999, pp. 597-603. doi:10.1016/S0264-410X(99)00316-3

[245] G. Ragupathi, P. Damani, K. Deng, M. M. Adams, J. Hang, C. George, P. O. Livingston and D. Y. Gin, "Preclinical Evaluation of the Synthetic Adjuvant SQS-21 and Its Constituent Isomeric Saponins," Vaccine, Vol. 28, No. 26, 2010, pp. 4260-4267. doi:10.1016/j.vaccine.2010.04.034

[246] O. Kashala, R. Amador, M. V. Valero, A. Moreno, A. Barbosa, B. Nickel, C. A. Daubenberger, F. Guzman, G. Pluschke and M. E. Patarroyo, "Safety, Tolerability and Immunogenicity of New Formulations of the Plasmodium
Falciparum Malaria Peptide Vaccine SPf66 Combined with the Immunological Adjuvant QS-21," Vaccine, Vol. 20, No. 17-18, May 2002, pp. 2263-2277. doi:10.1016/S0264-410X(02)00115-9

[247] T. G. Evans, M. J. McElrath, T. Matthews, D. Montefiori, K. Weinhold, M. Wolff, M. C. Keefer, E. G. Kallas, L. Corey, G. J. Gorse, R. Belshe, B. S. Graham, P. W. Spearman, D. Schwartz, M. J. Mulligan, P. Goepfert, P. Fast, P. Berman, M. Powell and D. Francis, "QS-21 Promotes an Adjuvant Effect Allowing for Reduced Antigen Dose during HIV-1 Envelope Subunit Immunization in Humans," Vaccine, Vol. 19, No. 15-16, February 2001, pp. 2080-2091. doi:10.1016/S0264-410X(00)00415-1

[248] I. Mbawuike, Y. Zang and R. B. Couch, "Humoral and cell-Mediated Immune Responses of Humans to Inactivated Influenza Vaccine with or without QS21 Adjuvant," Vaccine, Vol. 25, No. 17, April 2007, pp. 3263-3269. doi:10.1016/j.vaccine.2007.01.073

[249] Y. Xie, H. X. Sun and D. Li, "Platycodin D Is a Potent Adjuvant of Specific Cellular and Humoral Immune Responses against Recombinant Hepatitis B Antigen," Vaccine, Vol. 27, No. 5, January 2009, pp. 757-764. doi:10.1016/j.vaccine.2008.11.029

[250] G. Liu, C. Anderson, H. Scaltreto, J. Barbon and C. R. Kensil, "QS-21 Structure/Function Studies: Effect of Acylation on Adjuvant Activity," Vaccine, Vol. 20, No. 21-22, June 2002, pp. 2808-28015. doi:10.1016/S0264-410X(02)00209-8

[251] B. Karanam, R. Gambhira, S. Peng, S. Jagu, D. J. Kim, G. W. Ketner, P. L. Stern, R. J. Adams and R. B. Roden, "Vaccination with HPV16 L2E6E7 Fusion Protein in GPI-0100 Adjuvant Elicits Protective Humoral and Cell-Mediated Immunity," Vaccine, Vol. 27, No. 7, February 2009, pp. 1040-1049. doi:10.1016/j.vaccine.2008.11.099

[252] S. F. Slovin, G. Ragupathi, C. Fernandez, M. P. Jefferson, M. Diani, A. S. Wilton, S. Powell, M. Spassova, C. Reis, H. Clausen, S. Danishefsky, P. Livingston and H. I. Scher, "A Bivalent Conjugate Vaccine in the Treatment of Biochemically Relapsed Prostate Cancer: A Study of Glycosylated MUC-2-KLH and Globo H-KLH Conjugate Vaccines Given with the New Semi-Synthetic Saponin Immunological Adjuvant GPI-0100 OR QS-21," Vaccine, Vol. 23, No. 24, May 2005, pp. 3114-3122. doi:10.1016/j.vaccine.2005.01.072

[253]X. Song and S. Hu, "Adjuvant Activities of Saponins from Traditional Chinese Medicinal Herbs," Vaccine, Vol. 27, No. 36, August 2009, pp. 4883-4890. doi:10.1016/j.vaccine.2009.06.033

[254] H. X. Sun, "Adjuvant Effect of Achyranthes Bidentata Saponins on Specific Antibody and Cellular Response to Ovalbumin in Mice," Vaccine, Vol. 24, No. 17, April 2006, pp. 3432-3439. doi:10.1016/j.vaccine.2006.02.014

[255] H. X. Sun and H. J. Pan, "Immunological Adjuvant Effect of Glycyrrhiza Uralensis Saponins on the Immune Responses to Ovalbumin in Mice," Vaccine, Vol. 24, No. 
11, March 2006, pp. 1914-1920. doi:10.1016/j.vaccine.2005.10.040

[256] H. X. Sun, "Haemolytic Activities and Adjuvant Effect of Bupleurum Chinense Saponins on the Immune Responses to Ovalbumin in Mice," Vaccine, Vol. 24, No. 9, February 2006, pp. 1324-1331. doi:10.1016/j.vaccine.2005.09.030

[257] J. Sun, S. Hu and X. Song, “Adjuvant Effects of Protopanaxadiol and Protopanaxatriol Saponins from Ginseng Roots on the Immune Responses to Ovalbumin in Mice," Vaccine, Vol. 25, No. 6, January 2007, pp. 1114-1120. doi:10.1016/j.vaccine.2006.09.054

[258] G. T. Jennings and M. F. Bachmann, "The coming of age of virus-like particle vaccines," The Journal of Biological Chemistry, Vol. 389, No. 5, May 2008, pp. 521-36. doi:10.1515/BC.2008.064

[259] Z. Hunter, H. D. Smyth, P. Durfee and B. Chackerian, "Induction of Mucosal and Systemic Antibody Responses against the HIV Coreceptor CCR5 upon Intramuscular Immunization and Aerosol Delivery of a Virus-Like Particle Based Vaccine," Vaccine, Vol. 28, No. 2, 2010, pp. 403-414. doi:10.1016/j.vaccine.2009.10.035

[260] R. M. Ionescu, C. T. Przysiecki, X. Liang, V. M. Garsky, J. Fan, B. Wang, R. Troutman, Y. Rippeon, E. Flanagan, J. Shiver and L. Shi, "Pharmaceutical and Immunological Evaluation of Human Papillomavirus Viruslike Particle as an Antigen Carrier," Journal of Pharmaceutical Sciences, Vol. 95, No. 1, January 2006, pp. 70-79. doi:10.1002/ips.20493

[261] R. Lang, G. Winter, L. Vogt, A. Zurcher, B. Dorigo and B. Schimmele, "Rational Design of a Stable, FreezeDried Virus-Like Particle-Based Vaccine Formulation," Drug Development and Industrial Pharmacy, Vol. 35, No. 1, January 2009, pp. 83-97. doi:10.1080/03639040802192806

[262] T.-M. Fu, K. M. Grimm, M. P. Citron, D. C. Freed, J. Fan, P. M. Keller, J. W. Shiver, X. Liang and J. G. Joyce, "Comparative Immunogenicity Evaluations of Influenza A Virus M2 Peptide as Recombinant Virus-Like Particle or Conjugate Vaccines in Mice and Monkeys," Vaccine, Vol. 27, No. 9, 2009, pp. 1440-1447. doi:10.1016/i.vaccine.2008.12.034

[263] B. Bellier, C. Dalba, B. Clerc, D. Desjardins, R. Drury, F. L. Cosset, M. Collins and D. Klatzmann, "DNA Vaccines Encoding Retrovirus-Based Virus-Like Particles Induce Efficient Immune Responses without Adjuvant," Vaccine, Vol. 24, No. 14, March 2006, pp. 2643-2655. doi:10.1016/i.vaccine.2005.11.034

[264] S. Jain, A. J. Patrick and K. L. Rosenthal, "Multiple Tandem Copies of Conserved gp41 Epitopes Incorporated in Gag Virus-Like Particles Elicit Systemic and Mucosal Antibodies in an Optimized Heterologous Vector Delivery Regimen," Vaccine, Vol. 28, No. 43, 2010, pp. 7070-7080. doi:10.1016/j.vaccine.2010.08.009

[265] D. R. Tonkin, P. Jorquera, T. Todd, C. W. Beard, R. E. Johnston and M. Barro, "Alphavirus Replicon-Based Enhancement of Mucosal and Systemic Immunity Is Linked to the Innate Response Generated by Primary
Immunization," Vaccine, Vol. 28, No. 18, 2010, pp. 3238-3246. doi:10.1016/j.vaccine.2010.02.010

[266] T. D. Carroll, S. R. Matzinger, M. Barro, L. Fritts, M. B. McChesney, C. J. Miller and R. E. Johnston, “Alphavirus Replicon-Based Adjuvants Enhance the Immunogenicity and Effectiveness of Fluzone ${ }^{\circledR}$ in Rhesus Macaques,' Vaccine, Vol. 29, No. 5, 2011, pp. 931-940. doi:10.1016/j.vaccine.2010.11.024

[267] M. M. Erdman, K. I. Kamrud, D. L. Harris and J. Smith, "Alphavirus Replicon Particle Vaccines Developed for Use in Humans Induce High Levels of Antibodies to Influenza Virus Hemagglutinin in Swine: Proof of Concept," Vaccine, Vol. 28, No. 3, 2010, pp. 594-596. doi:10.1016/j.vaccine.2009.10.015

[268] E. M. Pöllabauer, R. Petermann and H. J. Ehrlich, "The Influence of Carrier Protein on the Immunogenicity of Simultaneously Administered Conjugate Vaccines in Infants," Vaccine, Vol. 27, No. 11, 2009, pp. 1674-1679. doi:10.1016/j.vaccine.2009.01.005

[269] J. Fan, X. Liang, M. S. Horton, H. C. Perry, M. P. Citron, G. J. Heidecker, T. M. Fu, J. Joyce, C. T. Przysiecki, P. M. Keller, V. M. Garsky, R. Ionescu, Y. Rippeon, L. Shi, M. A. Chastain, J. H. Condra, M. E. Davies, J. Liao, E. A. Emini and J. W. Shiver, "Preclinical Study of Influenza Virus A M2 Peptide Conjugate Vaccines in Mice, Ferrets, and Rhesus Monkeys," Vaccine, Vol. 22, No. 23-24, August 2004, pp. 2993-3003. doi:10.1016/j.vaccine.2004.02.021

[270] S. H. L. de Villiers, N. Lindblom, G. Kalayanov, S. Gordon, I. Baraznenok, A. Malmerfelt, M. M. Marcus, A. M. Johansson, and T. H. Svensson, "Nicotine Hapten Structure, Antibody Selectivity and Effect Relationships: Results from a Nicotine Vaccine Screening Procedure," Vaccine, Vol. 28, No. 10, 2010, pp. 2161-2168. doi:10.1016/j.vaccine.2009.12.051

[271] C. D. Pack, U. Kumaraguru, S. Suvas and B. T. Rouse, "Heat-Shock Protein 70 Acts as an Effective Adjuvant in Neonatal Mice and Confers Protection against Challenge with Herpes Simplex Virus," Vaccine, Vol. 23, No. 27, May 20 2005, pp. 3526-3534.

doi:10.1016/j.vaccine.2005.01.152

[272] X. Jinshu, L. Jingjing, P. Duan, Z. Zheng, M. Ding, W. Jie, C. Rongyue, H. Zhuoyi and R. S. Roque, "A Synthetic Gonadotropin-Releasing Hormone (GnRH) Vaccine for Control of Fertility and Hormone Dependent Diseases without Any Adjuvant," Vaccine, Vol. 23, No. 40, September 2005, pp. 4834-4843. doi:10.1016/j.vaccine.2005.05.010

[273] B. Valentinis, A. Capobianco, F. Esposito, A. Bianchi, P. Rovere-Querini, A. A. Manfredi and C. Traversari, "Human Recombinant Heat Shock Protein 70 Affects the Maturation Pathways of Dendritic Cells in Vitro and Has an in Vivo Adjuvant Activity," Journal of Leukocyte Biology, Vol. 84, No. 1, July 2008, pp. 199-206. doi: $10.1189 / \mathrm{jlb} .0807548$

[274] A. Bolhassani, F. Zahedifard, M. Taghikhani and S. Rafati, "Enhanced Immunogenicity of HPV16E7 Accompanied by Gp96 as an Adjuvant in Two Vaccination 
Strategies," Vaccine, Vol. 26, No. 26, June 19 2008, pp. 3362-3370. doi:10.1016/j.vaccine.2008.03.082

[275] D. Bellido, P. O. Craig, M. V. Mozgovoj, D. D. Gonzalez, A. Wigdorovitz, F. A. Goldbaum and M. J. Dus Santos, "Brucella Spp. lumazine Synthase as a Bovine Rotavirus Antigen Delivery System," Vaccine, Vol. 27, No. 1, January 2009, pp. 136-145. doi:10.1016/j.vaccine.2008.10.018

[276] M. T. De Magistris, "Zonula Occludens Toxin as a New Promising Adjuvant for Mucosal Vaccines," Vaccine, Vol. 24 Suppl 2, April 2006, pp. S2-60-1.

[277] Y. J. Lu, P. Yadav, J. D. Clements, S. Forte, A. Srivastava, C. M. Thompson, R. Seid, J. Look, M. Alderson, A. Tate, J. F. Maisonneuve, G. Robertson, P. W. Anderson and R. Malley, "Options for Inactivation, Adjuvant, and Route of Topical Administration of a Killed, Unencapsulated Pneumococcal Whole-Cell Vaccine," Clinical and Vaccine Immunology, Vol. 17, No. 6, June 2010, pp. 1005-1012. doi:10.1128/CVI.00036-10

[278] M. Kende, G. Del Giudice, N. Rivera and J. Hewetson, "Enhancement of Intranasal Vaccination in Mice with Deglycosylated Chain A Ricin by LTR72, a Novel Mucosal Adjuvant," Vaccine, Vol. 24, No. 12, March 2006, pp. 2213-2221. doi:10.1016/j.vaccine.2004.12.034

[279] Y. Hagiwar, T. Tsuji, T. Iwasaki, S. Kadowaki, H. Asanuma, Z. Chen, K. Komase, Y. Suzuki, C. Aizawa, T. Kurata and S. Tamura, "Effectiveness and Safety of Mutant Escherichia Coli Heat-Labile Enterotoxin (LT H44A) as an Adjuvant for Nasal Influenza Vaccine," Vaccine, Vol. 19, No. 15-16, February 2001, pp. 20712079. doi:10.1016/S0264-410X(00)00414-X

[280] M. Tempesta, M. Camero, A. L. Bellacicco, E. Tarsitano, A. Lorusso, V. Martella, N. Decaro, G. Del Giudice, A. Cassone, A. Quaranta and C. Buonavoglia, "Caprine Herpesvirus 1 Vaccine with the LTK63 Mutant as a Mucosal Adjuvant Induces Strong Protection against Genital Infection in Goats," Vaccine, Vol. 25, No. 46, November 2007, pp. 7927-7930. doi:10.1016/j.vaccine.2007.09.004

[281] C. Palma, E. Iona, F. Giannoni, M. Pardini, L. Brunori, L. Fattorini, G. Del Giudice and A. Cassone, "The LTK63 Adjuvant Improves Protection Conferred by Ag85B DNA-Protein Prime-Boosting Vaccination against Mycobacterium Tuberculosis Infection by Dampening IFNGamma Response," Vaccine, Vol. 26, No. 33, August 2008, pp. 4237-4243. doi:10.1016/j.vaccine.2008.05.050

[282] M. Isaka, T. Komiya, M. Takahashi, Y. Yasuda, T. Taniguchi, Y. Zhao, K. Matano, H. Matsui, J. Maeyama, K. Morokuma, K. Ohkuma, N. Goto and K. Tochikubo, "Recombinant Cholera Toxin B Subunit (rCTB) as a Mucosal Adjuvant Enhances Induction of Diphtheria and Tetanus Antitoxin Antibodies in Mice by Intranasal Administration with Diphtheria-Pertussis-Tetanus (DPT) Combination Vaccine," Vaccine, Vol. 22, No. 23-24, August 2004, pp. 3061-3068. doi:10.1016/j.vaccine.2004.02.019

[283] D. Mizuno, M. Ide-Kurihara, T. Ichinomiya, I. Kubo and H. Kido, "Modified Pulmonary Surfactant Is a Potent
Adjuvant That Stimulates the Mucosal IgA Production in Response to the Influenza Virus Antigen," The Journal of Immunology, Vol. 176, No. 2, January 2006, pp. 11221130.

[284] M. C. Gagliardi and M. T. De Magistris, "Maturation of Human Dendritic Cells Induced by the Adjuvant Cholera Toxin: Role of cAMP on Chemokine Receptor Expression," Vaccine, Vol. 21, No. 9-10, February 2003, pp. 856-861. doi:10.1016/S0264-410X(02)00532-7

[285] V. P. da Hora, F. R. Conceição, O. A. Dellagostin and D. L. Doolan, "Non-Toxic Derivatives of LT as Potent Adjuvants," Vaccine, Vol. 29, No. 8, 2011, pp. 15381544. doi:10.1016/j.vaccine.2010.11.091

[286]H. R. Shinefield, "Overview of the Development and Current Use of CRM197 Conjugate Vaccines for Pediatric Use," Vaccine, Vol. 28, No. 27, 2010, pp. 4335-4339. doi:10.1016/j.vaccine.2010.04.072

[287] E. Fingerut, B. Gutter, R. Meir, D. Eliahoo and J. Pitcovski, "Vaccine and Adjuvant Activity of Recombinant Subunit B of E. Coli Enterotoxin Produced in Yeast," Vaccine, Vol. 23, No. 38, September 2005, pp. 4685-4696. doi:10.1016/j.vaccine.2005.03.050

[288] F. Deauvieau, S. Dussurgey, D. Rossignol, A. de Montfort, N. Burdi and B. Guy, "Memory B and T Cell Responses Induced by Serotype 4 Streptococcus Pneumoniae Vaccines: Longitudinal Analysis Comparing Responses Elicited by Free Polysaccharide, Conjugate and Carrier," Vaccine, Vol. 28, No. 2, 2009, pp. 576-582. doi:10.1016/j.vaccine.2009.09.081

[289] C. E. Frasch, "Preparation of Bacterial Polysacchariderotein Conjugates: Analytical and Manufacturing Challenges," Vaccine, Vol. 27, No. 46, 2009, pp. 6468-6470. doi:10.1016/j.vaccine.2009.06.013

[290] C. Cheng, I. Bettahi, M. I. Cruz-Fisher, S. Pal, P. Jain, Z. Jia, J. Holmgren, A. M. Harandi and L. M. de la Maza, "Induction of Protective Immunity by Vaccination against Chlamydia Trachomatis Using the Major Outer Membrane Protein Adjuvanted with CpG Oligodeoxynucleotide Coupled to the Nontoxic B Subunit of Cholera Toxin," Vaccine, Vol. 27, No. 44, 2009, pp. 6239-6246. doi:10.1016/j.vaccine.2009.07.108

[291] S. L. Demento, S. C. Eisenbarth, H. G. Foellmer, C. Platt, M. J. Caplan, W. Mark Saltzman, I. Mellman, M. Ledizet, E. Fikrig, R. A. Flavell and T. M. Fahmy, "Inflammasome-Activating Nanoparticles as Modular Systems for Optimizing Vaccine Efficacy," Vaccine, Vol. 27, No. 23, May 2009, pp. 3013-3021. doi:10.1016/j.vaccine.2009.03.034

[292] S. P. Bak, E. Amiel, J. J. Walters and B. Berwin, "Calreticulin Requires an Ancillary Adjuvant for the Induction of Efficient Cytotoxic T Cell Responses," Molecular Immunology, Vol. 45, No. 5, March 2008, pp. 1414-1423. doi:10.1016/j.molimm.2007.08.020

[293] N. Petrovsky, "Novel Human Polysaccharide Adjuvants with Dual Th1 and Th2 Potentiating Activity," Vaccine, Vol. 24, Suppl 2, April 2006, pp. S2-26-9. 
[294] J. J. de Vries, L. Bungener, W. Ter Veer, L. van Alphen, P. van der Ley, J. Wilschut and A. Huckriede, "Incorporation of LpxL1, a Detoxified Lipopolysaccharide Adjuvant, in Influenza H5N1 Virosomes Increases Vaccine Immunogenicity," Vaccine, Vol. 27, No. 6, February 2009, pp. 947-955. doi:10.1016/j.vaccine.2008.11.046

[295] J. A. Balboa, M. Cuello, O. Cabrera, J. del Campo, M. Lastre, D. Gil, C. Taboada, M. Farinas, M. Hernandez and O. Perez, "Adjuvant Properties of Lipopolysaccharide from Neisseria Meningitidis Serogroup B Detoxified and Conjugated with Tetanus Toxoid," Vaccine, Vol. 24, Suppl 2, April 2006, pp. S2-63-4.

[296] M. Lobigs, M. Pavy, R. A. Hall, P. Lobigs, P. Cooper, T. Komiya, H. Toriniwa and N. Petrovsky, "An Inactivated Vero Cell-Grown Japanese Encephalitis Vaccine Formulated with Advax, a Novel Inulin-Based Adjuvant, Induces Protective Neutralizing Antibody against Homologous and Heterologous Flaviviruses," Journal of General Virology, Vol. 91, No. Pt 6, June 2010, pp. 14071417.

[297] Y. Sun and J. Liu, "Adjuvant Effect of Water-Soluble Polysaccharide (PAP) from the Mycelium of Polyporus Albicans on the Immune Responses to Ovalbumin in mice," Vaccine, Vol. 26, No. 31, July 2008, pp. 39323936. doi:10.1016/j.vaccine.2008.04.018

[298] A. Khajuria, A. Gupta, F. Malik, S. Singh, J. Singh, B. D. Gupta, K. A. Suri, P. Suden, V. K. Srinivas, K. Ella and G. N. Qazi, "A New Vaccine Adjuvant (BOS 2000) a Potent Enhancer Mixed Th1/Th2 Immune Responses in Mice Immunized with HBsAg," Vaccine, Vol. 25, No. 23, June 2007, pp. 4586-4594.

doi:10.1016/j.vaccine.2007.03.051

[299] Z. Guo, Y. Hu, D. Wang, X. Ma, X. Zhao, B. Zhao, J. Wang and P. Liu, "Sulfated Modification Can Enhance the Adjuvanticity of Lentinan and Improve the Immune Effect of ND Vaccine," Vaccine, Vol. 27, No. 5, January 2009, pp. 660-665. doi:10.1016/j.vaccine.2008.11.038

[300] V. K. Berner, M. E. Sura and K. W. Hunter, "Conjugation of Protein Antigen to Microparticulate Betalucan from Saccharomyces Cerevisiae: A New Adjuvant for Intradermal and Oral Immunizations," Applied Microbiology and Biotechnology, Vol. 80, No. 6, October 2008, pp. 1053-1061. doi:10.1007/s00253-008-1618-8

[301] C. R. Casella and T. C. Mitchell, "Putting Endotoxin to Work for Us: Monophosphoryl Lipid A as a Safe and Effective Vaccine Adjuvant," Cellular and Molecular Life Sciences, Vol. 65, No. 20, October 2008, pp. 32313240. doi:10.1007/s00018-008-8228-6

[302] B. Pajak, V. Garze, G. Davies, J. Bauer, M. Moser and C. Chiavaroli, "The Adjuvant OM-174 Induces Both the Migration and Maturation of Murine Dendritic Cells in Vivo," Vaccine, Vol. 21, No. 9-10, February 2003, pp. 836-842. doi:10.1016/S0264-410X(02)00529-7

[303] M. Golkar, M. A. Shokrgozar, S. Rafati, K. Musset, M. Assmar, R. Sadaie, M. F. Cesbron-Delauw and C. Mercier, "Evaluation of Protective Effect of Recombinant Dense Granule Antigens GRA2 and GRA6 Formulated in Monophosphoryl Lipid A (MPL) Adjuvant against Toxo- plasma Chronic Infection in Mice," Vaccine, Vol. 25, No. 21, May 2007, pp. 4301-4311.

doi:10.1016/j.vaccine.2007.02.057

[304] S. L. Baldwin, N. Shaverdian, Y. Goto, M. S. Duthie, V. S. Raman, T. Evers, F. Mompoint, T. S. Vedvick, S. Bertholet, R. N. Coler and S. G. Reed, "Enhanced Humoral and Type 1 Cellular Immune Responses with Fluzone ${ }^{\circledR}$ Adjuvanted with a Synthetic TLR4 Agonist Formulated in an Emulsion," Vaccine, Vol. 27, No. 43, 2009, pp. 5956-5963. doi:10.1016/j.vaccine.2009.07.081

[305] R. N. Coler, S. Bertholet, M. Moutaftsi, J. A. Guderian, H. P. Windish, S. L. Baldwin, E. M. Laughlin, M. S. Duthie, C. B. Fox, D. Carter, M. Friede, T. S. Vedvick and S. G. Reed, "Development and Characterization of Synthetic Glucopyranosyl Lipid Adjuvant System as a Vaccine Adjuvant," PLoS One, Vol. 6, No. 1, 2011, p. e16333. doi:10.1371/journal.pone.0016333

[306] Y. Goto, L. Y. Bogatzki, S. Bertholet, R. N. Coler and S. G. Reed, "Protective Immunization against Visceral Leishmaniasis Using Leishmania Sterol 24-c-Ethyltransferase Formulated in Adjuvant," Vaccine, Vol. 25, No. 42, Oct 16 2007, pp. 7450-7458. doi:10.1016/j.vaccine.2007.08.001

[307] A. W. Wheeler, J. S. Marshall and J. T. Ulrich, "A Th1-Inducing Adjuvant, MPL, Enhances Antibody Profiles in Experimental Animals Suggesting It Has the Potential to Improve the Efficacy of Allergy Vaccines," International Archives of Allergy and Immunology, Vol. 126, No. 2, October 2001, pp. 135-139. doi:10.1159/000049504

[308] G. B. Patel and W. Chen, "Archaeal Lipid Mucosal Vaccine Adjuvant and Delivery System," Expert Review of Vaccines, Vol. 9, No. 4, April 2010, pp. 431-440. doi:10.1586/erv.10.34

[309] G. B. Patel, H. Zhou, A. Ponce, G. Harris and W. Chen, "Intranasal Immunization with an Archaeal Lipid Mucosal Vaccine Adjuvant and Delivery Formulation Protects against a Respiratory Pathogen Challenge," PLOS One, Vol. 5, No. 12, 2010, p. e15574.

doi:10.1371/journal.pone.0015574

[310] L. Perrin-Cocon, S. Agaugue, F. Coutant, P. SaintMezard, A. Guironnet-Paquet, J. F. Nicolas, P. Andre and V. Lotteau, "Lysophosphatidylcholine is a Natural Adjuvant That Initiates Cellular Immune Responses," Vaccine, Vol. 24, No. 9, February 2006, pp. 1254-1263. doi:10.1016/j.vaccine.2005.09.036

[311] R. Acevedo, D. Gil, J. del Campo, G. Bracho, Y. Valdes and O. Perez, "The Adjuvant Potential of Synthetic Alkylglycerols," Vaccine, Vol. 24, Suppl 2, April 2006, pp. S2-32-3.

[312] M. Mizrahi, G. Lalazar, A. Ben Ya'acov, D. M. Livovsky, Y. Horowitz, L. Zolotarov, R. Adler, D. Shouval and Y. Ilan, "Beta-Glycoglycosphingolipid-Induced Augmentation of the Anti-HBV Immune Response is Associated with Altered CD8 and NKT Lymphocyte Distribution: A Novel Adjuvant for HBV Vaccination," Vaccine, Vol. 26, No. 21, May 2008, pp. 2589-2595. doi:10.1016/j.vaccine.2008.03.026 
[313] A. N. Courtney, P. N. Nehete, B. P. Nehete, P. Thapa, D. Zhou and K. J. Sastry, "Alpha-Galactosylceramide is an Effective Mucosal Adjuvant for Repeated Intranasal or Oral Delivery of HIV Peptide Antigens," Vaccine, Vol. 27, No. 25-26, May 2009, pp. 3335-3341. doi:10.1016/j.vaccine.2009.01.083

[314] P. Thapa, G. Zhang, C. Xia, A. Gelbard, W. W. Overwijk, C. Liu, P. Hwu, D. Z. Chang, A. Courtney, J. K. Sastry, P. G. Wang, C. Li and D. Zhou, "Nanoparticle Formulated Alpha-Galactosylceramide Activates NKT Cells without Inducing Anergy," Vaccine, Vol. 27, No. 25-26, May 2009, pp. 3484-3488. doi:10.1016/j.vaccine.2009.01.047

[315] X. Li, M. Fujio, M. Imamura, D. Wu, S. Vasan, C. H. Wong, D. D. Ho and M. Tsuji, "Design of a Potent CD1d-Binding NKT Cell Ligand as a Vaccine Adjuvant," Proceedings of National Acadamic Science USA, Vol. 107, No. 29, July 2010, pp. 13010-13015. doi:10.1073/pnas.1006662107

[316] N. N. Padte, X. Li, M. Tsuji and S. Vasan, "Clinical Development of a Novel CD1d-Binding NKT Cell Ligand as a Vaccine Adjuvant," Clinical Immunology, December 2010, Article in Press.

[317] J. Hinkula, C. Devito, B. Zuber, R. Benthin, D. Ferreira, B. Wahren and U. Schroder, "A Novel DNA Adjuvant, N3, Enhances Mucosal and Systemic Immune Responses Induced by HIV-1 DNA and Peptide Immunizations," Vaccine, Vol. 24, No. 21, May 2006, pp. 4494-4497. doi:10.1016/j.vaccine.2005.08.015

[318] A. Brave, D. Hallengard, U. Schroder, P. Blomberg, B. Wahren and J. Hinkula, "Intranasal Immunization of Young Mice with a Multigene HIV-1 Vaccine in Combination with the N3 Adjuvant Induces Mucosal and Systemic Immune Responses," Vaccine, Vol. 26, No. 40, September 2008, pp. 5075-5078. doi:10.1016/j.vaccine.2008.03.066

[319] Z. H. Jiang, W. A. Budzynski, D. Qiu, D. Yalamati and R. R. Koganty, "Monophosphoryl Lipid A Analogues with Varying 3-O-Substitution: Synthesis and Potent Adjuvant Activity," Carbohydrate Research, Vol. 342, No. 6, May 2007, pp. 784-796. doi:10.1016/j.carres.2007.01.012

[320] H. Kayamuro, Y. Yoshioka, Y. Abe, H. Kamada, S. Tsunoda and Y. Tsutsumi, "Application of Bioactive Mutant TNF Alpha to a Mucosal Vaccine Adjuvant," Yakugaku Zasshi, Vol. 130, No. 1, January 2010, pp. 55-61. doi:10.1248/yakushi.130.55

[321] H. Kayamuro, Y. Abe, Y. Yoshioka, K. Katayama, T. Yoshida, K. Yamashita, T. Yoshikawa, Y. Kawai, T. Mayumi, T. Hiroi, N. Itoh, K. Nagano, H. Kamada, S. Tsunoda and Y. Tsutsumi, "Mutant TNF-Alpha, mTNF-K90R, is a Novel Candidate Adjuvant for a Mucosal Vaccine against HIV," Pharmazie, Vol. 65, No. 4, April 2010, pp. 254-256.

[322] L. Bracci, I. Canini, M. Venditti, M. Spada, S. Puzelli, I. Donatelli, F. Belardelli and E. Proietti, "Type I IFN as a Vaccine Adjuvant for Both Systemic and Mucosal Vaccination against Influenza Virus," Vaccine, Vol. 24, Suppl 2, April 2006, pp. S2-56-7.
[323] M. G. Tovey, C. Lallemand, J. F. Meritet and C. Maury, "Adjuvant Activity of Interferon Alpha: Mechanism(s) of Action," Vaccine, Vol. 24, Suppl 2, April 2006, pp. S2-46-7.

[324] M. E. Miquilena-Colina, T. Lozano-Rodriguez, L. Garciaozo, A. Saez, P. Rizza, I. Capone, M. Rapicetta, P. Chionne, M. Capobianchi, M. Selleri, C. Castilletti, F. Belardelli, O. L. Iacono and C. Garcia-Monzon, "Recombinant Interferon-Alpha2b Improves Immune Response to Hepatitis B Vaccination in Haemodialysis Patients: Results of a Randomised Clinical Trial," Vaccine, Vol. 27, No. 41, September 2009, pp. 5654-5660. doi:10.1016/j.vaccine.2009.07.014

[325] G. Cheng, X. Zhao, W. Yan, W. Wang, X. Zuo, K. Huang, Y. Liu, J. Chen, J. Wang, W. Cong, M. Liu, H. Gao, Y. $\mathrm{Lu}$ and $\mathrm{Z}$. Zheng, "Alpha Interferon is a Powerful Adjuvant for a Recombinant Protein Vaccine against Foot-and-Mouth Disease Virus in Swine, and an Effective Stimulus of in Vivo Immune Response," Vaccine, Vol. 25, No. 28, July 2007, pp. 5199-5208. doi:10.1016/j.vaccine.2007.04.089

[326] L. Bracci, I. Canini, S. Puzelli, P. Sestili, M. Venditti, M. Spada, I. Donatelli, F. Belardelli and E. Proietti, "Type I IFN is a Powerful Mucosal Adjuvant for A Selective Intranasal Vaccination against Influenza Virus in Mice and Affects Antigen Capture at Mucosal Level," Vaccine, Vol. 23, No. 23, April 2005, pp. 2994-3004. doi:10.1016/j.vaccine.2004.12.006

[327] R. B. Couch, R. L. Atmar, T. R. Cate, J. M. Quarles, W. A. Keitel, N. H. Arden, J. Wells, D. Nino and P. R. Wyde, "Contrasting Effects of Type I Interferon as a Mucosal Adjuvant for Influenza Vaccine in Mice and Humans," Vaccine, Vol. 27, No. 39, August 2009, pp. 5344-5348. doi:10.1016/j.vaccine.2009.06.084

[328] G. Parmiani, C. Castelli, L. Pilla, M. Santinami, M. P. Colombo and L. Rivoltini, "Opposite immune functions of GM-CSF administered as vaccine adjuvant in cancer patients," Annals of Oncology, Vol. 18, No. 2, February 2007, pp. 226-232. doi:10.1093/annonc/mdl158

[329] M. Cruciani, C. Mengoli, G. Serpelloni, R. Mazzi, O. Bosco and M. Malena, "Granulocyte Macrophage Colony-Stimulating Factor as an Adjuvant for Hepatitis B Vaccination: A Meta-Analysis," Vaccine, Vol. 25, No. 4, January 2007, pp. 709-178. doi:10.1016/j.vaccine.2006.08.015

[330] J. T. Qiu, T. C. Chang, C. T. Lin, Y. M. Chen, F. Q. Li, Y. K. Soong and C. H. Lai, "Novel Codon-Optimized GM-CSF Gene as an Adjuvant to Enhance the immunity of a DNA Vaccine against HIV-1 GAG," Vaccine, Vol. 25, No. 2, January 2007, pp. 253-263. doi:10.1016/j.vaccine.2006.07.034

[331] M. Yagci, K. Acar, G. T. Sucak, K. Yamac and R. Haznedar, "Hepatitis B Virus Vaccine in Lymphoproliferative Disorders: A Prospective Randomized Study Evaluating the Efficacy of Granulocyte-Macrophage Colony Stimulating Factor as a Vaccine Adjuvant," European Journal of Haematology, Vol. 79, No. 4, October 
2007 , pp. 292-296 doi:10.1111/j.1600-0609.2007.00912.X

[332] R. Xu, S. Megati, V. Roopchand, A. Luckay, A. Masood, D. Garcia-Hand, M. Rosati, D. B. Weiner, B. K. Felber, G. N. Pavlakis, M. K. Sidhu, J. H. Eldridge and M. A. Egan, "Comparative Ability of Various Plasmid-Based Cytokines and Chemokines to Adjuvant the Activity of HIV Plasmid DNA Vaccines," Vaccine, Vol. 26, No. 37, September 2008, pp. 4819-4829. doi:10.1016/j.vaccine.2008.06.103

[333] P. Spearman, S. Kalams, M. Elizaga, B. Metch, Y. L. Chiu, M. Allen, K. J. Weinhold, G. Ferrari, S. D. Parker, M. J. McElrath, S. E. Frey, J. D. Fuchs, M. C. Keefer, M. D. Lubeck, M. Egan, R. Braun, J. H. Eldridge, B. F. Haynes and L. Corey, "Safety and Immunogenicity of a CTL Multiepitope Peptide Vaccine for HIV with or without GM-CSF in a Phase I trial," Vaccine, Vol. 27, No. 2, January 2009, pp. 243-249.

[334] J. Somani, S. Lonial, H. Rosenthal, S. Resnick, I. Kakhniashvili and E. K. Waller, "A Randomized, Placebo-Controlled Trial of Subcutaneous Administration of GM-CSF as a Vaccine Adjuvant: Effect on Cellular and Humoral Immune Responses," Vaccine, Vol. 21, No. 3-4, December 2002, pp. 221-230. doi:10.1016/S0264-410X(02)00463-2

[335] A. K. Wright, D. E. Briles, D. W. Metzger and S. B. Gordon, "Prospects for Use of Interleukin-12 as a Mucosal Adjuvant for Vaccination of Humans to Protect against Respiratory Pneumococcal Infection," Vaccine, Vol. 26, No. 38, September 2008, pp. 4893-4903. doi:10.1016/j.vaccine.2008.06.058

[336] J. E. Portielje, W. H. Kruit, A. J. Eerenberg, M. Schuler, A. Sparreboom, C. H. Lamers, J. W. Gratama, G. Stoter, C. Huber and C. E. Hack, "Subcutaneous Injection of Interleukin 12 Induces Systemic Inflammatory Responses in Humans: Implications for the Use of IL-12 as Vaccine Adjuvant," Cancer Immunology, Immunotherapy, Vol. 54, No. 1, January 2005, pp. 37-43. doi:10.1007/s00262-004-0574-0

[337] M. A. Jacobson, E. Sinclair, B. Bredt, L. Agrillo, D. Black, C. L. Epling, A. Carvidi, T. Ho, R. Bains, V. Girling and S. P. Adler, "Safety and Immunogenicity of Towne Cytomegalovirus Vaccine with or without Adjuvant Recombinant Interleukin-12," Vaccine, Vol. 24, No. 25, June 2006, pp. 5311-5319. doi:10.1016/i.vaccine.2006.04.017

[338] E. B. Schadeck, M. Sidhu, M. A. Egan, S. Y. Chong, P. Piacente, A. Masood, D. Garcia-Hand, S. Cappello, V. Roopchand, S. Megati, J. Quiroz, J. D. Boyer, B. K. Felber, G. N. Pavlakis, D. B. Weiner, J. H. Eldridge and Z. R. Israel, “A Dose Sparing Effect by Plasmid Encoded IL-12 Adjuvant on a SIVgag-Plasmid DNA Vaccine in Rhesus Macaques," Vaccine, Vol. 24, No. 21, May 2006, pp. 4677-4687. doi:10.1016/j.vaccine.2005.10.035

[339] H. Yamanaka, T. Hoyt, R. Bowen, X. Yang, K. Crist, S. Golden, M. Maddaloni and D. W. Pascual, "An IL-12 DNA Vaccine Co-Expressing Yersinia Pestis Antigens
Protects against Pneumonic Plague," Vaccine, Vol. 27, No. 1, January 2009, pp. 80-87.

doi:10.1016/j.vaccine.2008.10.021

[340] H. Yamanaka, T. Hoyt, X. Yang, S. Golden, C. M. Bosio, K. Crist, T. Becker, M. Maddaloni and D. W. Pascual, "A Nasal Interleukin-12 DNA Vaccine Coexpressing Yersinia Pestis F1-V Fusion Protein Confers Protection against Pneumonic Plague," Infection and Immunity, Vol. 76, No. 10, October 2008, pp. 4564-4573. doi:10.1128/IAI.00581-08

[341] J. Hedlund, B. Langer, H. B. Konradsen and A. Ortqvist, "Negligible Adjuvant Effect for Antibody Responses and Frequent Adverse Events Associated with IL-12 Treatment in Humans Vaccinated with Pneumococcal Polysaccharide," Vaccine, Vol. 20, No. 1-2, October 2001, pp. 164-169. doi:10.1016/S0264-410X(01)00253-5

[342] P.-Y. Perera, S. C. Derrick, K. Kolibab, F. Momoi, M. Yamamoto, S. L. Morris, T. A. Waldmann and L. P. Perera, "A Multi-Valent Vaccinia Virus-Based Tuberculosis Vaccine Molecularly Adjuvanted with Interleukin15 Induces Robust Immune Responses in Mice," Vaccine, Vol. 27, No. 15, 2009, pp. 2121-2127.

doi:10.1016/j.vaccine.2009.01.132

[343] K. Kolibab, A. Yang, S. C. Derrick, T. A. Waldmann, L. P. Perera and S. L. Morris, "Highly Persistent and Effective Prime/Boost Regimens against Tuberculosis That Use a Multivalent Modified Vaccine Virus AnkaraBased Tuberculosis Vaccine with Interleukin-15 as a Molecular Adjuvant," Clinical and Vaccine Immunology, Vol. 17, No. 5, May 2010, pp. 793-801. doi:10.1128/CVI.00006-10

[344] Y. Sui, Q. Zhu, S. Gagnon, A. Dzutsev, M. Terabe, M. Vaccari, D. Venzon, D. Klinman, W. Strober, B. Kelsall, G. Franchini, I. M. Belyakov and J. A. Berzofsky, "Innate and Adaptive Immune Correlates of Vaccine and Adjuvant-Induced Control of Mucosal Transmission of SIV in Macaques," Proceeedings of National Acadamic Science USA, Vol. 107, No. 21, May 2010, pp. 9843-9848. doi:10.1073/pnas.0911932107

[345] Z. Yang, L. Wang, H. Wang, X. Shang, W. Niu, J. Li and Y. Wu, "A Novel Mimovirus Vaccine Containing Survivin Epitope with Adjuvant IL-15 Induces LongLasting Cellular Immunity and High Antitumor Efficiency," Molecular Immunology, Vol. 45, No. 6, March 2008, pp. 1674-1681. doi:10.1016/j.molimm.2007.10.026

[346] S. A. Calarota, A. Dai, J. N. Trocio, D. B. Weiner, F. Lori and J. Lisziewicz, "IL-15 as Memory T-Cell Adjuvant for Topical HIV-1 DermaVir Vaccine," Vaccine, Vol. 26, No. 40, September 2008, pp. 5188-5195. doi:10.1016/j.vaccine.2008.03.067

[347] M. P. Ramanathan, M. A. Kutzler, Y. C. Kuo, J. Yan, H. Liu, V. Shah, A. Bawa, B. Selling, N. Y. Sardesai, J. J. Kim and D. B. Weiner, "Coimmunization with an Optimized IL15 Plasmid Adjuvant Enhances Humoral Immunity via Stimulating B Cells Induced by Genetically Engineered DNA Vaccines Expressing Consensus JEV and WNV E DIII," Vaccine, Vol. 27, No. 32, July 2009, pp. 4370-4380. doi:10.1016/j.vaccine.2009.01.137 
[348] R. Nagill and S. Kaur, "Enhanced Efficacy and Immunogenicity of $78 \mathrm{kDa}$ Antigen Formulated in Various Adjuvants against Murine Visceral Leishmaniasis," Vaccine, Vol. 28, No. 23, May 2010, pp. 4002-4012. doi:10.1016/i.vaccine.2010.01.015

[349] R. J. Lechleider, P. M. Arlen, K. Y. Tsang, S. M. Steinberg, J. Yokokawa, V. Cereda, K. Camphausen, J. Schlom, W. L. Dahut and J. L. Gulley, "Safety and Immunologic Response of a Viral Vaccine to ProstatePecific Antigen in Combination with Radiation Therapy When Metronomic-Dose Interleukin 2 is Used as an Adjuvant," Clinical Cancer Research, Vol. 14, No. 16, August 2008, pp. 5284-5291. doi:10.1158/1078-0432.CCR-07-5162

[350] W. M. Gwinn, S. M. Kirwan, S. H. Wang, K. A. Ashcraft, N. L. Sparks, C. R. Doil, T. G. Tlusty, L. S. Casey, S. K. Hollingshead, D. E. Briles, R. S. Dondero, A. J. Hickey, W. M. Foster and H. F. Staats, "Effective Induction of Protective Systemic Immunity with Nasally Administered Vaccines Adjuvanted with IL-1," Vaccine, Vol. 28, No. 42, October 2010, pp. 6901-6914. doi:10.1016/i.vaccine.2010.08.006

[351] C. Zhang, B. Wang and M. Wang, "GM-CSF and IL-2 as Adjuvant Enhance the Immune Effect of Protein Vaccine against Foot-and-Mouth Disease," Virology Journal, Vol. 8, 2011, p. 7. doi:10.1186/1743-422X-8-7

[352] A. Toubaji, S. Hill, M. Terabe, J. Qian, T. Floyd, R. M. Simpson, J. A. Berzofsky and S. N. Khleif, "The Combination of GM-CSF and IL-2 as Local Adjuvant Shows Synergy in Enhancing Peptide Vaccines and Provides Long Term Tumor Protection," Vaccine, Vol. 25, No. 31, August 2007, pp. 5882-5891. doi:10.1016/j.vaccine.2007.05.040

[353] M. C. Aichinger, M. Ginzler, J. Weghuber, L. Zimmermann, K. Riedl, G. Schütz, E. Nagy, A. von Gabain, R. Schweyen and T. Henics, "Adjuvating the Adjuvant: Facilitated Delivery of an Immunomodulatory Oligonucleotide to TLR9 by a Cationic Antimicrobial Peptide in Dendritic Cells," Vaccine, Vol. 29, No. 3, 2011, pp. 426-436. doi:10.1016/j.vaccine.2010.11.003

[354] E. M. Agger, I. Rosenkrands, A. W. Olsen, G. Hatch, A. Williams, C. Kritsch, K. Lingnau, A. von Gabain, C. S. Andersen, K. S. Korsholm and P. Andersen, "Protective Immunity to Tuberculosis with Ag85B-ESAT-6 in a Synthetic Cationic Adjuvant System IC31," Vaccine, Vol. 24, No. 26, June 2006, pp. 5452-5460. doi:10.1016/j.vaccine.2006.03.072

[355] K. Riedl, R. Riedl, A. von Gabain, E. Nagy and K. Lingnau, "The Novel Adjuvant IC31 Strongly Improves Influenza Vaccine-Specific Cellular and Humoral Immune Responses in Young Adult and Aged Mice," Vaccine, Vol. 26, No. 27-28, June 2008, pp. 3461-3468. doi:10.1016/j.vaccine.2008.04.029

[356] C. G. Lee, S. Y. Choi, S. H. Park, K. S. Park, S. H. Ryu and Y. C. Sung, "The Synthetic Peptide Trp-Lysyr-Met-Val-D-Met as a Novel Adjuvant for DNA Vaccine," Vaccine, Vol. 23, No. 38, September 2005, pp. 4703-4710. doi:10.1016/j.vaccine.2005.03.051
[357] G. V. Hegde, E. Meyers-Clark, S. S. Joshi and S. D. Sanderson, "A Conformationally-Biased, ResponseElective Agonist of C5a Acts as a Molecular Adjuvant by Modulating Antigen Processing and Presentation Activities of Human Dendritic Cells," International Immunopharmacology, Vol. 8, No. 6, June 2008, pp. 819-827. doi:10.1016/j.intimp.2008.01.031

[358] E. L. Morgan, B. N. Morgan, E. A. Stein, E. L. Vitrs, M. L. Thoman, S. D. Sanderson and J. A. Phillips, "Enhancement of in Vivo and in Vitro Immune Functions by a Conformationally Biased, Response-Selective Agonist of Human C5a: Implications for a Novel Adjuvant in Vaccine Design," Vaccine, Vol. 28, No. 2, 2009, pp. 463469. doi:10.1016/j.vaccine.2009.10.029

[359] E. L. Morgan, M. L. Thoman, S. D. Sanderson and J. A. Phillips, "A Novel Adjuvant for Vaccine Development in the Aged," Vaccine, Vol. 28, No. 52, 2010, pp. 8275-279. doi:10.1016/j.vaccine.2010.10.008

[360] J. Kindrachuk, H. Jenssen, M. Elliott, R. Townsend, A. Nijnik, S. F. Lee, V. Gerdts, L. A. Babiuk, S. A. Halperin and R. E. Hancock, "A Novel Vaccine Adjuvant Comprised of a Synthetic Innate Defence Regulator Peptide and $\mathrm{CpG}$ Oligonucleotide Links Innate and Adaptive Immunity," Vaccine, Vol. 27, No. 34, July 2009, pp. 4662-4671. doi:10.1016/j.vaccine.2009.05.094

[361] E. Scruten, J. Kovacs-Nolan, P. J. Griebel, L. Latimer, J. Kindrachuk, A. Potter, L. A. Babiuk, S. v. D. L.-v. d. Hurk and S. Napper, "Retro-Inversion Enhances the Adjuvant and $\mathrm{CpG}$ Co-Adjuvant Activity of Host Defence Peptide Bac2A," Vaccine, Vol. 28, No. 17, 2010, pp. 2945-2956. doi:10.1016/j.vaccine.2010.02.015

[362] J. Turanek, M. Ledvina, A. Kasna, A. Vacek, V. Hribalova, J. Krejci and A. D. Miller, "Liposomal Preparations of Muramyl Glycopeptides as Immunomodulators and Adjuvants,"Vaccine, Vol. 24, Suppl 2, April 2006, pp. S2-901 .

[363] R. Segura-Velazquez, A. Perez-Torres, G. Rosas, A. Toledo, M. Restelli, E. Acosta, R. Corral, F. Rosetti, G. Fragoso, S. Grinstein and E. Sciutto, "A Novel Synthetic Adjuvant Effectively Enhances the Immunogenicity of the Influenza Vaccine," Vaccine, Vol. 24, No. 8, February 2006, pp. 1073-1080. doi:10.1016/j.vaccine.2005.09.014

[364] Y. Charoenvit, N. Goel, M. Whelan, K. S. Rosenthal and D. H. Zimmerman, "CEL-1000: A Peptide with Adjuvant Activity for Th1 Immune Responses," Vaccine, Vol. 22, No. 19, June 2004, pp. 2368-2373. doi:10.1016/j.vaccine.2003.11.062

[365] P. D. Becker, S. Fiorentini, C. Link, G. Tosti, T. Ebensen, A. Caruso and C. A. Guzman, "The HIV-1 Matrix Protein p17 Can be Efficiently Delivered by Intranasal Route in Mice Using the TLR 2/6 Agonist MALP-2 as Mucosal Adjuvant," Vaccine, Vol. 24, No. 25, June 2006, pp. 5269-5276. doi:10.1016/j.vaccine.2005.11.008

[366] S. Borsutzky, T. Ebensen, C. Link, P. D. Becker, V. Fiorelli, A. Cafaro, B. Ensoli and C. A. Guzman, "Efficient Systemic and Mucosal Responses against the HIV-1 Tat Protein by Prime/Boost Vaccination Using the 
Lipopeptide MALP-2 as Adjuvant," Vaccine, Vol. 24, No. 12, March 2006, pp. 2049-2056.

doi:10.1016/j.vaccine.2005.11.025

[367] A. Cataldi, T. Yevsa, D. A. Vilte, K. Schulze, M. Castroarodi, M. Larzabal, C. Ibarra, E. C. Mercado and C. A. Guzman, "Efficient Immune Responses against Intimin and EspB of Enterohaemorragic Escherichia Coli after Intranasal Vaccination Using the TLR2/6 Agonist MALP-2 as Adjuvant," Vaccine, Vol. 26, No. 44, October 2008, pp. 5662-5667. doi:10.1016/j.vaccine.2008.07.027

[368] J. K. Actor, S. A. Hwang and M. L. Kruzel, "Lactoferrin as a Natural Immune Modulator," Current Pharmaceutical Design, Vol. 15, No. 17, 2009, pp. 1956-1973. doi:10.2174/138161209788453202

[369] S. A. Hwang and J. K. Actor, "Lactoferrin Modulation of BCG-Infected Dendritic Cell Functions," International Immunology, Vol. 21, No. 10, October 2009, pp. 11851197. doi:10.1093/intimm/dxp084

[370] S. A. Hwang, K. M. Wilk, M. Budnicka, M. Olsen, Y. A. Bangale, R. L. Hunter, M. L. Kruzel and J. K. Actor, "Lactoferrin Enhanced Efficacy of the BCG Vaccine to Generate Host Protective Responses against Challenge with Virulent Mycobacterium Tuberculosis," Vaccine, Vol. 25, No. 37-38, September 2007, pp. 6730-6743. doi:10.1016/j.vaccine.2007.07.005

[371] S. A. Hwang, K. Wilk, M. L. Kruzel and J. K. Actor, "A Novel Recombinant Human Lactoferrin Augments the BCG Vaccine and Protects Alveolar Integrity upon Infection with Mycobacterium Tuberculosis in Mice," Vaccine, Vol. 27, No. 23, May 2009, pp. 3026-3034. doi:10.1016/j.vaccine.2009.03.036

[372] T. A. Barr, J. Carlring and A. W. Heath, "CD40 Antibody as a Potent Immunological Adjuvant: CD40 Antibody Provides the CD40 Signal to B Cells, but does not Substitute for T Cell Help in Responses to TD Antigens," Vaccine, Vol. 23, No. 26, May 2005, pp. 3477-3482. doi:10.1016/j.vaccine.2004.12.025

[373] J. Carlring, T. A. Barr, A. L. McCormick and A. W. Heath, "CD40 Antibody as an Adjuvant Induces Enhanced T Cell Responses," Vaccine, Vol. 22, No. 25-26, September 2004, pp. 3323-3328.

doi:10.1016/j.vaccine.2004.02.043

[374] J. Liu, Q. Yu, G. W. Stone, F. Y. Yue, N. Ngai, R. B. Jones, R. S. Kornbluth and M. A. Ostrowski, "CD40L Expressed from the Canarypox Vector, ALVAC, Can Boost Immunogenicity of HIV-1 Canarypox Vaccine in Mice and Enhance the in Vitro Expansion of Viral Specific CD8+ T Cell Memory Responses from HIV-1Infected and HIV-1-Uninfected Individuals," Vaccine, Vol. 26, No. 32, July9 2008, pp. 4062-4072. doi:10.1016/j.vaccine.2008.05.018

[375] T. Barr, J. Carlring, C. Hatzifoti and A. W. Heath, "Antibodies against Cell Surface Antigens as Very Potent Immunological Adjuvants," Vaccine, Vol. 24, Suppl 2, April 2006, pp. S2-20-1.

[376] K. Dorgham, V. Abadie, M. Iga, O. Hartley, G. Gorochov and B. Combadiere, "Engineered CCR5 Superagonist
Chemokine as Adjuvant in Anti-Tumor DNA Vaccination," Vaccine, Vol. 26, No. 26, June 2008, pp. 3252 3260. doi:10.1016/j.vaccine.2008.04.003

[377] C. E. Hioe, M. L. Visciano, R. Kumar, J. Liu, E. A. Mack, R. E. Simon, D. N. Levy and M. Tuen, "The Use of Immune Complex Vaccines to Enhance Antibody Responses against Neutralizing Epitopes on HIV-1 Envelope GP120," Vaccine, Vol. 28, No. 2, 2009, pp. 352-360. doi:10.1016/j.vaccine.2009.10.040

[378] N. Pakravan, S. M. Hashemi and Z. M. Hassan, "Adjuvant Activity of GP96 C-Terminal Domain towards Her2/Neu DNA Vaccine is Fusion Direction-Dependent," Cell Stress Chaperones, Vol. 16, No. 1, January 2011, pp. 41-48. doi:10.1007/s12192-010-0219-5

[379] P. O. Ilyinskii, G. Thoidis, M. Y. Sherman and A. Shneider, "Adjuvant Potential of Aggregate-Forming polyglutamine Domains," Vaccine, Vol. 26, No. 26, June 2008, pp. 3223-3226. doi:10.1016/j.vaccine.2008.03.078

[380] B. Jin, T. Sun, X. H. Yu, C. Q. Liu, Y. X. Yang, P. Lu, S. F. Fu, H. B. Qiu and A. E. Yeo, "Immunomodulatory Effects of dsRNA and Its Potential as Vaccine Adjuvant," Journal of Biomed Biotechnology, Vol. 2010, 2010, p. 690438. doi: $10.1155 / 2010 / 690438$

[381] Y. F. Lau, L. H. Tang, A. W. McCall, E. E. Ooi and K. Subbarao, "An Adjuvant for the Induction of Potent, Protective Humoral Responses to an H5N1 Influenza Virus Vaccine with Antigen-Sparing Effect in Mice," Journal of Virology, Vol. 84, No. 17, September 2010, pp. 8639-8649. doi:10.1128/JVI.00596-10

[382] M. L. Salem, S. A. El-Naggar, A. Kadima, W. E. Gillanders and D. J. Cole, "The Adjuvant Effects of the Toll-Like Receptor 3 Ligand Polyinosinic-Cytidylic Acid Poly (I:C) on Antigen-Specific CD8+ T Cell Responses are Partially Dependent on NK Cells with the Induction of a Beneficial Cytokine Milieu," Vaccine, Vol. 24, No. 24, June 2006, pp. 5119-5132. doi:10.1016/j.vaccine.2006.04.010

[383] B. Salaun, M. Greutert and P. Romero, "Toll-Like Receptor 3 is Necessary for dsRNA Adjuvant Effects," Vaccine, Vol. 27, No. 12, 2009, pp. 1841-1847. doi:10.1016/j.vaccine.2009.01.044

[384] H. Ezoe, Y. Akeda, Z. Piao, T. Aoshi, S. Koyama, T. Tanimoto, K. J. Ishii and K. Oishi, "Intranasal Vaccination with Pneumococcal Surface Protein A plus poly(I:C) Protects against Secondary Pneumococcal Pneumonia in Mice," Vaccine, Vol. 29, No. 9, 2011, pp. 1754-1761. doi:10.1016/j.vaccine.2010.12.117

[385] A. Ainai, T. Ichinohe, S. Tamura, T. Kurata, T. Sata, M. Tashiro and H. Hasegawa, "Zymosan Enhances the Mucosal Adjuvant Activity of Poly(I:C) in a Nasal Influenza Vaccine," Journal of Medical Virology, Vol. 82, No. 3, March 2010, pp. 476-84. doi:10.1002/jmv.21694

[386] T. Ichinohe, A. Ainai, M. Tashiro, T. Sata and H. Hasegawa, "PolyI:polyC12U Adjuvant-Combined Intranasal Vaccine Protects Mice against Highly Pathogenic H5N1 Influenza Virus Variants," Vaccine, Vol. 27, No. 45, 2009, pp. 6276-6279. doi:10.1016/j.vaccine.2009.04.074 
[387] T. Ichinohe, A. Ainai, Y. Ami, N. Nagata, N. Iwata, A. Kawaguchi, Y. Suzaki, T. Odagiri, M. Tashiro, H. Takahashi, D. R. Strayer, W. A. Carter, J. Chiba, S. Tamura, T. Sata, T. Kurata and H. Hasegawa, "Intranasal Administration of Adjuvant-Combined Vaccine Protects Monkeys from Challenge with the Highly Pathogenic Influenza A H5N1 Virus," Journal of Medical Virology, Vol. 82, No. 10, October 2010, pp. 1754-1761. doi:10.1002/jmv.21824

[388] K. Tewari, B. J. Flynn, S. B. Boscardin, K. Kastenmueller, A. M. Salazar, C. A. Anderson, V. Soundarapandian, A. Ahumada, T. Keler, S. L. Hoffman, M. C. Nussenzweig, R. M. Steinman and R. A. Seder, "Poly(I:C) is an Effective Adjuvant for Antibody and Multi-Functional CD4+T Cell Responses to Plasmodium Falciparum Circumsporozoite Protein (CSP) and Alphadec-CSP in Non-Human Primates," Vaccine, Vol. 28, No. 45, October 2010, pp. 7256-7266. doi:10.1016/j.vaccine.2010.08.098

[389] K. Oda, Y. Sato, S. Katayama, A. Ito and T. Ohgitani, "Separation and Characterization of Adjuvant Oligosaccharide Oleate Ester Derived from Product Mixture of Mannitol-Oleic Acid Esterification," Vaccine, Vol. 22, No. 21-22, Jul 29 2004, pp. 2812-2821. doi:10.1016/j.vaccine.2004.01.047

[390] S. Ascarateil and L. Dupuis, "Surfactants in Vaccine Adjuvants: Description and Perspectives," Vaccine, Vol. 24, Suppl 2, April 2006, pp. S2-83-5.

[391] L. A. Hilgers and A. G. Blom, "Sucrose Fatty Acid Sulphate Esters as Novel Vaccine Adjuvant," Vaccine, Vol. 24, Suppl 2, April 2006, pp. S2-81-2.

[392] J. M. Katz, X. Lu, C. W. Todd and M. J. Newman, “A Nonionic Block Co-Polymer Adjuvant (CRL1005) Enhances the Immunogenicity and Protective Efficacy of Inactivated Influenza Vaccine in Young and Aged Mice," Vaccine, Vol. 18, No. 21, April 2000, pp. 2177-2187. doi:10.1016/S0264-410X(00)00022-0

[393] R. K. Evans, D. M. Zhu, D. R. Casimiro, D. K. Nawrocki, H. Mach, R. D. Troutman, A. Tang, S. Wu, S. Chin, C. Ahn, L. A. Isopi, D. M. Williams, Z. Xu, J. W. Shiver and D. B. Volkin, "Characterization and Biological Evaluation of a Microparticle Adjuvant Formulation for Plasmid DNA Vaccines," Journal of Pharmaceutical Sciences, Vol. 93, No. 7, July 2004, pp. 1924-1939. doi:10.1002/jps.20112

[394] T. Stegmann, T. Kamphuis, T. Meijerhof, E. Goud, A. de Haan and J. Wilschut, "Lipopeptide-Adjuvanted Respiratory Syncytial Virus Virosomes: A Safe and Immunogenic Non-Replicating Vaccine Formulation," Vaccine, Vol. 28, No. 34, 2010, pp. 5543-5550. doi:10.1016/j.vaccine.2010.06.041

[395] C. Klinguer, A. Beck, P. De-Lys, M. C. Bussat, A. Blaecke, F. Derouet, J. Y. Bonnefoy, T. N. Nguyen, N. Corvaia and D. Velin, "Lipophilic Quaternary Ammonium Salt Acts as a Mucosal Adjuvant When Co-Administered by the Nasal Route with Vaccine Antigens," Vaccine, Vol. 19, No. 30, July 2001, pp. 4236-4244. doi:10.1016/S0264-410X(01)00156-6
[396] C. Klinguer-Hamour, C. Libon, H. Plotnicky-Gilquin, M. C. Bussat, L. Revy, T. Nguyen, J. Y. Bonnefoy, N. Corvaia and A. Beck, "DDA Adjuvant Induces a Mixed Th1/Th2 Immune Response When Associated with BBG2Na, a Respiratory Syncytial Virus Potential Vaccine," Vaccine, Vol. 20, No. 21-22, June 2002, pp. 27432751. doi:10.1016/S0264-410X(02)00193-7

[397] L. E. Davidson, A. M. Fiorino, D. R. Snydman and P. L. Hibberd, "Lactobacillus GG as an Immune Adjuvant for Live-Attenuated Influenza Vaccine in Healthy Adults: A Randomized Double-Blind Placebo-Controlled Trial," European Journal of Clinical Nutrition, Vol. 65, No. 4, April 2011, pp. 501-507. doi:10.1038/ejen.2010.289

[398] V. Saluja, J. P. Amorij, M. L. van Roosmalen, K. Leenhouts, A. Huckriede, W. L. Hinrichs and H. W. Frijlink, "Intranasal Delivery of Influenza Subunit Vaccine Formulated with GEM Particles as an Adjuvant," AAPS Journal, Vol. 12, No. 2, June 2010, pp. 109-116. doi:10.1208/s12248-009-9168-2

[399] J. M. Grange, O. Bottasso, C. A. Stanford and J. L. Stanford, "The Use of Mycobacterial Adjuvant-Based Agents for Immunotherapy of Cancer," Vaccine, Vol. 26, No. 39, September 2008, pp. 4984-4990. doi:10.1016/j.vaccine.2008.06.092

[400] B. Jalilian, A. R. Omar, M. H. Bejo, N. B. Alitheen, M. Rasoli and S. Matsumoto, "Development of Avian Influenza Virus H5 DNA Vaccine and MDP-1 Gene of Mycobacterium Bovis as Genetic Adjuvant," Genetic Vaccines and Therapy, Vol. 8, 2010, p. 4.

[401] L. O. Moreira, A. M. Smith, A. A. DeFreitas, J. E. Qualls, K. C. El Kasmi and P. J. Murray, "Modulation of Adaptive Immunity by Different Adjuvant-Antigen Combinations in Mice Lacking Nod2," Vaccine, Vol. 26, No. 46, October 2008, pp. 5808-5813. doi:10.1016/j.vaccine.2008.08.038

[402] B. Halassy, M. Krstanovic, R. Frkanec and J. Tomasic, "Adjuvant Activity of Peptidoglycan Monomer and Its Metabolic Products," Vaccine, Vol. 21, No. 9-10, February 2003, pp. 971-976. doi:10.1016/S0264-410X(02)00547-9

[403] B. Halassy Spoljar, T. Cimbora, I. Hanzl-Dujmovic, B. Dojnovic, A. Sabioncello, M. Krstanovic and J. Tomasic, "Influence of Adjuvant-Active Peptidoglycan Monomer on Specific T Cell Responses in Mice," Vaccine, Vol. 20, No. 29-30, October 2002, pp. 3543-3550. doi:10.1016/S0264-410X(02)00336-5

[404]E. Meshcheryakova, E. Makarov, D. Philpott, T. Andronova and V. Ivanov, "Evidence for Correlation between the Intensities of Adjuvant Effects and NOD2 Activation by Monomeric, Dimeric and Lipophylic Derivatives of N-Acetylglucosaminyl-N-Acetylmuramyl Peptides," Vaccine, Vol. 25, No. 23, June 2007, pp. 45154520. doi:10.1016/j.vaccine.2007.04.006

[405] A. D. Ogunniyi, J. C. Paton, A. C. Kirby, J. A. McCullers, J. Cook, M. Hyodo, Y. Hayakawa and D. K. Karaolis, "c-di-GMP is an Effective Immunomodulator and Vaccine Adjuvant against Pneumococcal Infection," Vaccine, 
Vol. 26, No. 36, August 2008, pp. 4676-4685. doi:10.1016/i.vaccine.2008.06.099

[406] W. Chen, R. KuoLee and H. Yan, "The Potential of 3',5'-Cyclic Diguanylic Acid (c-di-GMP) as an Effective Vaccine Adjuvant," Vaccine, Vol. 28, No. 18, 2010, pp. 3080-3085. doi:10.1016/j.vaccine.2010.02.081

[407] T. Ebensen, K. Schulze, P. Riese, C. Link, M. Morr and C. A. Guzman, "The Bacterial Second Messenger Cyclic diGMP Exhibits Potent Adjuvant Properties," Vaccine, Vol. 25, No. 8, February 2007, pp. 1464-1469. doi:10.1016/j.vaccine.2006.10.033

[408] J.-M. Huang, H. A. Hong, H. Van Tong, T. H. Hoang, A. Brisson and S. M. Cutting, "Mucosal Delivery of Antigens Using Adsorption to Bacterial Spores," Vaccine, Vol. 28, No. 4, 2010, pp. 1021-1030. doi:10.1016/j.vaccine.2009.10.127

[409] A. G. Barnes, V. Cerovic, P. S. Hobson and L. S. Klavinskis, "Bacillus Subtilis Spores: A Novel Microparticle Adjuvant Which Can Instruct a Balanced Th1 and Th2 Immune Response to Specific Antigen," European Journal of Immunology, Vol. 37, No. 6, June 2007, pp. 1538-1547. doi:10.1002/eji.200636875

[410] Y. Adar, Y. Singer, R. Levi, E. Tzehoval, S. Perk, C. Banet-Noach, S. Nagar, R. Arnon and T. Ben-Yedidia, "A Universal Epitope-Based Influenza Vaccine and Its Efficacy against H5N1," Vaccine, Vol. 27, No. 15, 2009, pp. 2099-2107. doi:10.1016/j.vaccine.2009.02.011

[411] L. Song, Y. Zhang, N. E. Yun, A. L. Poussard, J. N. Smith, J. K. Smith, V. Borisevich, J. J. Linde, M. A. Zacks, H. Li, U. Kavita, L. Reiserova, X. Liu, K. Dumuren, B. Balasubramanian, B. Weaver, J. Parent, S. Umlauf, G. Liu, J. Huleatt, L. Tussey and S. Paessler, "Superior Efficacy of a Recombinant Flagellin:H5N1 HA Globular Head Vaccine is Determined by the Placement of the Globular Head within Flagellin," Vaccine, Vol. 27, No. 42, 2009, pp. 5875-5884. doi:10.1016/j.vaccine.2009.07.060

[412] D. Johnston and J. C. Bystryn, "Topical Imiquimod is a Potent Adjuvant to a Weakly-Immunogenic Protein Prototype Vaccine," Vaccine, Vol. 24, No. 11, March 2006, pp. 1958-1965. doi:10.1016/j.vaccine.2005.10.045

[413] M. Igartua and J. L. Pedraz, "Topical Resiquimod: A Promising Adjuvant for Vaccine Development?" Expert Review of Vaccines, Vol. 9, No. 1, January 2010, pp. 23-27. doi:10.1586/erv.09.135

[414] J. Du, Z. Wu, S. Ren, Y. Wei, M. Gao, G. J. Randolph and C. Qu, "TLR8 Agonists Stimulate Newly Recruited Monocyte-Derived Cells into Potent APCs That Enhance HBsAg Immunogenicity," Vaccine, Vol. 28, No. 38, 2010, pp. 6273-6281. doi:10.1016/j.vaccine.2010.06.117

[415] N. H. Jazani, M. Karimzad, E. Mazloomi, M. Sohrabpour, Z. M. Hassan, H. Ghasemnejad, S. Roshan-Milani and S. Shahabi, "Evaluation of the Adjuvant Activity of Naloxone, an Opioid Receptor Antagonist, in Combination with Heat-Killed Listeria Monocytogenes Vaccine," Microbes and Infection, Vol. 12, No. 5, May 2010, pp. 382-388. doi:10.1016/j.micinf.2010.02.001
[416] W. Yan, W. C. Chen, Z. Liu and L. Huang, "Bryostatin-I: A Dendritic Cell Stimulator for Chemokines Induction and a Promising Adjuvant for a Peptide Based Cancer Vaccine," Cytokine, Vol. 52, No. 3, December 2010, pp. 238-244. doi:10.1016/j.cyto.2010.08.010

[417] W. J. Morrow, Y. W. Yang and N. A. Sheikh, "Immunobiology of the Tomatine Adjuvant," Vaccine, Vol. 22, No. 19, June 2004, pp. 2380-2384 doi:10.1016/j.vaccine.2004.03.022

[418] L. Yuan, L. Wu, J. Chen, Q. Wu and S. Hu, "Paclitaxel Acts as an Adjuvant to Promote Both Th1 and Th2 Immune Responses Induced by Ovalbumin in Mice," Vaccine, Vol. 28, No. 27, 2010, pp. 4402-4410. doi:10.1016/j.vaccine.2010.04.046

[419] A. Khajuria, A. Gupta, S. Singh, F. Malik, J. Singh, K. A. Suri, N. K. Satti, G. N. Qazi, V. K. Srinivas, Gopinathan and K. Ella, "RLJ-NE-299A: A New Plant Based Vaccine Adjuvant," Vaccine, Vol. 25, No. 14, March 2007, pp. 2706-2715. doi:10.1016/j.vaccine.2006.06.036

[420] H. M. S. Kumar, P. P. Singh, N. A. Qazi, J. Srinivas, F. Malik, T. Sidiq, A. Gupta, A. Khajuria, K. A. Suri, N. K. Satti and G. N. Qazi, "Development of Novel Lipidated Analogs of Picroside as Vaccine Adjuvants: Acylated Analogs of Picroside-II Elicit Strong Th1 and Th2 Response to Ovalbumin in Mice," Vaccine, Vol. 28, No. 52, 2010, pp. 8327-8337. doi:10.1016/j.vaccine.2010.07.062

[421] E. I. Rigopoulou, W. G. Abbott, R. Williams and N. V. Naoumov, "Direct Evidence for Immunomodulatory Properties of Ribavirin on T-Cell Reactivity to Hepatitis C Virus," Antiviral Research, Vol. 75, No. 1, July 2007, pp. 36-42. doi:10.1016/j.antiviral.2006.11.008

[422] E. Y. Enioutina, D. Visic and R. A. Daynes, "The Induction of Systemic and Mucosal Immune Responses to Antigen-Adjuvant Compositions Administered into the Skin: Alterations in the Migratory Properties of Dendritic Cells Appears to be Important for Stimulating Mucosal Immunity," Vaccine, Vol. 18, No. 24, June 2000, pp. 2753-2767. doi:10.1016/S0264-410X(00)00059-1

[423] E. Y. Enioutina, D. Visic, Z. A. McGee and R. A. Daynes, "The Induction of Systemic and Mucosal Immune Responses Following the Subcutaneous Immunization of Mature Adult Mice: Characterization of the Antibodies in Mucosal Secretions of Animals Immunized with Antigen Formulations Containing a Vitamin D3 Adjuvant," Vaccine, Vol. 17, No. 23-24, August 1999, pp. 3050-3064. doi:10.1016/S0264-410X(99)00147-4

[424] D. Jiang, G. S. Premachandra, C. Johnston and S. L. Hem, "Structure and Adsorption Properties of Commercial Calcium Phosphate Adjuvant," Vaccine, Vol. 23, No. 5, December 2004, pp. 693-698.

doi:10.1016/j.vaccine.2004.06.029

[425] S. Sakure, V. D. Negi, S. K. Mitra, K. S. Nandakumar and D. Chakravortty, "Vaccine with Herbal Adjuvant: A Better Cocktail to Combat the Infection," Vaccine, Vol. 26, No. 27-28, June 2008, pp. 3387-3388. doi:10.1016/j.vaccine.2008.01.060 
[426]X. Yang, S. Huang, J. Chen, N. Song, L. Wang, Z. Zhang, G. Deng, H. Zheng, X.-Q. Zhu and F. Lu, "Evaluation of the Adjuvant Properties of Astragalus Membranaceus and Scutellaria Baicalensis GEORGI in the Immune Protection Induced by UV-Attenuated Toxoplasma Gondii in Mouse Models," Vaccine, Vol. 28, No. 3, 2010, pp. 737-743. doi:10.1016/j.vaccine.2009.10.065

[427] P. V. Licciardi and J. R. Underwood, "Identification of a Novel Vaccine Adjuvant That Stimulates and Maintains Diphtheria Toxoid Immunity," Vaccine, Vol. 28, No. 22, 2010, pp. 3865-3873. doi:10.1016/j.vaccine.2010.02.073

[428] J. Li, A. V. King, S. L. Stickel, K. E. Burgin, X. Zhang, T. E. Wagner and Y. Wei, "Whole Tumor Cell Vaccine with Irradiated S180 Cells as Adjuvant," Vaccine, Vol. 27, No. 4, November 2009, pp. 558-564. doi:10.1016/i.vaccine.2008.11.014

[429] J. Li, A. V. King, S. L. Stickel, K. E. Burgin, X. Zhang, T. E. Wagner and Y. Wei, "Whole Tumor Cell Vaccine with Irradiated S180 Cells as Adjuvant," Vaccine, Vol. 27, No. 4, November 2009, pp. 558-564.

[430] X. Chen, P. Kim, B. Farinelli, A. Doukas, S. H. Yun, J. A. Gelfand, R. R. Anderson and M. X. Wu, "A Novel Laser Vaccine Adjuvant Increases the Motility of Antigen Presenting Cells," PLoS One, Vol. 5, No. 10, 2010, p. e13776. doi:10.1371/journal.pone.0013776

[431] T. F. Schwarz, M. Spaczynski, A. Schneider, J. Wysocki, A. Galaj, P. Perona, S. Poncelet, T. Zahaf, K. Hardt, D. Descamps and G. Dubin, "Immunogenicity and Tolerability of an HPV-16/18 AS04-Adjuvanted Prophylactic Cervical Cancer Vaccine in Women Aged 15-55 Years," Vaccine, Vol. 27, No. 4, Jan 22 2009, pp. 581-587. doi:10.1016/j.vaccine. 2008.10 .088

[432] F. Ambrosch, G. Wiedermann, M. Kundi, G. Leroux-oels, I. Desombere, N. Garcon, C. Thiriart, M. Slaoui and S. Thoelen, "A Hepatitis B Vaccine Formulated with a Novel Adjuvant System," Vaccine, Vol. 18, No. 20, April 2000, pp. 2095-101. doi:10.1016/S0264-410X(99)00566-6

[433] T. Sugai, M. Mori, M. Nakazawa, M. Ichino, T. Naruto, N. Kobayashi, Y. Kobayashi, M. Minami and S. Yokota, "A CpG-Containing Oligodeoxynucleotide as an Efficient Adjuvant Counterbalancing the Th1/Th2 Immune Response in Diphtheria-Tetanus-Pertussis Vaccine," Vaccine, Vol. 23, No. 46-47, November 2005, pp. 5450-5456. doi:10.1016/j.vaccine.2004.09.041

[434] F. Wu, X. Y. Yuan, J. Li and Y. H. Chen, "The Codministration of CpG-ODN Influenced Protective Activity of Influenza M2e Vaccine," Vaccine, Vol. 27, No. 32, July 2009, pp. 4320-4324. doi:10.1016/j.vaccine.2009.04.075

[435] S. Rojo-Montejo, E. Collantes-Fernandez, J. Regidorerrillo, A. Rodriguez-Bertos, A. Prenafeta, M. Gomezautista and L. M. Ortega-Mora, "Influence of Adjuvant and Antigen Dose on Protection Induced by an Inactivated Whole Vaccine against Neospora Caninum Infection in Mice," Vet Parasitol, Vol. 175, No. 3-4, February 2011, pp. 220-229. doi:10.1016/j.vetpar.2010.10.028
[436] N. H. Jazani, S. Parsania, M. Sohrabpour, E. Mazloomi, M. Karimzad and S. Shahabi, "Naloxone and Alum Synergistically Augment Adjuvant Activities of Each Other in a Mouse Vaccine Model of Salmonella Typhimurium Infection," Immunobiology, Vol. 216, No. 6, October 2010, pp. 744-751.

[437] N. H. Jazani, M. Sohrabpour, E. Mazloomi and S. Shahabi, "A Novel Adjuvant, a Mixture of Alum and the General Opioid Antagonist Naloxone, Elicits Both Humoral and Cellular Immune Responses for Heat-Killed Salmonella Typhimurium Vaccine," FEMS Immunology and Medical Microbiology, Vol. 61, No. 1, February 2011, pp. 54-62. doi:10.1111/j.1574-695X.2010.00747.x

[438] S. M. Bal, S. Hortensius, Z. Ding, W. Jiskoot and J. A. Bouwstra, "Co-Encapsulation of Antigen and Toll-Like Receptor Ligand in Cationic Liposomes Affects the Quality of the Immune Response in Mice after Intradermal Vaccination," Vaccine, Vol. 29, No. 5, 2011, pp. 1045 1052. doi:10.1016/j.vaccine.2010.11.061

[439] A. Joseph, I. Louria-Hayon, A. Plis-Finarov, E. Zeira, Z. Zakay-Rones, E. Raz, T. Hayashi, K. Takabayashi, Y. Barenholz and E. Kedar, "Liposomal Immunostimulatory DNA Sequence (ISS-ODN): An Efficient Parenteral and Mucosal Adjuvant for Influenza and Hepatitis B Vaccines," Vaccine, Vol. 20, No. 27-28, September 2002, pp. 3342-3354. doi:10.1016/S0264-410X(02)00295-5

[440] S. de Jong, G. Chikh, L. Sekirov, S. Raney, S. Semple, S. Klimuk, N. Yuan, M. Hope, P. Cullis and Y. Tam, "Encapsulation in Liposomal Nanoparticles Enhances the Immunostimulatory, Adjuvant and Anti-Tumor Activity of Subcutaneously Administered CpG ODN," Cancer Immunology, Immunotherapy, Vol. 56, No. 8, August 2007, pp. 1251-1264. doi:10.1007/s00262-006-0276-x

[441] D. Johnston, B. Zaidi and J. C. Bystryn, "TLR7 Imidazoquinoline Ligand 3M-019 is a Potent Adjuvant for Pure Protein Prototype Vaccines," Cancer Immunology, Immunotherapy, Vol. 56, No. 8, August 2007, pp. 1133-1141. doi:10.1007/s00262-006-0262-3

[442] J. Myschik, F. Eberhardt, T. Rades and S. Hook, "Immunostimulatory Biodegradable Implants Containing the Adjuvant Quil-A-Part I: Physicochemical Characterisation," Journal of Drug Targeting, Vol. 16, No. 3, April 2008, pp. 213-223.

[443] M. Rao, K. K. Peachman, Q. Li, G. R. Matyas, S. B. Shivachandra, R. Borschel, V. I. Morthole, C. Fernandez-rada, C. R. Alving and V. B. Rao, "Highly Effective Generic Adjuvant Systems for Orphan or Poverty-Related Vaccines," Vaccine, Vol. 29, No. 5, 2011, pp. 873-877. doi:10.1016/j.vaccine.2010.11.049

[444] D. I. Bernstein, N. Farley, F. J. Bravo, J. Earwood, M. McNeal, J. Fairman and R. Cardin, "The Adjuvant CLDC Increases Protection of a Herpes Simplex Type 2 Glycoprotein D Vaccine in Guinea Pigs," Vaccine, Vol. 28, No. 21, 2010, pp. 3748-3753. doi:10.1016/j.vaccine.2009.10.025

[445] M. G. Chaitra, R. Nayak and M. S. Shaila, "Modulation of Immune Responses in Mice to Recombinant Antigens 
from PE and PPE Families of Proteins of Mycobacterium Tuberculosis by the Ribi Adjuvant," Vaccine, Vol. 25, No. 41, October 2007, pp. 7168-7176. doi:10.1016/j.vaccine.2007.07.026

[446] B. C. Baudner, M. M. Giuliani, J. C. Verhoef, R. Rappuoli, H. E. Junginger and G. D. Giudice, "The Concomitant Use of the LTK63 Mucosal Adjuvant and of ChitosanBased Delivery System Enhances the Immunogenicity and Efficacy of Intranasally Administered Vaccines," Vaccine, Vol. 21, No. 25-26, September 2003, pp. 38373844. doi:10.1016/S0264-410X(03)00305-0

[447] D. T. O'Hagan, M. Ugozzoli, J. Barackman, M. Singh, J. Kazzaz, K. Higgins, T. C. Vancott and G. Ott, "Microparticles in MF59, a Potent Adjuvant Combination for a Recombinant Protein Vaccine Against HIV-1," Vaccine, Vol. 18, No. 17, March 2000, pp. 1793-1801. doi:10.1016/S0264-410X(99)00522-8

[448] T. Jones, S. Cyr, F. Allard, N. Bellerose, G. H. Lowell and D. S. Burt, "Protollin: A Novel Adjuvant for Intranasal Vaccines," Vaccine, Vol. 22, No. 27-28, September 2004, pp. 3691-3697. doi:10.1016/j.vaccine.2004.03.035

[449] W. R. Santos, V. M. de Lima, E. P. de Souza, R. R. Bernardo, M. Palatnik and C. B. Palatnik de Sousa, "Saponins, IL12 and BCG Adjuvant in the FML-Vaccine Formulation against Murine Visceral Leishmaniasis," Vaccine, Vol. 21, No. 1-2, November 2002, pp. 30-43. doi:10.1016/S0264-410X(02)00444-9

[450] Z. Cui and L. Huang, "Liposome-Polycation-DNA (LPD) Particle as a Carrier and Adjuvant for Protein-Based Vaccines: Therapeutic Effect against Cervical Cancer," Cancer Immunology, Immunotherapy, Vol. 54, No. 12, December 2005, pp. 1180-1190. doi:10.1007/s00262-005-0685-2

[451] Y. Li, K. Svehla, N. L. Mathy, G. Voss, J. R. Mascola and R. Wyatt, "Characterization of Antibody Responses Elicited by Human Immunodeficiency Virus Type 1 Primary Isolate Trimeric and Monomeric Envelope Glycoproteins in Selected Adjuvants," The Journal of Virology, Vol. 80, No. 3, February 2006, pp. 1414-1426. doi:10.1128/JVI.80.3.1414-1426.2006

[452] M. E. Polhemus, A. J. Magill, J. F. Cummings, K. E. Kester, C. F. Ockenhouse, D. E. Lanar, S. Dutta, A. Barbosa, L. Soisson, C. L. Diggs, S. A. Robinson, J. D. Haynes, V. A. Stewart, L. A. Ware, C. Brando, U. Krzych, R. A. Bowden, J. D. Cohen, M. C. Dubois, O. Oforinyinam, E. De-Kock, W. R. Ballou and D. G. Heppner, "Phase I Dose Escalation Safety and Immunogenicity Trial of Plasmodium Falciparum Apical Membrane Protein (AMA-1) FMP2.1, Adjuvanted with AS02A, in Malaria-Naive Adults at the Walter Reed Army Institute of Research," Vaccine, Vol. 25, No. 21, May 2007, pp. 4203-4212.

doi:10.1016/i.vaccine.2007.03.012

[453] C. L. Tielemans, J. Vlasak, D. Kosa, J.-M. Billiouw, G. A. Verpooten, I. Mezei, M. Ryba, P. C. Peeters, O. Mat, M. Y. Jadoul, V. Polakovic, M. Dhaene, S. Treille, S. O. Kuriyakose, M. Leyssen, S. A. Houard and M. Surquin,
"Immunogenicity and Safety of an Investigational AS02v-Djuvanted Hepatitis B Vaccine in Patients with Renal Insufficiency Who Failed to Respond or to Maintain Antibody Levels after Prior Vaccination: Results of Two Open, Randomized, Comparative Trials," Vaccine, Vol. 29, No. 6, 2011, pp. 1159-1166. doi:10.1016/j.vaccine.2010.12.009

[454] V. A. Stewart, S. M. McGrath, D. S. Walsh, S. Davis, A. S. Hess, L. A. Ware, K. E. Kester, J. F. Cummings, J. R. Burge, G. Voss, M. Delchambre, N. Garcon, D. B. Tang, J. D. Cohen and D. G. Heppner, "Pre-Clinical Evaluation of New Adjuvant Formulations to Improve the Immunogenicity of the Malaria Vaccine RTS,S/ AS02A," Vaccine, Vol. 24, No. 42-43, October 2006, pp. 6483-6492. doi:10.1016/j.vaccine.2006.06.033

[455] P. Vandepapeliere, B. Rehermann, M. Koutsoukos, P. Moris, N. Garcon, M. Wettendorff and G. Leroux-Roels, "Potent Enhancement of Cellular and Humoral Immune Responses against Recombinant Hepatitis B Antigens Using AS02A Adjuvant in Healthy Adults," Vaccine, Vol. 23, No. 20, April 2005, pp. 2591-2601.

doi:10.1016/j.vaccine.2004.11.034

[456] K. E. Kester, J. F. Cummings, O. Ofori-Anyinam, C. F. Ockenhouse, U. Krzych, P. Moris, R. Schwenk, R. A. Nielsen, Z. Debebe, E. Pinelis, L. Juompan, J. Williams, M. Dowler, V. A. Stewart, R. A. Wirtz, M. C. Dubois, M. Lievens, J. Cohen, W. R. Ballou and D. G. Heppner, "Randomized, Double-Blind, Phase 2a Trial of Falciparum Malaria Vaccines RTS,S/AS01B and RTS, /AS02A in Malaria-Naive Adults: Safety, Efficacy, and Immunologic Associates of Protection," Journal of Infectious Diseases, Vol. 200, No. 3, August 2009, pp. 337-346. doi: $10.1086 / 600120$

[457] P. Vandepapeliere, Y. Horsmans, P. Moris, M. Van Mechelen, M. Janssens, M. Koutsoukos, P. Van Belle, F. Clement, E. Hanon, M. Wettendorff, N. Garcon and G. Leroux-Roels, "Vaccine Adjuvant Systems Containing Monophosphoryl Lipid A and QS21 Induce Strong and Persistent Humoral and $\mathrm{T}$ Cell Responses against Hepatitis B Surface Antigen in Healthy Adult Volunteers," Vaccine, Vol. 26, No. 10, March 2008, pp. 13751386. doi:10.1016/j.vaccine.2007.12.038

[458] J. F. Cummings, M. D. Spring, R. J. Schwenk, C. F. Ockenhouse, K. E. Kester, M. E. Polhemus, D. S. Walsh, I.-K. Yoon, C. Prosperi, L. Y. Juompan, D. E. Lanar, U. Krzych, B. T. Hall, L. A. Ware, V. A. Stewart, J. Williams, M. Dowler, R. K. Nielsen, C. J. Hillier, B. K. Giersing, F. Dubovsky, E. Malkin, K. Tucker, M.-C. Dubois, J. D. Cohen, W. R. Ballou and D. G. H. Jr, "Recombinant Liver Stage Antigen-1 (LSA-1) Formulated with AS01 or AS02 is Safe, Elicits High Titer Antibody and Induces IFN-[gamma]/IL-2 CD4+ T Cells but does not Protect against Experimental Plasmodium Falciparum Infection," Vaccine, Vol. 28, No. 31, 2010, pp. 5135-5144.

doi:10.1016/j.vaccine.2009.08.046

[459] W. Huisman, B. E. Martina, G. F. Rimmelzwaan, R. A. Gruters and A. D. Osterhaus, "Vaccine-Induced Enhance- 
ment of Viral Infections," Vaccine, Vol. 27, No. 4, January 2009, pp. 505-512.

doi:10.1016/j.vaccine.2008.10.087

[460] C. Coban, M. Yagi, K. Ohata, Y. Igari, T. Tsukui, T. Horii, K. J. Ishii and S. Akira, "The Malarial Metabolite Hemozoin and Its Potential Use as a Vaccine Adjuvant," Allergology International, Vol. 59, No. 2, June 2010, pp. $115-124$

doi:10.2332/allergolint.10-RAI-0194

[461] R. E. Flarend, S. L. Hem, J. L. White, D. Elmore, M. A. Suckow, A. C. Rudy and E. A. Dandashli, "In Vivo Absorption of Aluminium-Containing Vaccine Adjuvants Using 26Al," Vaccine, Vol. 15, No. 12-13, August-
September 1997, pp. 1314-1318. doi:10.1016/S0264-410X(97)00041-8

[462] L. S. Burrell, J. L. White and S. L. Hem, "Stabilityof Aluminium-Containing Adjuvants during Aging at Room Temperature," Vaccine, Vol. 18, No. 21, April 2000, pp. 2188-2192. doi:10.1016/S0264-410X(00)00031-1

[463] J. Klein, M. Ushio, L. S. Burrell, B. Wenslow and S. L. Hem, "Analysis of Aluminum Hydroxyphosphate Vaccine Adjuvants by (27)Al MAS NMR," Journal of Pharmaceutical Sciences, Vol. 89, No. 3, March 2000, pp. 311-321.

doi:10.1002/(SICI)1520-6017(200003)89:3<311::AID-JP $\underline{\mathrm{S} 3>3.0 . \mathrm{CO} ; 2-8}$ 